NUREG/CR-1689

6. BNL-NUREG-51206

\title{
AN ASSESSMENT OF NUCLEAR POWER PLANT SITING METHODS
}

Michael D. Rowe, Benjamin F. Hobbs, barbara L. Pierce, and Peter M. Meier

\section{DO NOT MICROFILM COVER}

November 1979

\author{
DIVISION OF REGIONAL STUDIES \\ NATIONAL CENTER FOR ANALYSIS OF ENERGY SYSTEMS \\ BROOKHAVEN NATIONAL LABORATORY \\ UPTON, NEW YORK 11973
}

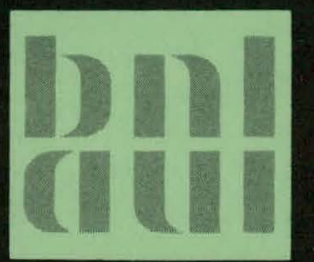

Prepared for Site Standards Designation Branch

U.S. Nuclear Regulatory Commission

Washington, D.C. 20555 


\section{DISCLAIMER}

This report was prepared as an account of work sponsored by an agency of the United States Government. Neither the United States Government nor any agency Thereof, nor any of their employees, makes any warranty, express or implied, or assumes any legal liability or responsibility for the accuracy, completeness, or usefulness of any information, apparatus, product, or process disclosed, or represents that its use would not infringe privately owned rights. Reference herein to any specific commercial product, process, or service by trade name, trademark, manufacturer, or otherwise does not necessarily constitute or imply its endorsement, recommendation, or favoring by the United States Government or any agency thereof. The views and opinions of authors expressed herein do not necessarily state or reflect those of the United States Government or any agency thereof. 


\section{DISCLAIMER}

Portions of this document may be illegible in electronic image products. Images are produced from the best available original document. 
This report was prepared as an account of work sponsored by an agency of the United States

Government. Neither the United States Government nor any agency thereof, nor any of their employees, makes any warranty, express or implied, or assumes any legal liability or responsibility for the accuracy, completeness, or usefulness of any information, apparatus, product, or process disclosed, or represents that its use would not infringe privately owned rights. Reference herein to any specific commercial product, process, or service by trade name, trademark, manufacturer, or otherwise does not necessarily constitute or imply its endorsement, recommendation, or favoring by the United States Government or any agency thereof. The views and opinions of authors expressed herein do not necessarily state or reflect those of the United States Government or any agency thereof.

\title{
AN ASSESSMENT OF NUCLEAR POWER PLANT SITING METHODS
}

\author{
Michael D. ROWE, Benjamin F. HObBS, \\ Barbara L. Pierce, and Peter M. Meier
}

November 1979

\author{
DIVISION OF REGIONAL STUDIES \\ NATIONAL CENTER FOR ANALYSIS OF ENERGY SYSTEMS \\ BROOKHAVEN NATIONAL LABORATORY \\ UPTON, NEW YORK 11973
}

NUREG/CR--1689 
NOTICE

This report was prepared as an account of work sponsored by an agency of the United States Government. Neither the United States Government nor any agency thereof, or any of their employees, makes any warranty, expressed or implied, or assumes any legal liability or responsibility for any third party's use, or the results of such use, of any information, apparatus, product or process disclosed in this report, or represents that its use by such third party would not infringe privately owned rights.

The views expressed in this report are not necessarily those of the U.S. Nuclear Regulatory Commission.

Available from GPO Sales Program

Division of Technical Information and Document Control

U.S. Nuclear Regulatory Commission

Washington, D.C. 20555 and

National Technical Information Service Springfield, Virginia 22161 
THIS PAGE

\section{WAS INTENTIONALLY LEFT BLANK}




\section{PREFACE}

i)

This report is one of a series on quantitative methods for nuclear power plant siting prepared by the BNL Division of Regional Studies for the Site Standards Designation Branch of the U.S. Nuclear Regulatory Comission. The other reports in this series are:

- Hobbs, Benjamin F., Analytical Multiobjective Decision Methods for Power Plant Siting: A Review of Theory and Applications, BNL-NUREG-51204, Division of Regional Studies, Brookhaven National Laboratory; Upton, N.Y., September 1979 .

- Pierce, Barbara L., and Michael D. Rowe, Quantitative Nuclear Power Plant Siting Methods: A Review of Current Practice, BNL-NUREG-28115, Division of Regional Studies, Brookhaven National Laboratory, Upton, N.Y., February 1979 .

- Hobbs, Benjamin F., and Michael D. Rowe, A Comparison of Regional Screening Methods, BNL-NUREG-51205, Division of Regional Studies, Brookhaven National Laboratory, Upton, N.Y.

- Rowe, Michael D., and Barbara L. Pierce, A Comparison of Site Evaluation Methods, BNL-NUREG-51203, Division of Regional Studies, Brookhaven National Laboratory, Upton, N.Y., August 1979 . 


\section{TABLE OF CONTENTS}

Preface............................................

List of Tables...............................................

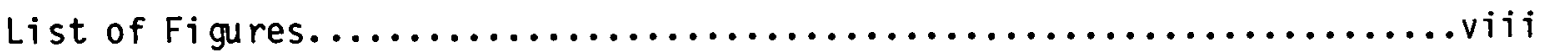

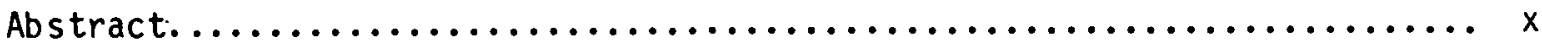

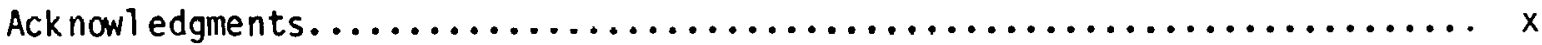

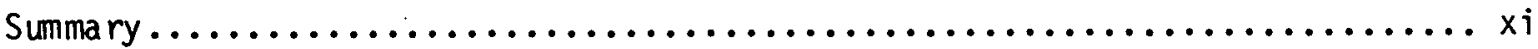

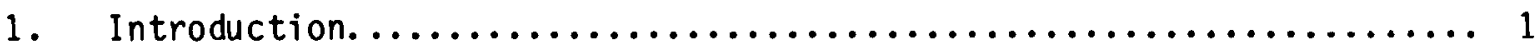

2. Review of Multiobjective Decision-Making Methods.............. 3

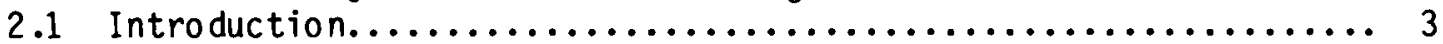

2.2 Analytical Siting Me thodologies: Is sues and Criteria for

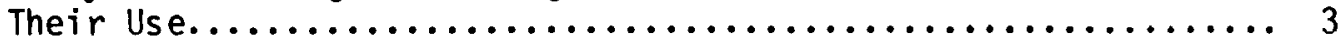

2.3 Choosing and Scaling Siting Attributes.................. 4

2.4 Noninferior Set Generation and Display.................. 8

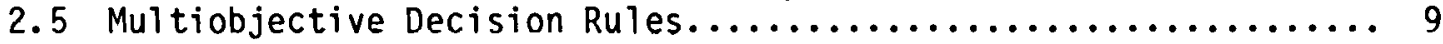

2.5.1 Decision Rules Using Ordinal Attribute Value Functions... 9

2.5.1.1 Exclusionary Screening...................... 9

2.5.1.2 Conjunctive-Ranking................... 9

2.5.1.3 Copeland's Reasonable Social Welfare Function... 10

2.5.1.4 Direct Determination of Indifference Curves..... 10

2.5.2 Decision Rules Requiring Interval or Ratio Attribute

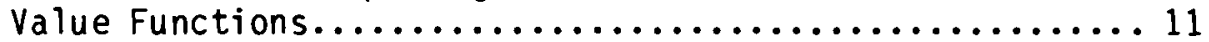

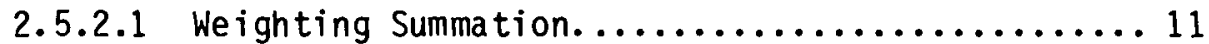

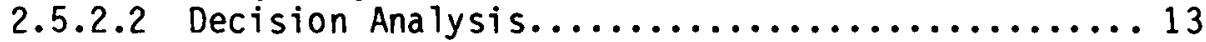

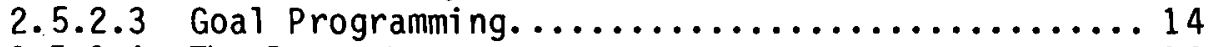

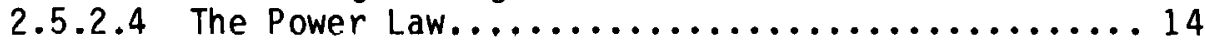

2.5.2.5 Hu rwicz Procedures.................... 14

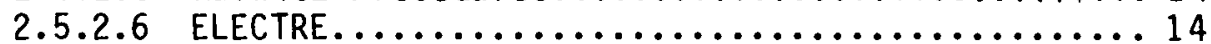

2.5.3 Empirical Comparisons of Decision Rules.............. 16

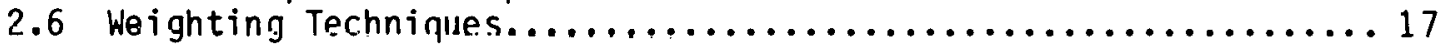

2.7 Iterative Methods for Expressing Preferences............... 20

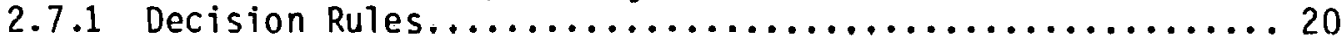

2.7.1.1 The Zionts-Wallenius Procedure and STEM.......20

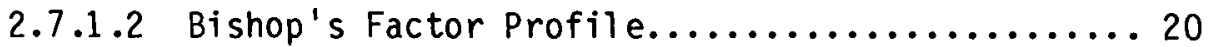

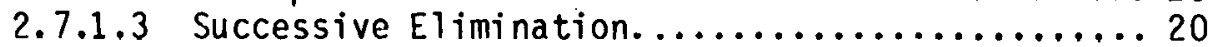

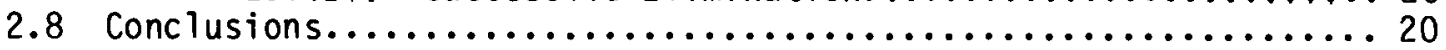

3. Survey of Current Applications of Quantitative Nuclear Power Plant

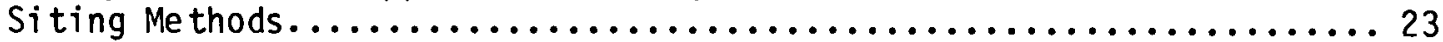

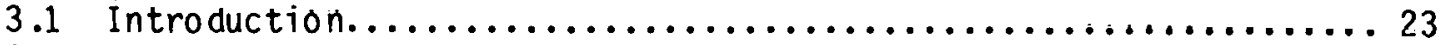

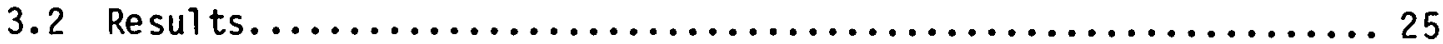

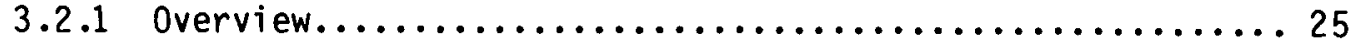

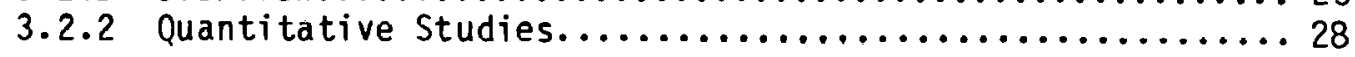


TABLE OF CONTENTS (Continued)

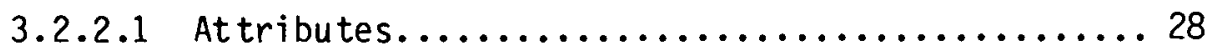

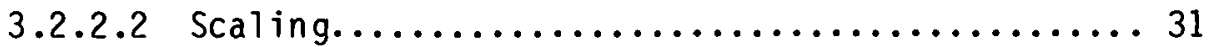

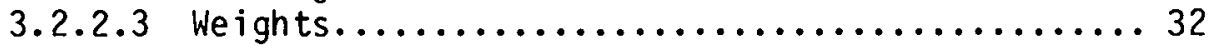

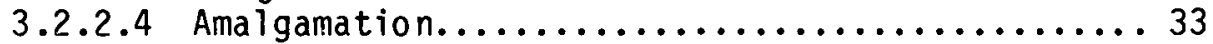

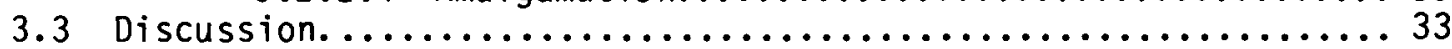

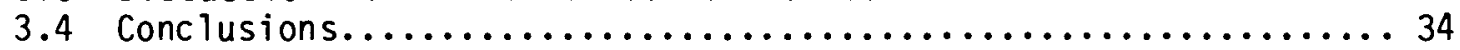

4. Tests of Regional Screening Methods.................... 37

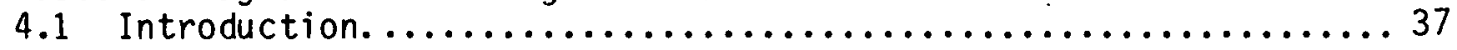

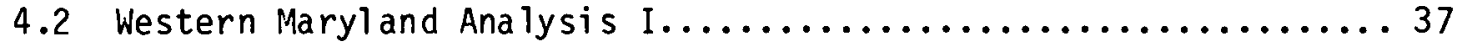

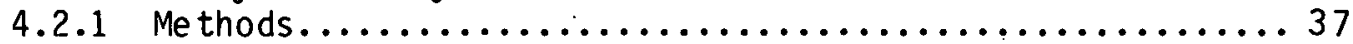

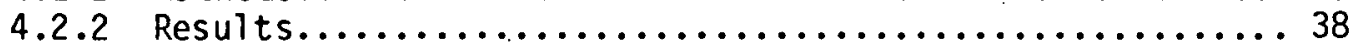

4.3 We stern Maryland Analyses I I........................... 46

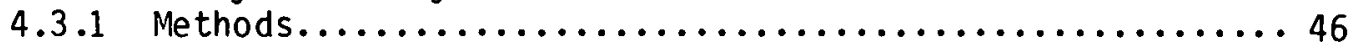

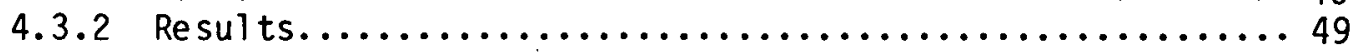

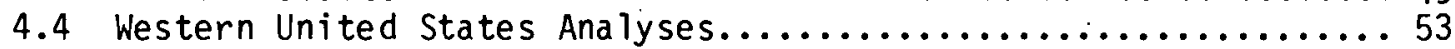

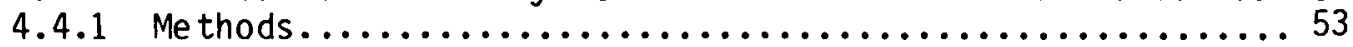

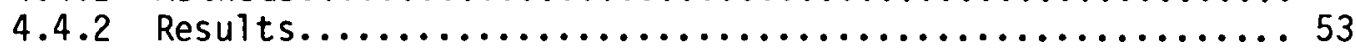

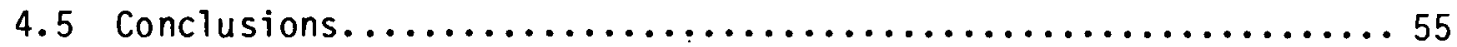

5. Tests of Final Si te Evaluation Me thods..................63

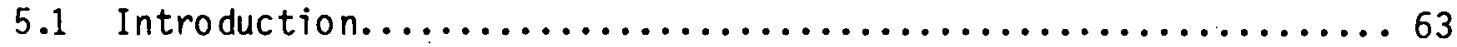

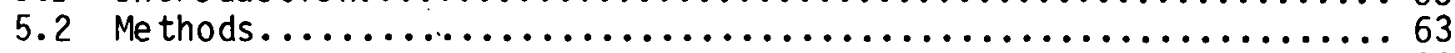

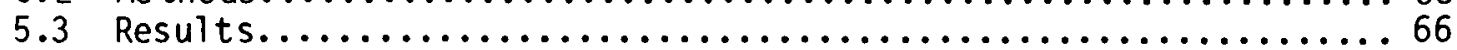

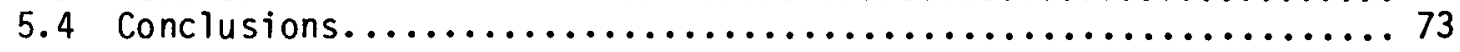

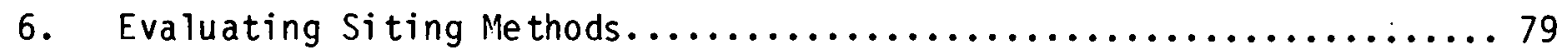

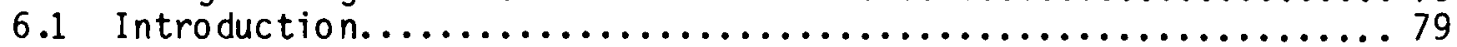

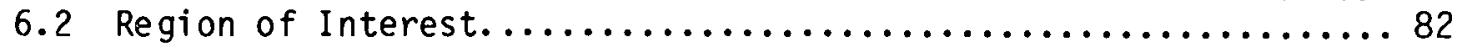

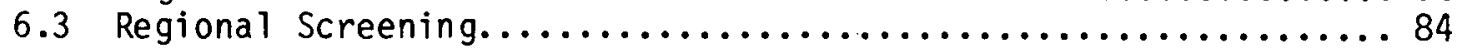

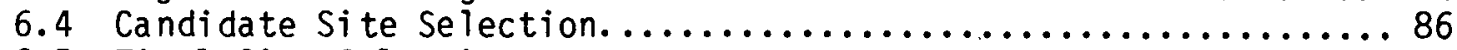

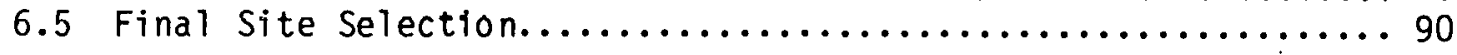

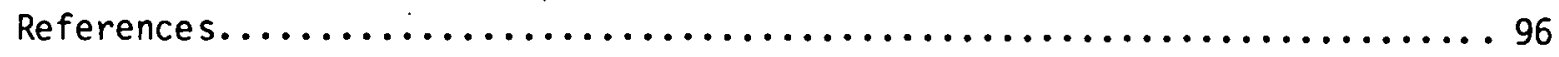


Table No.

Page No.

2.1. Methods of Scaling Physical Attributes

2.2 Methods of Weighting Scaled Attribute Values

3.1 Method Definitions

3.2

Classification of Site-Selection Studies

3.3 Summary of Review

4.1 MAGI Variables Included in Western Maryland Regional

Screening I

4.2

MAGI Variables Included in Western Maryland Screening II

Attributes Included in Western U.S. Screening

5.1

Summary of Site Descriptions Evaluated by the BNL Pane 1

5.2

Mean Between-Methods Correlations of Weights, BNL Panel

5.3 Mean Between-Methods Correlations of Attribute Values and Weights, Long Island Panel, First Meeting

5.4 Site Ranks by Weight Estimation and Amalgamation Method, BNL Panel

5.5 Site Ranks from Categorization (I), Rating (II), and Metfessel Allocation (III) Methods, Advisory Panel

5.6 Change in Probability of Error per Unit Complexity for Various Transformations of Ratio-Scaled Weights

6.1 Region of Interest Checklist

6.2

Regional Screening Checklist

6.3

Candidate Si te-Selection Checklist 
Figure No.

Page No.

2.1

Attribute Value Function for Ecosystem Damage Düe to Increased Temperature of Receiving Water

2.2 Site Characteristics and a Noninferior Curve

2.4 Indifference Curve Between Two Attributes

3.1 Nonlinear Attribute Value Function Favoring Extreme Values

4.1 Weighting Summation Candidate Areas, Mr. Mueller, Maryland Screening I

.4 .2 Weighting Summation Candidate Areas, Dr. Canham, Maryland Screening I

4.3 Cells Shared by the Top $8 \%$ of All Five Rating-Weighting Summation Candidate Areas, Maryland Screening I

Power Law Candidate Areas, Mr. Mueller, Maryland Screening I

4.5 Power Law Candidate Areas, Dr. Canham, Maryland Screening I

4.6 Exclusionary Screening Candidate Areas, Maryland

Screening I

4.7 Categorization Candidate Areas, Advisory Panel (HM), Maryland Screening II

4.8 Rating Candidate Areas, Advisory Panel (HM), Maryland Screening II

4.9 Metfessel Allocation Candidate Areas, Advisory Panel (HM), Maryland Screening II

4.10 Exclusionary Screening Candidate Areas, Advisory Panel (MH), Maryland Screening II

4.11 Exclusionary Screening Candidate Areas, Advisory Panel Group Median Criteria, Maryland Screening II

4.12 Categorization Candidate Areas, Advisory Panel (KN), Western U.S. Screening 


\section{LIST OF FIGURES (Continued)}

Figure No.

Page No.

4.13 Metfessel Allocation Candidate Areas, Advisory Panel $(K N)$, Western U.S. Screening

4.14 Categorization Candidate Areas, Advisory Pane1 (RK), Western.U.S. Screening

4.15 Metfessel Allocation Candidate Areas, Advisory Panel (JH), Western U.S. Screening

4.16 Number of Persons for Which Each Cell Passed All Exclusionary Criteria, Advisory Pane1, Western U.S. Screening

5.1 Major Clusters of Site Evaluation Methodology Results, BNL Panel

5.2 Comparisons of Categorized and Rated Weights, Advisory Pane 1

5.3 Weight Transformations Attributable to Weight Estimation Me thods

5.4 Probability of Decision Error Due to Logarithmic Perception as a Function of Decision Complexity 


\section{ABSTRACT}

Several different methods have been developed for selecting sites for nuclear power plants. This report summarizes the basic assumptions and formal requirements of each method and evaluates conditions under which each is correctly applied to power plant siting problems. It also describes conditions under which different siting methods can produce different results. Included are criteria for evaluating the skill with which siteselection methods have been applied.

\section{ACKNOWL EDGMENTS}

This report is a summary volume to a number of companion reports. The authors thank the many persons who contributed to these companion reports and who are mentioned specifically therein. S. Lee of the Site Standards Branch, Nuclear Regulatory Commission, served as project monitor; his guidance and support are gratefully acknowledged. We are also indebted to P. Miller for typing the manuscript. 
This report describes methods that have been developed for making quantitative evaluations of multiobjective decisions as they are applied to selection of nuclear power plant sites. It discusses formal requirements for applying the methods and outlines magnitudes and kinds of decision errors that can result from misapplying them.

Four independent approaches have been followed to generate the information herein. An extensive review of the literature on multiobjective decision-making methods provides a theoretical framework for how the methods should be applied and the kinds of errors commonly made in applying them. A review of siting methods described in the site-selection chapters of 48 Environmental Reports submitted to the Nuclear Regulatory Commission provides perspective on the range of possible methods that has actually been used. Applications of some commonly used methods by panels of experts provide understanding of the problems encountered in applying the methods and the variability that can be expected in the results. Finally, sensitivity analyses of artificial data provide generalizations of results that could not be made on the basis of applications of methods to a small range of circumstances.

SITING METHODS

The function of quantitative multiobjective decision-making methods is to disaggregate decision problems to smaller and simpler decisions that are easy to understand. They reduce the amount of information that must be considered by decision makers at any one time. Desirable characteristics for analytical decision methods are as follows.

1. Methods should allow for careful, consistent, and welldocumented examination of all factors, tangible and intangible. Important issues and tradeoffs among different factors should be considered explicitly. Decisions should reflect as accurately as possible the personal values of decision makers.

2. Methods should generate and preserve information about impacts of different sites and tradeoffs among them.

3. Methods should allow for input by more than one decision maker, including non-technical members of the general public. Procedures should be understandable and not 
difficult to use. Implications of different personal

values for siting considerations should be easy to determine.

Site evaluation begins with selection of physical attributes to be considered. Only important attributes that differ among sites should be included. Attributes can be chosen by a checklist method in which attributes are adapted from some general source, or by a hierarchical method in which overall objectives are defined and then disaggregated until specific attributes are identified. Measures of physical attributes are then converted (scaled) to subjective estimates of relative impact or suitability.

Scaling methods yield results having different levels of measurement and, therefore, different applications.

1. Ordinal scales, ranks and categories (high, medium, low, etc.), for example, do not have meaningful mathematical relationships among different levels; therefore, they should be-used only for comparisons and not in me.thods requiring addition or multiplication.

2. Interval scales have meaningful intervals among attribute levels but arbitrary zero points. The Fahrenheit and Celsius temperature scales are examples. These scales can be added, subtracted, and weighted, but should not be multiplied among themselves.

3. Ratio scales are interval scales having nonarbitrary zero points in which a zero attribute level means zero impact or zero suitability. All mathematical operations are valid.

One method, Decision Analysis, can also incorporate decision makers' attitudes toward risk.

Few methods require ratio-scaled attribute values; most require interval scales. There are also methods specifically designed for ordinal-level data, but most often ordinal scales are used incorrectly in methods involving mathematical operations and, therefore, requiring interval scales.

Once attribute values are established, there are many methods (decision rules) of combining those values into estimates of relative suitability of each alternative with respect to all attributes. Some, such as Noninferior 
Set Generation and Exclusionary Screening, only present a slate of alternatives which are not obviously inferior one to another, or which pass all of a set of minimum criteria. Others involve simple comparisons of attribute values with accumulations of scores for the number of times each alternative "wins" over other alternatives (Copeland's Reasonable Welfare Function). Still others require relatively complex mathematical manipulations. From a strictly theoretical perspective, the type and quality of information required by these different methods is important. Practical considerations are discussed below.

Methods that can correctly be applied to ordinal-level data are Exclusionary Screening, Conjunctive Ranking, Copeland's Reasonable Welfare Function, and direct determination of indifference curves. These methods compare attribute values among alternatives without mathematical manipulation. All other methods require at least interval-scaled attribute values. Many also require weights - estimates of relative importance of attributes one to another - which should always be ratio scaled.

Like methods for combining attribute values, weighting methods vary in the type of measurements they produce. By definition, weights should capture tradeoffs among different attributes that decision makers are willing to make. They should represent the relative importance of unit changes in attribute values. They must, therefore, be ratio scaled and be specific to the particular ranges of attribute values represented among the alternatives under consideration. Few weighting methods assure both characteristics; categorization and Ranking cannot provide either. Rating can, but assures neither. Ratio Questioning and Metfessel Allocation assure ratio scales but not the correct type of relative importance. Observer-derived weights can assure both under special conditions. The Churchman-Ack off Procedure, Indifference Tradeoff, and Decision Analysis lotteries assure both. In addition, Decision Analysis lotteries can account for decision makers' attitudes toward risk. The significance of these differences is discussed below.

Iterative methods for expressing preferences do not require weights. Thesc arc intuitive methods in which decision makers are required to make pairwise comparisons between alternatives and iteratively reduce the number of alternatives until only one or a few remain.

Empirical comparisons of weighting methods and decision rules have shown that different methods can produce different results, and the magnitudes of 
the differences tend to be related to differences in the conceptual bases of the methods. There are also differences in the ease of application of different methods. In general, the easier methods are less theoretically valid, so there is a tradeoff between potential for error due to theoretical problems and error due to difficulties in applying the method. Choosing a multiobjective method is, itself, a multiobjective problem.

\section{CURRENT PRACTICE}

The site-selection chapters of 48 Environmental Reports submitted to the Nuclear Regulatory Commission since February 1973 were reviewed to determine what methods have been used and whether or not they have been correctly applied. The site-selection process generally consists of three stages: candidate area selection, candidate site selection, and final or proposed site selection. Each stage can and often does use a different method. The methods found to have been used in practice include: (1) Favorability Selection; (2) Exclusion Screening; (3) Predefined Sites; (4) Qualitative Comparison; (5) Cost-effectiveness Analysis; (6) Regional Characterization; (7) Site Rating; and (8) Formalized Numerical Rating. The last three are quantitative methods. Of the 48 site-selection studies reviewed, 13 used one or more quantitative methods: 9 at the final site-selection stage, 2 at the candidate site-selection stage, and 2 at the candidate area-selection stage.

The most striking characteristic of the 48 site selection studies reviewed is absence of specific information about the site-selection process. Many studies contain elaborate descriptions of alternatives, but few present a clear picture of the methodology used or the tradeoffs made in selecting a proposed site. In addition, attributes used to evaluate alternatives are not concisely defined and methods of choosing weights, where used, are not specified. It is difficult, therefore, to determine whether or not the fundamental assumptions of the more quantitative methods are met. In general, from the information presented it is only possible to determine that an acceptable site was chosen, but not that a sound and comprehensive siteselection method was used.

The most common violation of methodological assumptions is algebraic manipulation of ordinal numbers, usually through application of categorized attribute values to the Weighting Summation decision rule. One study used two categories, acceptable and preferred, in a manner which lends itself well 
to use of Copeland's Reasonable Welfare Function, a decision rule specifical-

1. ly designed for ordinal values. Application of this decision rule to the data does not change the top-ranked site, but it does change the rank order of other sites.

Two studies used a variation of the Power Law not described in the literature. Ratings for a few major attribute categories are multiplied instead of added to yield a total site score. Multiplication causes differences among sites to produce proportional differences in total site score instead of additive differences; therefore, small differences among bad sites (low ratings) have a larger influence on total score than small differences among good sites. This causes the actual relative importance of each attribute to be different from the stated relative importance.

This difference between stated weights and the actual relative effect of each attribute ("effective" or "implied" weights) attributable to errors in applying methods occurs in five slightly different forms among the studies reviewed. The first is multiplication of weighted attribute levels instead of addition which causes weights and attribute levels to have a proportional instead of additive effect on total score. The second is double counting, usually of cost, which causes the double-counted attribute to have more than its stated share of influence. The third is use of unspecified nonlinear transformations in scaling attribute values which causes more extreme levels to have a relatively greater impact than less extreme levels. Included in this category is unequal ranges of scales used in equally weighted categories, which cause proportional changes in categories to have less than proportional influence on total score. The fourth is aggregation of different numbers of attributes into equally weighted categories so that the relative weights of the components of the categories are different. The fifth is possible reverse order of the scaling and weighting exercises so that the stated weights are not properly applied to the scaled attribute values. This can occur whenever attributes are weighted in a general sense without specification of the range of measured impacts and attribute values under consideration.

None of the studies reviewed acknowledge the existence of theoretical requirements or attempts to justify deviations from generally accepted forms. Most appear to violate one or more of the basic assumptions of the 
method used. Eight of 13 studies using Weighting Summation appear to violate the assumption of attribute independence; 10 appear to violate theoretical requirement of measurement theory. Nevertheless, conclusions about the significance of these errors to study results are necessarily nondefinitive, since most descriptions of methodologies lack sufficient detail to determine how methods were applied. Selected efforts to fill in these details, in some cases many years after the fact, were generally unsuccessful.

REGIONAL SCREENING

Regional screening methods were applied to two regions of the United States, western Maryland and the western United States, by two panels of siting experts. Decision rules tested included Exclusionary Screening, Weighting Summation, Power Law, and Decision Analysis; weighting methods tested included Categorization, Rating, Metfessel Allocation, ChurchmanAckoff, Indifference Tradeoff, and Decision Analysis lotteries. Results from each panel are reported separately.

Maryland Screening I

Five persons chose attribute weights using Rating, Indifference Tradeoff, Churchman-Ackoff, and Decision Analysis. Rating and Indifference Tradeoff weights vary greatly among participants and between methods for all participants. Weighting Summation candidate areas generated by the weights are strikingly different. Few cells are chosen by all participants and both methods. Differences between candidate areas chosen by the two weighting methods are about as great as differences between areas chosen by different persons using the same method.

The Churchman-Ack off procedure applied to Indifference Tradeoff weights produced few changes, none of significance.

Decision Analysis lottery results applied to Indifference Tradeoff ratios yielded weights that were not proportional to the Indifference Tradeoff weights as theory says they should be. Risk attitudes were inconsistent among different lottery results. It appears that the decision makers were unable to deal successfully with the hypothetical probabilities used in the lotteries. In spite of poor-quality results, candidate areas generated by the Decision Analysis multiplicative form were nearly identical among themselves; therefore, it appears that the data used in this study are insensitive to risk attitudes and the Weighting Summation form will suffice. 
Candidate areas were also generated using the Power Law with Rating and $\forall$ Indifference Tradeoff weights. Choice of decision rule between Weighting Summation and Power Law makes a greater difference in candidate areas than either weighting method or persons.

Exclusion criteria chosen by one person yielded candidate areas having even greater differences than those between Weighting Summation and Power Law. Exclusionary Screening, therefore, makes tradeoffs that this decision maker would not have approved had he been presented with them directly.

Maryland Screening II

The same data as used in the previous section were used by another panel of 14 siting experts of varied background. About half as many attributes were selected for screening as by the first panel. Each person chose exclusion levels for each attribute and weights using Categorization, Ratina, and Metfessel Allocation. These weighting methods are all similar and none guarantees the correct type of attribute importance. They are, however, easy for a large group to apply.

Between-methods correlations of weights and suitability scores are uniformly higher than those for the first panel. Unlike the results of the previous section, choice of person was more important to results than choice of weighting method. This is partly because of the simplicity and similarity of methods and partly because of carryover from one method to the next. We expect that a method which is not only conceptually different but also ensures the correct type of attribute importance, e.g., Indifference Tradeoff, would yield a greater difference in results than the simple methods used.

Exclusionary Screening candidate areas were significantly different from those of Weighting Summation using any weighting method, but not so different as those of the first panel. It appears that the results produced by Exclusionary Screening and Weighting Summation are more likely to be similar if few attributes are used than if there are many.

Western U.S. Screening

The 14-member panel of siting experts of the previous section applied the same exclusion screening and weighting methods to 7 attributes and value functions adapted from a nuclear energy center study of 11 western states.

Results are similar to the Maryland results for this panel. Correlations among weighting methods are high and choice of person has a greater effect on results than choice from among these simple methods. 
Differences between Exclusionary Screening and Weighting Summation candidate areas are again greater than differences among weighting methods, but not as great as for the larger number of attributes used by the first Maryland panel.

Combining all of the results above, it appears that choice of decision rule between Exclusionary Screening and Weighting Summation has the greatest influence on screening results. Decision makers should, therefore, give careful consideration to the nature of the screening problem. Exclusionary Screening is useful for selecting candidate areas which meet mandatory legal and engineering requirements, and perhaps for a few very important discretionary criteria. It tends to perform poorly, however, if more than a few discretionary criteria are included because it does not permit tradeoffs among desirable and undesirable levels of different attributes. The resulting candidate areas can, therefore, contain tradeoffs that decision makers would not be willing to make if they were presented with them directly.

Readers should keep in mind that differences in candidate areas do not necessarily imply differences in the quality of candidate sites that can be found therein. To a certain extent, quality of candidate sites depends on the skill and experience of the persons making the candidate si.te selection, but more important, the probability that "good" candidate areas can yield "good" candidate sites is a function of correlations among attributes used in screening, candidate site selection, and final site selection. The greater the correlations among these attributes in the region, the more likely that a screening and candidate site-selection process will be successful in identifying sites that are among the "best" available with respect to the attributes and values used. Also, the greater the correlations among attributes, the more important is the success of each stage of the siting process in providing choices to the next stage which have high probability of yielding "good" sites, and therefore the more important are the methods to that success.

FINAL SITE EVALUATION

Three panels having different levels of siting experience applied nine weight estimation methods and five decision rules to hypothetical data based on an existing siting study of Long Island, New York.

Among the methods tested there is a range of theoretical validity and difficulty of application. In general, the more valid methods are also more 
difficult to use. There is, therefore, a tradeoff between potential for error due to theoretical problems and potential for error due to difficulty in applying the methods. The simplest methods tested, Global Evaluation, Goal Programming, and Goal Attainment, all produce results obviously different from those produced by more valid methods. There are several reasons why these methods are expected to yield different results, and most probably they do not correctly accomplish the desired evaluation process. The most valid method tested, Decision Analysis, is also the most difficult. Results obtained with this method were so inconsistent among themselves that few weights could be calculated with which to estimate site suitabilities. Decision Analysis is clearly not appropriate for application by inexperienced persons without extensive training and consistency checking. We have no results with which to compare application of Decision Analysis by persons experienced in the method.

Weighting Summation and Power Law require estimation of weights. Of the weighting methods tested (other than Decision Analysis) only Indifference Tradeoff attempts to assure valid weights. Indifference Tradeoff weights were consisteitly different from those of other methods. The less valid weighting methods, Categorization, Rating, Ratio Estimation, and Metfessel Allocation, all require similar responses and all produce correspondingly similar weights. Of these, only Categorization stands out as producing obviously different results. This method has significantly reduced capability for dealing rigorously with the level of quantification required of the Weighting Summation and Power Law decision rules.

Responses of participants to application of these methods suggest that the assumption of additive independence, which is fundamental to the Wcighting Summation decision rule, probably does not hold for simpler weighting methods and may not hold for any weighting method.

In spite of some large differences in weights among methods, the two or three top-ranked sites selected by application of the weights to decision rules are all nearly identical. The robustness of outcome arises from the structure of the site attribute levels with respect to numbers and magnitudes of tradeoffs that must be made. If there are few tradeoffs, then results will be insensitive to magnitudes of weights; if there are many tradeoffs, the decision is complex and results will be very sensitive to magnitudes of 
weights and, therefore, to weighting method. An index is derived which quantifies this sensitivity for any combination of attributes and alternatives. With this index; decision makers can determine the complexity of a decision and the need for rigorous methodology. Tests of sensitivity of results from artificial siting data to methodological errors show that complexity has approximately twice the potential to introduce decision.errors as do other variables associated with estimation of weights, including method and individual uncertainty.

Complexity of a final site evaluation is controlled by the candidate site-selection stage. This is the least formalized part of the process and the one most likely to be conducted "by the seat of the pants." Usually a group of experienced persons sits down with a large number of maps and hunts up places that "look good." There is no reason why this method can not yield high-quality choices. Depending on the skill and biases of the persons taking part, however, it has high potential for introducing error. Neither bias nor sloppy workmanship is easy to discover after the fact except by finding an obviously superior alternative not included in the analysis, so careful attention should be given to the quality of workmanship required at this stage.

\section{EVALUATING SITING METHODOLOGIES}

It is a common misconception that a formula exists for siting which, if followed correctly, must necessarily produce a "good" site. In fact, this misconception extends even farther to a belief that such a formula can produce "the best" site. In this context, however, "goodness" is a subjective judgment dependent on the values of the participating decision makers. Until such time as a set of universal values is established by which goodness can be measured to the satisfaction of all, the concept of "best" has limited application in site evaluations.

What, then, is the purpose of complex siting methods? In this study we have viewed siting methods first to be a means of minimizing the amount of data and effort required to reach reasonable solutions to complex problems, and second to be a means of formalizing that data collection and use in such a manner that tradeoffs among different values are apparent and it is possible to determine, at least in a general way, who wins and who loses in a siting decision. 
One implication of the above statement is that, in the end, all decisions requiring tradeoffs among different sets of values must provide in some manner for political interactions. Another implication is that reviewers must not become engulfed in methods for their own sake and forget the objective of the siting process. It is not the method but the results that count. The specifics for evaluating siting methods in Environmental Reports in the body of this report are summarized in the following evaluation checklists.

\section{REGION OF INTEREST CHECKLIST}

I. How is region of interest defined (Section 6.2)?

A. Service Area?

B. If less than service area, by what criteria is the region reduced? 1. Nondiscretionary?

2. Discretionary? Can a reasonable case be made that these criteria are of importance so great that it is not possible for other characteristics to override them?

c. If this stage is bypassed by substitution of results of a previous study, does that study meet current requirements?

REGIONAL SCREENING CHECKLIST

I. Exclusionary Screening (Sections 2.5.1.1 and 4).

A. Are exclusion criteria nondiscretionary?

B. If not, are discretionary criteria of highest importance?

1. Avoiding important local political or environmental problems?

2. Avoiding other problems of local importance as demonstrated by previous siting attempts?

C. Is there any logic behind levels of discretionary criteria or are they set arbitrarily at levels established by historical precedent?

D. Are discretionary exclusion criteria established loosely at levels that allow for uncertainty?

E. Are discretionary exclusion criteria cost related? 
1. Does the report specify how much money is involved (expressed as proportion of total cost and as unit cost of electricity)? Is the cost increase in fact 1 arge?

2. Is there anything special about excluded areas that might make sites there worth the extra cost?

II. Comparison Screening (Weighting Summation) (Sections 2.5.2.1, 2.5.2.4, and 4$)$.

A. Comparison attributes must necessarily be discretionary.

B. Do the attributes meet requirements for independence, clarity of definition, and quantifiability required of the Weighting Summation decision rule?

C. What are the bases for converting attribute levels to subjective value estimates?

D. What weighting method is used (Sections 2.6, 4, and 5)?

1. Does the report specify whose weights are represented?

2. Is the weighting method described? Is it a standard form?

3. Does the method ensure ratio-scaled weights?

4. If not, is its use justified?

a. Is there awareness of problems related to implied weights arising from misapplication of methods.

E. Is the decision rule correctly applied (Sections 2.5, 4, and 5)?

1. Weighting Summation is the only commonly used method for screening. Are attribute values multiplied by weights and added? If not, why not?

F. Does the cutoff for inclusion among candidate areas have sufficient leeway to allow for uncertainty? Are any potential candidate areas excluded for reasons not included in the analysis? If so, are the exclusions justified?

III. Is this stage bypassed in deference to results of a previous study?

A. Is the study recent enough so that data are up to date?

B. Has the siting climate changed enough so that important attributes and attitudes towards them are no longer valid? If not, are they appropriate to this level of analysis? 
I. Is the method of candidate site selection specified (Sections 2.5,4.5, and 5.3)?

A. If so, is it a standard method or "seat of the pants?"

II. Are selection criteria specified (Section 2.3)?

A. Are they complete or, if incomplete, are they appropriate to this level of analysis?

1. Are they disproportionately cost related?

B. Is there any consideration of tradeoffs among attributes?

1. If so, are weights used?

2. Does the report specify whose weights are represented?

3. Is the weighting method described? Is it a standard form?

4. Does the method ensure ratio-scaled weights?

5. If not, is the reason why not justified?

6. Is the decision rule correctly applied?

III. Are criteria for reducing the original slate to a smaller number of sites specified (Section 4.5)?

A. Are tradeoffs considered?

1. If so, see II.B above.

IV. Does the final slate of alternatives include more than two sites?

A. If not, is the small number justified on some reasonable basis?

V. Is anything done that specifically affects complexity? Are there exogenous requirements that affect complexity (Section 5.3)?

A. If it is low, is there dominance or are all sites alike?

B. Is there evidence of possible "deck stacking" (extreme dominance)? 
FINAL SITE SELECTION CHECKLIST

I. Is the method of site selection specified? Is it a standard method (Section 2.5)?

A. If not, is its use justified? Does it seem reasonable with respect to the theoretical considerations discussed in the technical papers associated with this report?

1. How does it deal with tradeoffs?

2. Are weights included? If so, do they meet the requirements of the method with respect to measurement theory?

3. Does the decision rule create implied weights different from the specified weights?

II. If the method is standard, is it applied correctly (Section 2.5)?

A. Do the attributes meet requirements for independence, clarity of definition, and quantifiability?

B. What are the bases for converting attribute levels to subjective value estimates?

C. What weighting method is used?

1. Does the report specify whose weights are represented?

2. Is the weighting method described? Is it a standard form?

a. If not, why not?

3. Does the method ensure ratio-scaled weights or at least a nonarbitrary zero point?

4. If not, is its use justified?

III. If the method is not correctly applied, is the complexity of the slate of candidate sites sufficiently high so that correct application of the method might make a difference in decision (Section 5.3)?

IV. Have sensitivity analyses been made on results?

A. If results are sensitive, how is the final decision justified? 


\section{INTRODUCTION}

Choosing a site for a nuclear power plant requires both large amounts of information and a large number of value judgments on the relative importances of different desirable and undesirable site characteristics. Many methods have been developed for formalizing these value judgments and the site-selection process in which they are used. This report describes these methods, discusses the formal requirements for applying them, and outlines the magnitudes and kinds of decision errors that can be made by misapplication. The purpose of the report is to provide a basis for evaluating alternative site studies submitted in Environmental Reports to the Nuclear Regulatory Commission (NRC) as part of construction permit applications.

This project is a natural extension of a brief review and evaluation of siting methods conducted for NRC in 1978 by Scandia Laboratories. 1 Portions of the experimental design are derived directly from that study. Many of the results are extensions or confirmations of the more theoretical results reported for that study. This project is different, however, in the extent to which various siting methods are tested empirically and results are compared one with another. We are able, therefore, to generalize many of the isolated observations of that study, and to expand empirical results into areas outside the scope of all other methodology comparisons reported in the literature of multiobjective decision making.

Three independent approaches have been applied in generating the information reported here. An extensive review and evaluation of the literature on multiobjective decision-making methods provide a theoretical framework for how the various methods should be applied and the kinds of errors commonly made in applying them. A review of siting methods described in site-selection chapters of 48 Environmental Reports submitted to NRC between 1973 and 1978 provides perspective on the range of possible methods that has actually been applied. Applications of some commonly used methods by panels of experts specially selected for different levels of knowledge of the siting process and the specifics of siting methods provide understanding of the problems encountered while using these methods and the variability that can be expected in the results. Finally, sensitivity testing of an artificial data base containing 48 independent siting problems extends results to a sufficiently large number of observations to permit generalizations not possible 
on the basis of the limited circumstances tested by direct applications of methods.

These approaches and their results are documented in several technical reports of which this report is a summary and evaluation. Readers are referred first to the summary of this report which is a "summary of summaries" containing important conclusions. The body of this report contains brief descriptions of each independent study with details of results and conclusions. In each study an attempt is made to address three basic questions. First, what are the formal requirements for methods appropriate to each level of analysis?. Second, what kinds of mistakes are commonly made and what is their significance? Third, what is the potential for these mistakes to change a site evaluation sufficiently to cause a change of decision? In the final chapter of this report, these results are discussed as they apply to evaluation of siting studies reported in the Environmental Reports submitted as part of construction permit applications. For details of the studies on which each chapter is based, readers are referred to the appropriate technical report. 


\section{REVIEW OF MULTIOBJECTIVE DECISION MAKING METHODS}

2.1 INTRODUCTION

Utilities increasingly rely on use of sophisticated methods to screen regions and choose power plant sites. Multiobjective decision rules lie at the heart of methods which combine diverse considerations and produce rank orders of sites. A large body of theory defines conditions under which decision rules accurately model the values of decision makers, and how those rules should be applied. More often than not, siting applications do not meet these conditions. This chapter summarizes the assumptions of many multiobjective methods, giving conditions under which the assumptions are correct, and the possible consequences of their violation. It also summarizes their flexibility and ease of use, and, where possible, discusses whether or not different methods produce different results. The purpose of this chapter is to:

1. Introduce readers to the range of multiobjective methods available and to the burgeoning, chaotic, and conflicting literature of multiobjective decision making.

2. Help utilities choose methods and use them correctly.

3. Assist reviewers in critiquing siting studies.

This chapter is a summary of a larger technical report on multiobjective decision-making methods. 2 Readers are referred to that report for details.

\subsection{ANALYTICAL SITING METHODS: ISSUES AND CRITERIA FOR THEIR USE}

Analytical siting methods have both proponents and detractors. Those favoring their use contend that oniy systematized methods can explicitly and rigorously account for all siting considerations and assert that unassisted human judgment is incapable of balancing risk, multiple objectives, and multiple interest groups, while fulfilling legal mandates. Others, however, hold that multiobjective methods are impractical, simple minded, and misleading number games that only obscure important information and tradeoffs.

Both sides agree, however, on the following criteria for use of analytical methods:

1. Siting methods should allow for careful, consistent, and well documented examination of all factors, tangible and intangible. Important issues and tradeoffs should be considered explicitly. Site 
choices should reflect decision makers' values as accurately as possible.

2. Methods should generate and preserve information about impacts of different sites and tradeoffs among them.

3. Methods should allow for input by more than one decision maker, including nontechnical members of the public. Procedures should be understandable and not difficult to use. Implications of different personal values for siting considerations should be readily discernible.

These criteria are often in conflict; hence, the choice of a multiobjective method itself becomes a multiobjective problem.

\subsection{CHOOSING AND SCALING SITING ATTRIBUTES}

Sites are described in terms of physical attributes - those impacts and site characteristics that are included in an evaluation. Two different ways to decide which attributes should be included are:

1. The Bottom-up or Checklist method, in which attributes are simply listed according to historical precedent.

2. The Top-down or Hierarchy approach in which overall objectives are first defined and then disaggregated until attributes are specified.

Only important attributes that differ among sites should be included. The expense of data acquisition is also relevant. The following criteria should be used for constructing hierarchies:

1. Each set of subdivisions should be comprehensive and unique.

2. No duplication should occur within a group.

3. Each group should have as little complexity and division as possible.

Any real-world hierarchy falls short of these ideals; nevertheless hierarchy construction requires care, since many important value judgments are made at this stage.

Physical attributes are not applied directly by most multiobjective methods. They first must be scaled in terms of suitability ("value" or "utility") for the intended purpose. The functional relationship between 


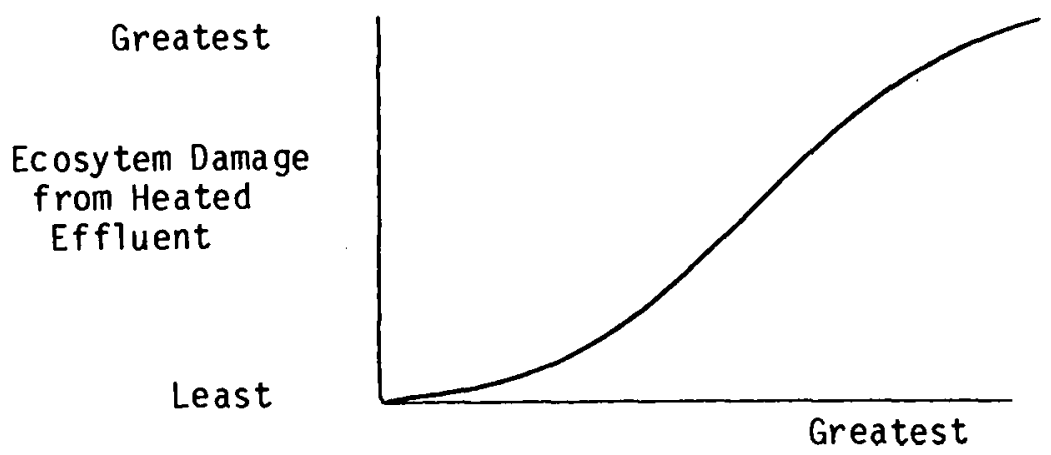

Annual Highest Temperature of Receiving Body of Water

Figure 2.1. Attribute Value Function for Ecosystem Damage Due to Increased Temperature of Receiving Water.

measured quantities and suitability is called an attribute value function (Figure 2.1). Many scaling methods exist (Table 1), differing in the types of scales they produce and the kinds of questions they address, as well as in their flexibility and ease of use. The most important scale characteristic is level of measurement, of which three are important in siting:

1. Ordinal - Scales whose only meaningful relations are $>$, $=$ and $<$. They can consist of rank orders, discrete categories, or continuous non-interval scales. "Cool," "Warm," or "Hot" is an ordinal temperature scale. Theory permits no addition or multiplication of such scales.

2. Interval - Scales in which differences between numbers are meaningful, although the zero point is arbitrary. Degrees Fahrenheit and Celsius are interval temperature scales; they can be added, subtracted, and weighted.

3. Ratio - An interval scale whose zero point indicates zero amount of the characteristic measured. Degrees Kelvin is a ratio temperature scale. Theory allows all algebrdic operations.

Table 2.1 shows that scaling methods are available for each of the three levels of measurement. Different multiobjective methods require attribute values having different levels of measurement. 
TABLE 2.1

METHODS OF SCALING PHYSICAL ATTRIBUTES

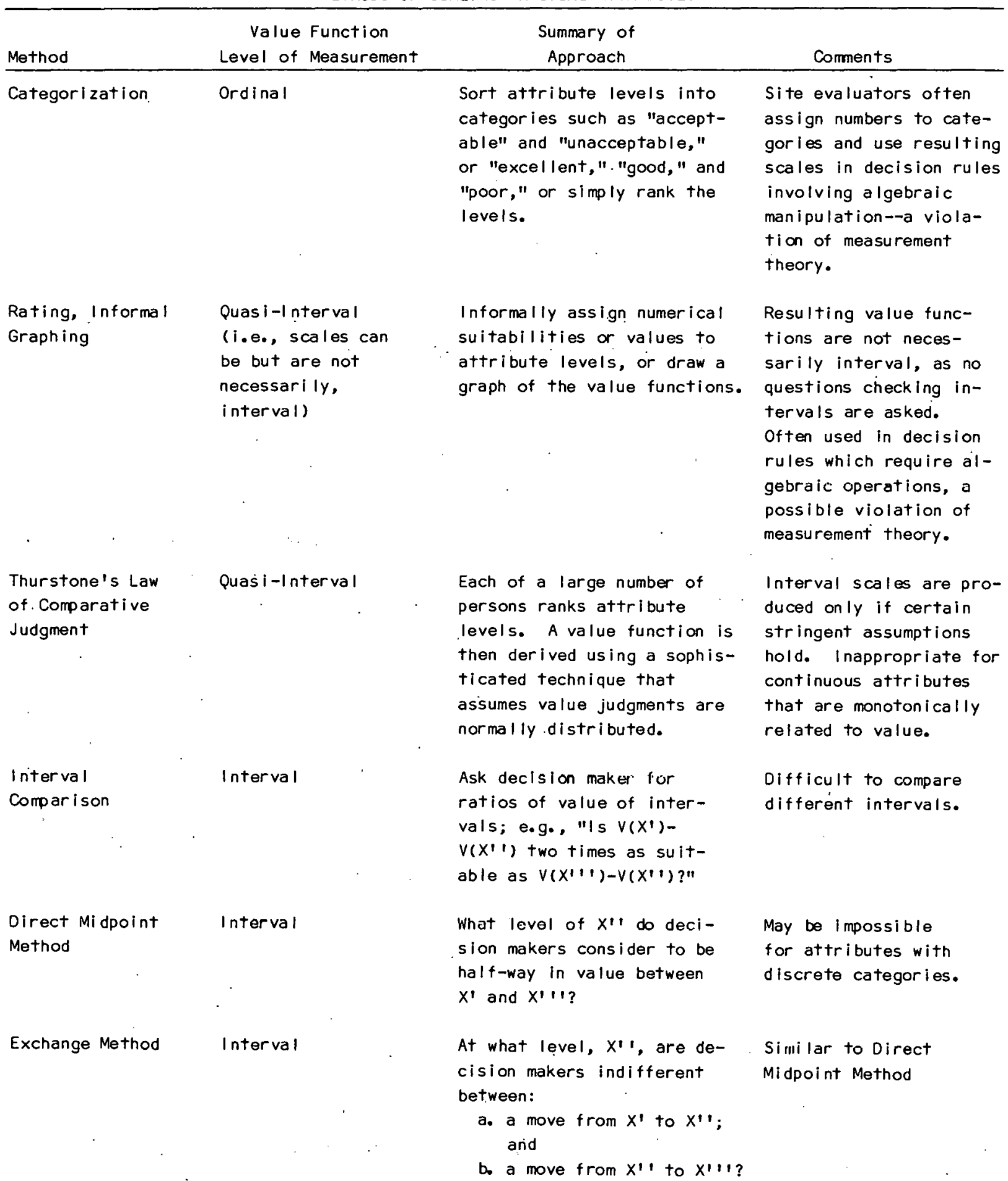


TABLE 2.1

METHODS OF SCALING PHYSICAL ATTRIBUTES

\begin{tabular}{|c|c|c|c|}
\hline Method & $\begin{array}{c}\text { Value Function } \\
\text { Level of Measurement }\end{array}$ & $\begin{array}{c}\text { Summary of } \\
\text { Approach }\end{array}$ & Comments \\
\hline Direct-Ordered Metric & Interval & $\begin{array}{l}\text { Decision makers rank all pos- } \\
\text { sible intervals; linear pro- } \\
\text { gramming is used to find the } \\
\text { value function most consistent } \\
\text { with the rank order. }\end{array}$ & $\begin{array}{l}\text { Difficult to compare } \\
\text { different intervals. } \\
\text { If no scale is con- } \\
\text { t sistent with rank } \\
\text { order, more complex } \\
\text { analysis is re- } \\
\text { quired. }\end{array}$ \\
\hline The Gamble Method & Interval & $\begin{array}{l}\text { At what chance } p \text {, given level } \\
X^{\prime \prime} \text { ' (or } X^{\prime} ' \text {, given } p \text { ) are de- } \\
\text { cision maker's indifferent be- } \\
\text { tween: } \\
\text { 1. level } x^{\prime \prime} \text {, and } \\
\text { 2. a gamble, with chance } \\
\text { p of obtaining } x^{\prime \prime \prime}, \\
\text { and chance (1-p) of } \\
\text { getting } x^{\prime} \text { ? }\end{array}$ & $\begin{array}{l}\text { Creates utility } \\
\text { function } U(x) \text { incor- } \\
\text { porating } r i s k \text { atti- } \\
\text { tudes. } U\left(X^{\prime} '\right) \\
\text { equals } p U\left(X^{\prime \prime} 1\right)+ \\
(1-p) U\left(X^{\prime}\right) \text {. }\end{array}$ \\
\hline $\begin{array}{l}\text { Methods Involving } \\
\text { Two Attributes }\end{array}$ & Interval & $\begin{array}{l}\text { An exarrile is the single } \\
\text { Tradeoff method. Two } \\
\text { equally suitable sites } \\
\text { are defined that difter } \\
\text { in only two attributes. } \\
\text { The absolute value of the } \\
\text { change in the first attri- } \\
\text { bute must be as valuable } \\
\text { as the absolute value of } \\
\text { the change in the second. } \\
\text { If one of the value func- } \\
\text { lions is known, the other } \\
\text { can be inferred. }\end{array}$ & $\begin{array}{l}\text { A difficult approach. } \\
\text { May be better than } \\
\text { considering each } \\
\text { attribute in isola- } \\
\text { tion. If attributes } \\
\text { are not "difference } \\
\text { independent (see Ref- } \\
\text { erence } 2 \text { ), then only } \\
\text { ordinal scale is pro- } \\
\text { duced. There are } \\
\text { many tcchniques of } \\
\text { this type. }\end{array}$ \\
\hline Ratio Questioning & Ratio & $\begin{array}{l}\text { Aak tor tho rotio if lihe } \\
\text { value of } x^{\prime} \text { and } x^{\prime} \text { '. }\end{array}$ & $\begin{array}{l}\text { Katio scale only if } \\
\text { logarithmic percep- } \\
\text { tion is not a prob- } \\
\text { lem. (See discussion } \\
\text { of Power Law deci- } \\
\text { slon rule.) }\end{array}$ \\
\hline Metfessel Allocation & Ratio & $\begin{array}{l}\text { Al locate } 100 \text { points amnng } \\
\text { the attribute levels in pro- } \\
\text { portion to their value. }\end{array}$ & $\begin{array}{l}\text { Rosults have been } \\
\text { shown to be nearly } \\
\text { identiral to Ratio } \\
\text { Questioning. }\end{array}$ \\
\hline
\end{tabular}


Attribute value functions can also incorporate decision makers' attitudes towards risk; those that do are called utility functions. Such functions are needed when decision makers require information on probability distributions of possible outcomes. Only the Gamble scaling technique, part of the Decision Analysis methodology, captures these attitudes. Deterministic value functions (which do not reflect risk attitudes) can be transformed into utility functions (which do), provided that decision makers' risk attitudes are "constant." Decision makers have constant attitudes towards risk if they are risk averse (or neutral or preferring) to the same degree for all levels of an attribute. In at least one siting study this assumption has been shown to be invalid. Risk neutrality means that utility and deterministic value functions are identical. In at least one siting study, however, this assumption has been shown to be invalid.

Data on differences between results of different scaling methods are scarce. Theoretically, ordinal scales could result in choice of sites different from those chosen by interval scales when used in decision rules not designed for them. Nevertheless, many siting studies are guilty of this violation. One siting study yielded identical attribute value functions from the Direct Midpoint and Single Tradeoff methods (Table 1). In that study the scalers were not risk neutral, however, so the utility functions created by the Gamble technique differed. Those differences would probably not affect site choice; in two of three Decision Analysis studies examined in this project ${ }^{2}$ use of 1 inear attribute value functions instead of utility functions did not significantly change ranks of alternatives.

\subsection{NONINFERIOR SET GENERATION AND DISPLAY}

Some multiobjective methods only provide information on tradeoffs among sites. Those methods determine what sites are dominated in all. attributes by at least one other site and thus should be dropped from consideration. The remaining sites are "noninferior" in that they require tradeoffs between higher levels of one attribute and lower levels of another. Such sites can be displayed on graphs, with each axis representing an attribute (Figure 2.2); more than three attributes makes this difficult and confusing. "Factor profiles," a type of bar graph with each bar representing an attribute, can . be substituted. Alternatively, one can aggregate groups of attributes into super-factors (e.g., "Environment" or "Engineering Feasibility") for graphic 
display. Noninferior sets and tradeoffs are presented to decision makers

v. without further evaluation.

Constraint and Weighting are two methods used to generate noninferior sites. The Constraint method optimizes one attribute while permuting lower bounds on the values of the others. The Weighting method maximizes the Weighing Summation model for a number of arbitrary weight sets. Practical aspects of the two methods are similar. These techniques are most relevant to siting problems formulated as mathematical programs with many sites and attributes. They are unnecessary for simpler siting problems.

Paretian Analysis analyzes tradeoffs among interest groups instead of site attributes. A decision rule is defined for each group, each site is evaluated by each rule, and the sites are plotted in group-space. The noninferior set in this case is called the "Pareto Frontier." The political nature of siting requires that decision illkers consider who wins and who loses in a decision; Paretian Analysis provides insights into the distribution of impacts among groups.

\subsection{MULTIOBJECTIVE DECISION RULES}

Multiobjective decision rules produce at least a partial rank order of sites by combining attributes in a specified manner. Some rules use attribute value functions that are on an ordinal level of measurement. 0thers which use algebraic operations require interval- or even ratio-scaled value functions. Weights reflecting relative importances of attributes are also applied by most rules.

\subsubsection{Decision Rules Using Ordinal Attribute Value Functions}

2.5.1.1 Exclusionary Screening rejects sites that are unsatisfactory in one or more attributes (Figure 2.3). It is most useful in defining candidate areas within a study region. All attributes can be considered at once, or in sequence until a sufficiently small set of areas remains. A basic problem of the method is that only rarely are alternatives clearly acceptable or unacceptable; there is usually a gradation of acceptability. The method also ignores important tradeoffs among attributes and subtle differences among sites.

2.5.1.2 Conjunctive-Ranking screens out unacceptable sites using all attributes but one. The last attribute is then used to rank the remaining sites. As in Exclusionary screening, tradeoffs are not considered. 


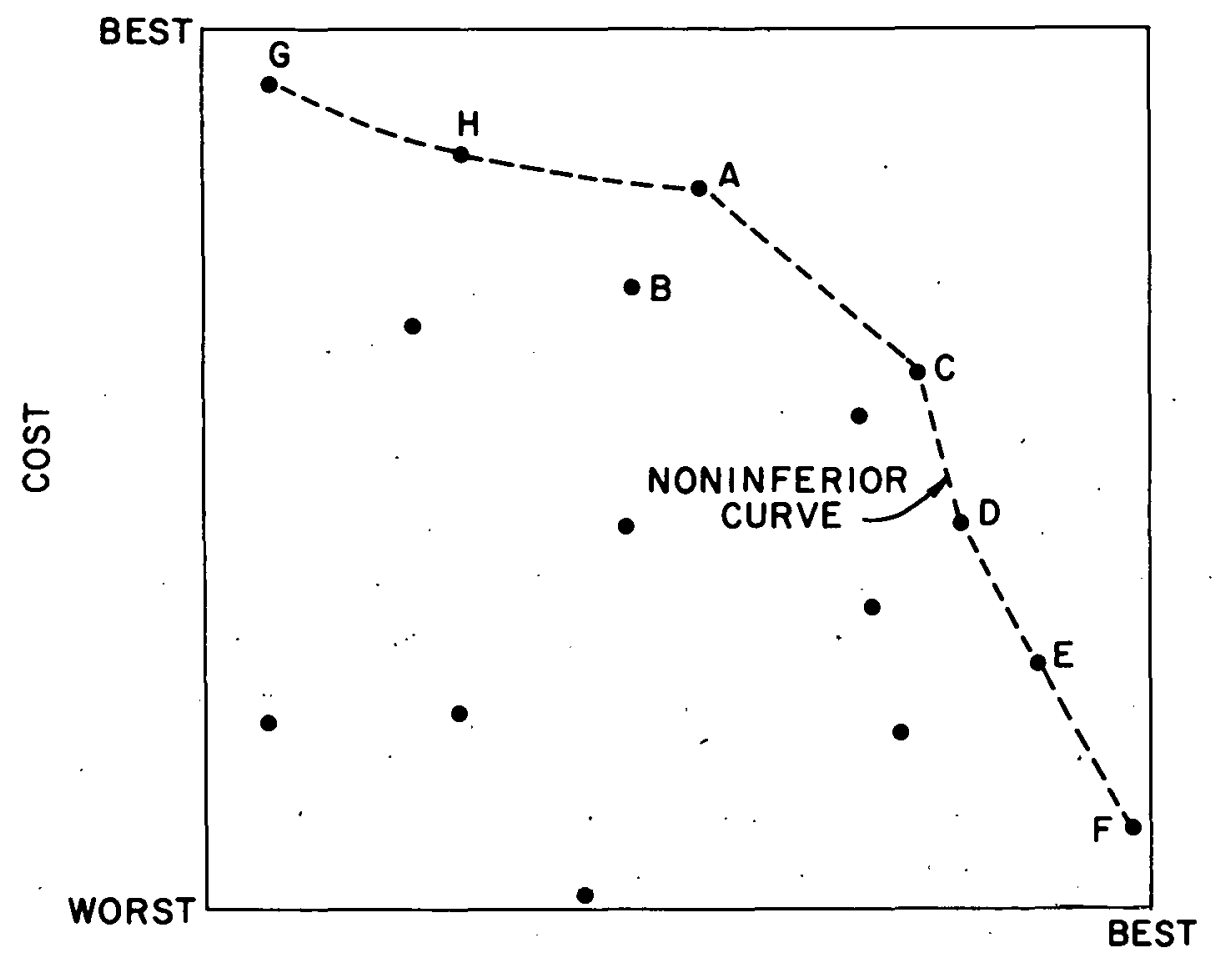

ENVIRONMENTAL IMPACT

Figure 2.2. Site Characteristics and a Noninferior Curve. .

2.5.1.3 Copeland's Reasonable Social Welfare Function selects the site that "wins" the most pairwise comparisons. Each site is compared with every other site, one at. a time, using the Majority Rule. That rule scores a win for the site that is best in most attributes. Alternatively, weights car, be applied, and a win is given to the site having the higher weighted sum of attributes in which it is best. This method disregards the degree to which one site is better than another in any attribute.

2.5.1.4 Direct Determination of Indifference Curves requires that decision makers decide what combinations of attribute levels are the same in terms of suitability. An "Indifference curve" is a locus of sites in attribute space that are equally suitable (Figure 2.4). The method yields a contour map whose lines represent different levels of equal suitability. The site lying on the highest indifference curve is then chosen. The method's advantage is that no arbitrary model of decision makers' values is imposed. The approach is tedious, however, which precludes application when there are more than three attributes or "super-factors." Interactive computer programs can ease the process. 


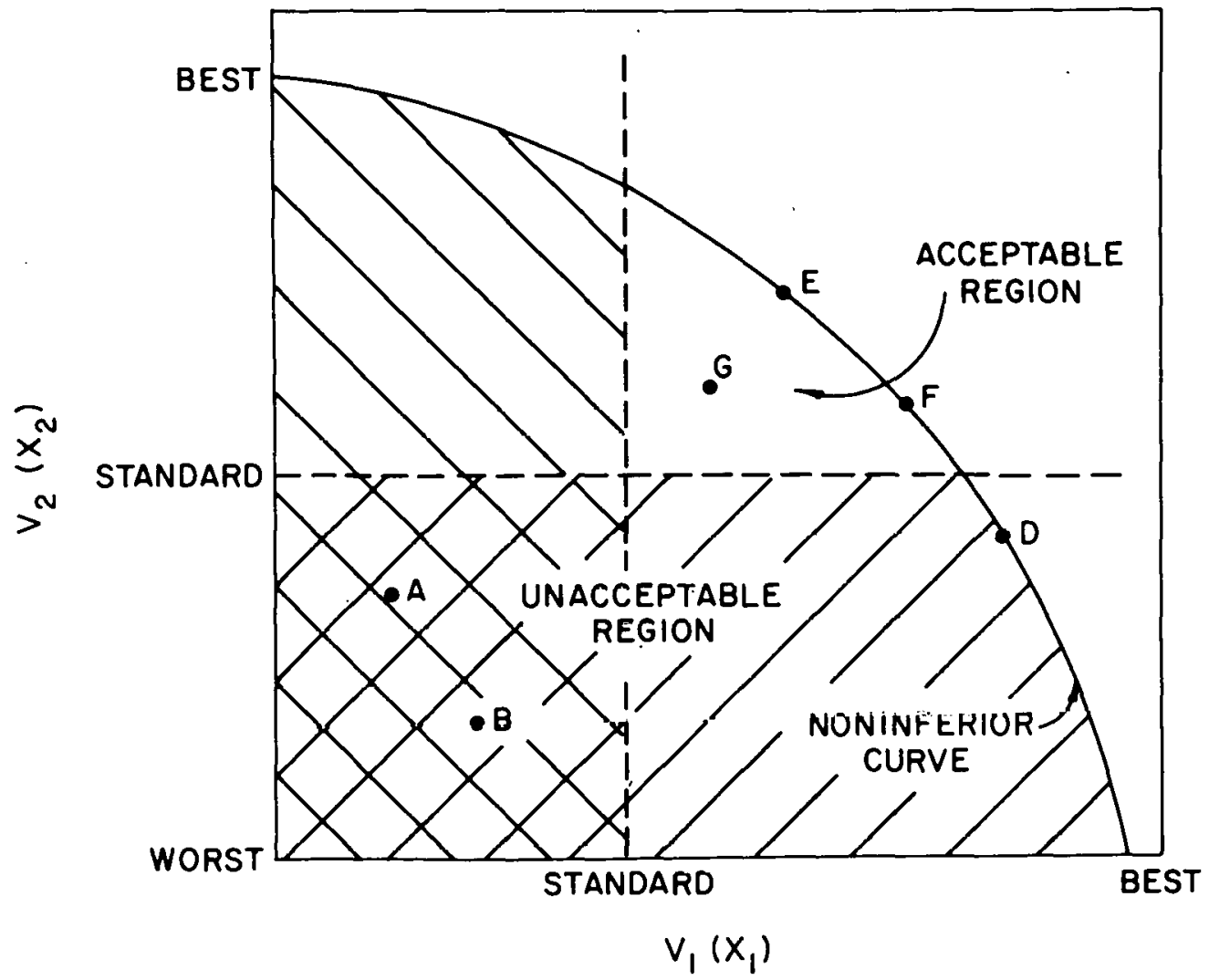

(VALUE FUNCTION FOR ATTRIBUTE $X_{1}$ )

Figure 2.3. Exclusionary Screening.

\subsubsection{Decision Rules Requiring Interval or Ratio Attribute Value Functions}

Interval-scaled attribute value functions must be used in all of the remaining decision rules but the Power Law which requires ratio-scaled value functions.

2.5.2.1 Weighting Summation, after exclusionary screening, is the most commonly applied decision rule in siting. It chooses the site maximizing

$$
\text { Suitability }=\sum_{i=1}^{n} w_{i} v_{i}\left(x_{i}\right) \text {, }
$$

where $w_{i}$ is the weight and $v_{i}\left(x_{j}\right)$ is the value function of attribute $x_{i}$. 


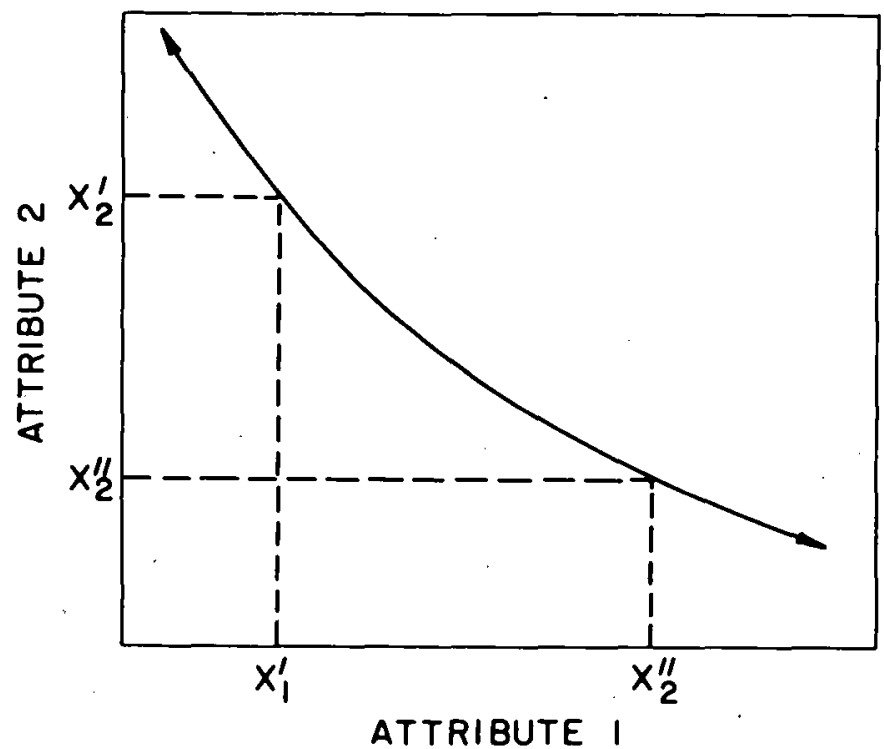

Figure 2.4. Indifference Curve Between Two Attributes.

Applications often ignore a number of important assumptions of this decision rule. They are as follows.

1. Attributes are additive independent:

a. Each interval attribute value function is constant over all levels of other attributes ("difference" or "utility independence").

b. Tradeoffs that decision makers are willing to make among attribute value functions do not depend on the levels of any attributes ("preference independence").

c. Attribute values are known with certainty, or decision makers care only about marginal probability distributions of attributes, not their joint distribution.

2. Attribute value functions are interval scaled.

3. Weights are ratio scaled, and represent the relative importance of unit changes in attribute value functions. That is, $w_{1}=1$ and $w_{2}$ $=2$ implies that decision makers are indifferent to a change in $v_{1}\left(x_{1}\right)$ of 1.0 or a change in $v_{2}\left(x_{2}\right)$ of 0.5 . 
4. Decision makers are concerned more with optimal tradeoffs than with achieving prespecified goals; further, they are able to state what tradeoffs they are willing to make without knowing the noninferior set.

Other decision rules using interval value function share most of these assumptions. If any are incorrect, then Weighting Summation does not accurately model decision makers' values.

Weighting Summation is used for both regional screening and final site selection. Regional screening applications are usually computer based because large amounts of information must be processed for many areal units. The method selects an area for further analysis if its suitability is equal to or greater than some specified number.

2.5.2.2 Decision Analysis is the only method which validly reflects preferences regarding uncertainty and risk. It uses attribute utility functions (by the Gamble technique) instead of deterministic value functions. If utility and preference independence (among other assumptions) hold for all attributes, then either the Weighting Summation (with utility functions) or the multiplicative form is valid. The latter is

$$
\text { Suitability }=\left\{\left[\prod_{i=1}^{n}\left[1+k w_{i} U_{i}\left(x_{i}\right)\right]-1\right\} / k\right. \text {, }
$$

where:

$$
\begin{aligned}
U_{j}\left(X_{j}\right), W_{i}= & \text { Utflity function and Decision Analysis weight for } \\
& \text { attribute } X_{j} \text {. } \\
k= & \text { Constant, forcing suitability to range between } 0 \text { and } 1 .
\end{aligned}
$$

The more complex form is adopted when decision makers care not only about marginal probability distributions of attributes, but also about joint distributions. This is true when decision makers choose Decision Analysis weights that do not sum to 1 . More complicated decision rules are used in Decision Analysis when preference independence does not hold for all attributes.

In theory, weighting Summation models using deterministic value functions can validly be converted into Decision Analysis rules reflecting risk preferences. To do this, decision makers must have "constant" attitudes 
towards risk. That is, their degree of risk aversion (or neutrality or preference) must not change from attribute to attribute.

Although Decision Analysis is the most valid decision rule, it is also the most difficult to use. There is some question, therefore, about the accuracy of the results when applied by persons unfamiliar with the method. There may be a tradeoff between theoretical validity and unreliable results caused by inexperience.

2.5.2.3 Goal Programming finds the alternative having the smallest deviations from a set of prespecified goals, $G_{j}$ :

$$
\text { MINIMIZE } \sum_{i=1}^{n}\left|G_{i}-w_{i} v_{i}\left(x_{i}\right)\right|^{p} \text {. }
$$

The parameter $p$ reflects decision makers' willingness to make tradeoffs (Figure 2.5). When $p$ equals 1.0, Goal Programming is similar to Weighting Summation; when $p$ equals $\infty$ (the Goal Attainment Method), decision makers are only concerned with the worst performing attribute and will make no tradeoffs at al1. Goal Programming assigns a site that is $X$ units better than a goal to be just as bad as one $X$ units worse.

2.5.2.4 The Power Law assumes, as some researchers assert, that people perceive proportions in a logarithmic rather than a linear manner. If so, attributes weighted $1,2,3$ are actually $\mathrm{e}^{1}, \mathrm{e}^{2}$, and $\mathrm{e}^{3}$ in importance. The Power Law has the following form:

$$
\text { Suitability }=\prod_{i=1}^{n} v_{i}\left(x_{i}\right) w_{i} \text {. }
$$

If any $V_{j}\left(X_{j}\right)$ is zero, suitability is zero (a type of Exclusionary Screening). Hence, as the zero point cannot be arbitrary, ratio-scaled value functions are required.

2.5.2.5 Hurwicz Procedures include the minimax and maximax decision rules, for which each site's worst (minimax) or best (maximax) attribute value is of concern. The approach is useful for examining "sore thumb" alternatives but generally not for selecting a best site when tradeoffs are imp ortant.

2.5.2.6 ELECTRE combines elements. of Copeland's Reasonable Social Welfare Function and Hurwicz procedures. Each site is compared with every other site one at a time, and two indices are calculated: 


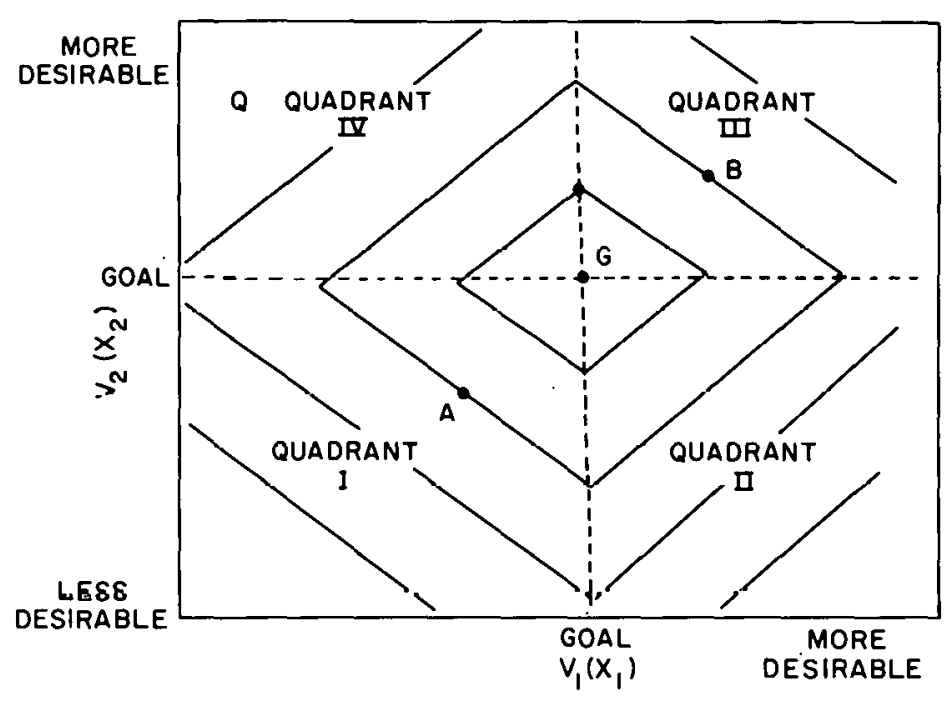

a. Form 1: Absolute Value of Deviation

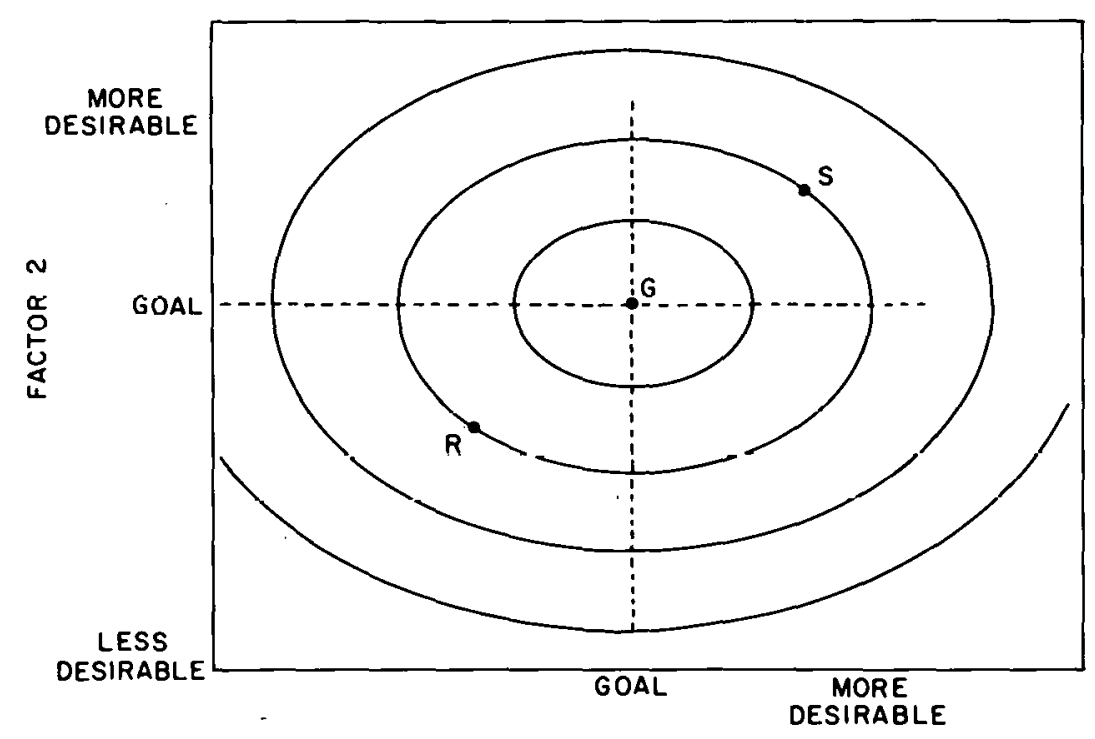

b. Form 2: Squared Values of Deviations

Figure 2.5. Indifference Curves Implied by Goal Programming. 
1. A concordance index, equal to a weighted sum of the number of attributes for which the first site is superior to the second.

2. A discordance index, equal to the maximum weighted difference in values of attributes for which the first site is inferior to the second.

The first site is said to "outrank" the second when the concordance index exceeds a prespecified threshold, while the discordance index is not worse than another given leve1. Many sites not outranked by any alternative can remain. For this reason, ELECTRE is most appropriate for reducing a large number of candidate sites to a more manageable set for final selection.

\subsubsection{Empirical Comparisons of Decision Rules}

Many studies outside of siting use multiple regression to fit decision rules to judgmental or "holistic" ratings of multiattributed alternatives. Almost invariably, Weighting Summation "fits" best (i.e., has the highest correlation coefficient). When interactive terms (products of attributes) are significant, they still account for only a small amount of the variance. Many studies show that Weighting Summation assessed without regression predicts holistic decisions well, though one found that it leads to less disagreement between different groups than holistic judgment.

Few studies compare results of different decision rules assessed without regression. Two such studies demonstrate that Exclusionary Screening and Weighting Summation choose different siting candidate areas. Another study, in one case, found that directly determined indifference curves are more nonlinear than curves resulting from Decision Analysis. Decision Analysis and Weighting Summation rank orders usually resemble each other closely, although risk preferences make an important difference in one siting study. Three watershed planning studies found that Decision Analysis, Goal Programming ( $p$ $=1,2$, and $\infty$ ), ELECTRE, the Power Law, and Weighting Summation choose the same two plans, though the same one was not best in each case. In two siting studies using the Power Law, Weighting Summation would have chosen the same sites. The Power Law and Goal Programming $(p=2, \infty)$ have also been applied to two Decision Analysis siting studies. Power Law and Decision Analysis resulted in the same ranks in one case, and different ranks in another. Goal Programming made even more of a difference in both instances in comparison to Decision Analysis. 


\subsection{WEIGHTING TECHNIQUES}

Some methods attempt to assure ratio-scaled weights reflecting the relative importance of unit changes in attribute value functions; other easier techniques do not. Other definitions of attribute importance are possible, but are incorrect. Only one method, Decision Analysis, incorporates decision makers' attitudes towards risk. Table 2.2 summarizes the available weighting methods, the questions they address, and the theoretical validity of weights they produce. They are listed in approximate order of ease of use leasiest to most difficult), except for Observer-derived Weighting, whose difficulty depends on the number of attributes and al ternatives being evaluated.

There are many ways to obtain weights from groups. Individual questionnaires are one. The Delphi Method, which feeds back means and standard deviations of each weight before asking for weights again, is another. The Nominal Group Process structures group interaction to avoid problems that lower the effectiveness of informal groups.

Whether or not methods produce theoretically valid weights is not an academic question; different weighting methods can result in choice of different sites. In one siting study using Weighting Summation, Rating chose different candidate areas from Indifference Tradeoff, a more valid method. The differences were comparable to those due to having different people choose weights or using Exclusionary Screening instead of Weighting Summation. Differences caused by decision-maker uncertainty were less important. Decision Analysis lottery weights were not proportional to Indifference Tradeoff weights in that study, despite theory saying that they should be.

other comparisons of weighting methods conclude that:

1. Ranking and Rating choose similar weights.

2. The Churchman-Ack off method can, but does not always, significantly modify Rating weights.

3. Rating and Metfessel Allocation weights can differ.

4. Multiple regression weights are more concentrated on a few attributes than weights chosen by other techniques. Sometimes even the signs of regrcssion weights differ from those selected by other methods. 
Table 2.2

METHODS OF WEIGHTING SCALED ATTRIBUTE VALUES

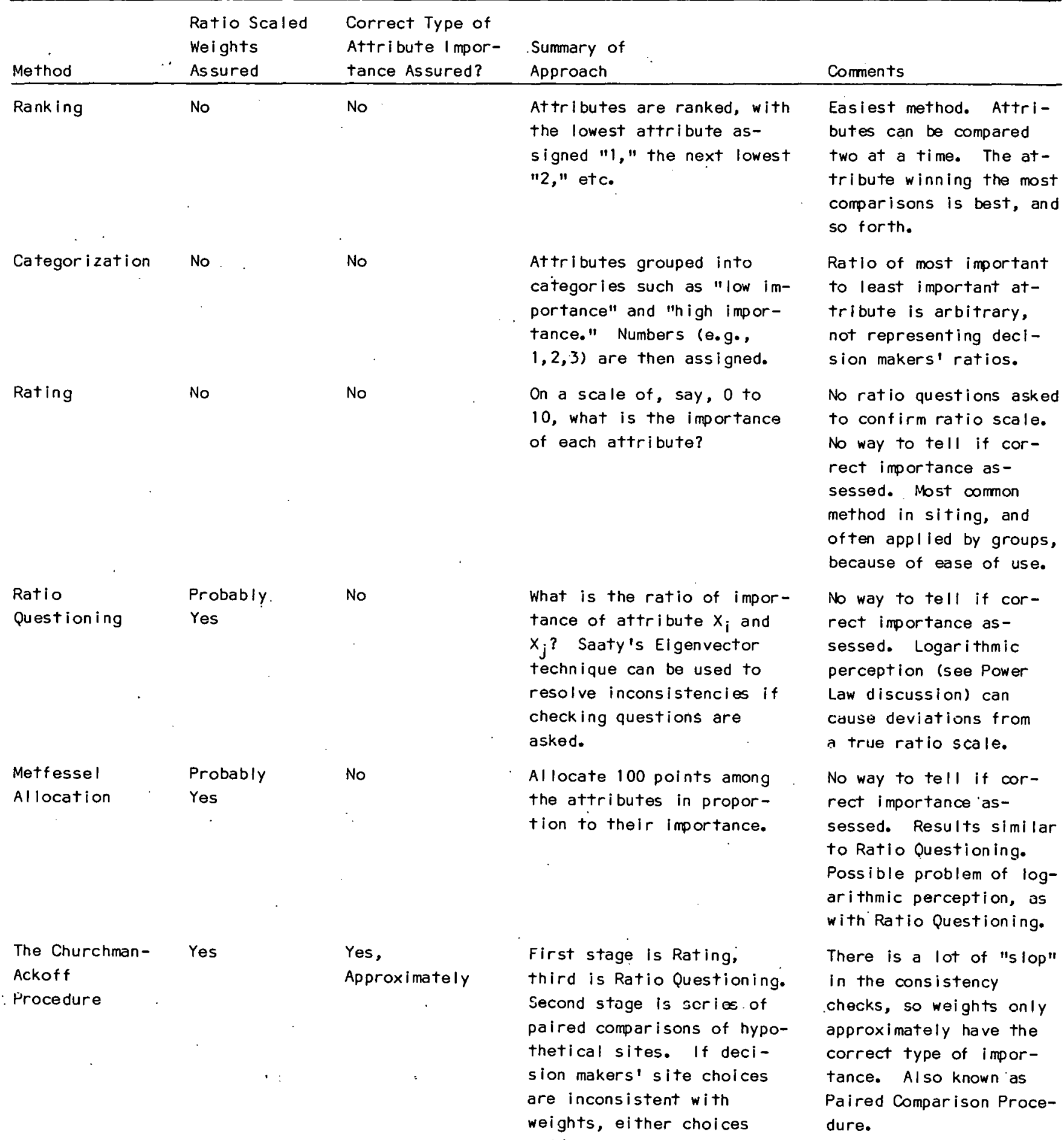


Table 2.2 (Continued)

\begin{tabular}{|c|c|c|c|c|}
\hline Method & $\begin{array}{l}\text { Ratio Scaled } \\
\text { Weights } \\
\text { Assured }\end{array}$ & $\begin{array}{l}\text { Correct Type of } \\
\text { Attribute I mpor- } \\
\text { tance Assured? }\end{array}$ & $\begin{array}{l}\text { Summary of } \\
\text { Approach }\end{array}$ & Comments \\
\hline $\begin{array}{l}\text { Indifference } \\
\text { Tradeoff }\end{array}$ & Yes & Yes & $\begin{array}{l}\text { Questions such as: how much } \\
\text { of attribute } x_{i} \text { would you } \\
\text { give up to obtain } \Delta x_{j} \text { more of } \\
x_{j} \text { ? More than the minimum } \\
\text { number of questions (one less } \\
\text { than the number of attri- } \\
\text { butes) should be asked as } \\
\text { consistency checks. }\end{array}$ & $\begin{array}{l}\text { Some consider this to be } \\
\text { more realistic than sim- } \\
\text { pler methods; others be- } \\
\text { lieve it to be too dif- } \\
\text { ficult. Theoretically, } \\
\text { these weights will he } \\
\text { proportional to weights } \\
\text { from other valid methods } \\
\text { (Churchman-Ackoff, Deci- } \\
\text { sion Analysis). }\end{array}$ \\
\hline $\begin{array}{l}\text { Declsion } \\
\text { Analysis }\end{array}$ & Yes & Yes & $\begin{array}{l}\text { There are many alternative } \\
\text { ways, each involving a lot- } \\
\text { tery. For instance: At what } \\
\text { probability } p \text { are you indif- } \\
\text { ferent to a cholce between: } \\
\text { 1. A site with attribute } x_{j} \\
\text { at its best level, and } \\
\text { all other attributes at } \\
\text { their worst; and } \\
\text { 2. a lottery, where there } \\
\text { is } \\
\text { a. chance p of getting } \\
\text { all attributes at } \\
\text { their best levels; } \\
\text { b. chance ( } 1 \text {-p) of get- } \\
\text { ting all attributes } \\
\text { at their worst lev- } \\
\text { els? } \\
\text { The welght of } x_{i} \text { is pre- } \\
\text { cisely p. }\end{array}$ & $\begin{array}{l}\text { The most difficult method } \\
\text { and the only one incorpo- } \\
\text { rating decision makers' at- } \\
\text { titudes towards risk. If } \\
\text { the sum of Decision Analy- } \\
\text { sis weights is not } 1.0 \text { a } \\
\text { decision maker is not risk- } \\
\text { neutral, and the Decision } \\
\text { Analysis multiplicative } \\
\text { decision rule should be } \\
\text { used. A set of Decision } \\
\text { Analysis weights can be } \\
\text { found by choosing one } \\
\text { weight as shown (say, } W_{i} \\
\text { for attribute } x_{i} \text { ) and mul- } \\
\text { tiplying a set of Indiffer- } \\
\text { ence Tradeoff (IT) weights } \\
\text { by } W_{i} / W_{k} \text {, where } W_{i} \text { is the } \\
\text { IT weight for } x_{i} \text {. } \\
\text {. }\end{array}$ \\
\hline $\begin{array}{l}\text { Observer- } \\
\text { Derived } \\
\text { Weighting }\end{array}$ & $\begin{array}{l}\text { Only if } \\
\text { Attributes } \\
\text { are Uncorre- } \\
\text { lated }\end{array}$ & $\begin{array}{l}\text { Only if } \\
\text { Attributes } \\
\text { are Uncorrelated }\end{array}$ & $\begin{array}{l}\text { Decision makers judge the } \\
\text { suitability of each of a } \\
\text { large number of sites. Tlie } \\
\text { judgments are then 'fitted' } \\
\text { to the sites' attribute } \\
\text { levels using either multiple } \\
\text { regression or linear pro- } \\
\text { gramming. }\end{array}$ & $\begin{array}{l}\text { Approach presumes that un- } \\
\text { aided judgment is to be } \\
\text { Imitated as closely as pos- } \\
\text { sible, rather than be im- } \\
\text { proved. Because of attri- } \\
\text { bute intercorrelations, } \\
\text { regression coefficients } \\
\text { may bear little resemblance } \\
\text { to results uf uller meth- } \\
\text { ods. If there are too many } \\
\text { attributes, the task can be } \\
\text { too difficult and decision } \\
\text { makers will ignore less im- } \\
\text { portant attributes. }\end{array}$ \\
\hline
\end{tabular}




\subsection{ITERATIVE METHODS FOR EXPRESSING PREFERENCES}

Decision rules such as those discussed above evaluate sites in one step; furthermore, decision makers must specify attribute weights and value functions without knowing how those judgments affect site choices. There is another approach, iterative in nature, which allows decision makers to express preferences through a series of steps.

\subsubsection{Decision Rules}

2.7.1.1 The Zionts-Wallenius Procedure and STEM are two examples, which generally proceed as follows:

1. A noninferior site is generated.

2. Decision makers consider the site with respect to achievenent of goals, or compare it with other noninferior sites.

3. Responses of decision makers' are incorporated into the process and used to generate a new noninferior site.

4. These steps are repeated until decision makers are satisfied with the suitability of the site or some termination rule ends the iterations.

These two methods are useful only for siting problems with many attributes and alternatives. For simpler problems, either of the following two more informal procedures is better.

2.7.1.2 Bishop's Factor Profile compares sites in pairs. Decision makers choose between noninferior sites, by first making tradeoffs among Community and Environmental attributes. Then those considerations are traded off against Engineering and Economic attributes. Other groupings of attributes are possible.

2.7.1.3 Successive Elimination, another informal method, requires decision makers to give ranges instead of point estimates for attribute values and weights. Using any decision rule, the method then eliminates sites less desirable than others under any set of values and weights within the specified ranges. Decision makers gradually tighten those ranges until a sufficiently small subset of sites remains.

\subsection{CONCLUSIONS}

1. The potential advantages of analytical multiobjective siting techniques are many, but so are the potential problems if they are mis- 
used. Violations of measurement theory in scaling and weighting attributes are all too frequent. Furthermore, decision makers often apply methods without understanding their assumptions with the result that the site chosen does not accurately represent their values. Some studies report that choice of decision rule or weighting method made a difference in actual decisions.

2. Choosing a multiobjective method is a multiobjective problem. A technique's theoretical validity, ease of use, flexibility, and results compared to other techniques are all of concern. The choice depends on the siting problem faced. Data availability, number and complexity of alternatives, staff time and resources, level of public participation, and presence and importance of risk and uncertainty all make a difference. For instance, in regional screening, Exclusionary Screening is best if there are regulatory criteria that candidate areas must satisfy, while Weighting Summation is better if tradeoffs among attributes are important. Decision Analysis is preferred to Weighting Summation for final site selection if probability distributions for attributes are quantified and important to decision makers. 
3. SURVEY OF CURRENT APPLICATIONS OF QUANTITATIVE NUCLEAR POWER PLANT SITING METHODS

\subsection{INTRODUCTION}

The purpose of this survey is to analyze site-selection methodologies in use by utility companies and their consultants for siting nuclear power plants and, for quantitative methodologies, to determine whether or not they have been correctly applied. To that end we have reviewed the site-selection chapters of 48 Environmental Reports submitted to the Nuclear Regulatory Commission (NRC) since February 1973.

Site selection is generally a three-stage process: candidate area selection, candidate site selection, and final or proposed site selection (see Table 3.1). Site selection methodologies fall into the following categories: favorability selection, exclusion screening, regional characterization, predefined sites, qualitative comparison, cost-effectiveness analysis, site rating, and formalized numerical rating. Regional characterization, site rating, and formalized numerical rating are quantitative methods. This classification scheme was developed only to facilitate analysis and does not comment on the validity of the methodologies or their application.

Quantitative site-selection methods were used in 13 of the 48 studies: 9 at the final site selection leve 1, 2 at the candidate site selection level, and 2 at the candidate area selection level. These have been analyzed to determine if the methods used are theoretically valid.

In addition, four consultant studies referenced in Environmental Reports were reviewed to determine if they contain information about the site-selection methodology that is not presented in the Environmental Reports. Three of these studics contain no additional information; the fourth is included as Siting Study J-II. Siting Study J contains very little information about the site-selection process; weights used in the study are not even presented. The consultant Report (Study J-II), however, does contain significantly more information although it does not present more detailed information than site-selection chapters of other Environmental Reports.

For more detailed descriptions of the siting studies reviewed, readers are referred to Pierce and Rowe (3) of which this chapter is a summary. 


\section{TABLE 3.1}

METHOD DEFINITIONS

\section{Candidate Areas}

Favorability Selection. Candidate areas are selected because of one or more favorable characteristics.

Exclusion Screening. A set of explicitily stated exclusionary criteria is applied to a Region of Interest. Candidate areas are those areas which remain after this screening. Emphasis is on defining minimum standards of acceptability.

Regional Characterization. This involves ranking various areas within a region of interest using weighted and rated attributes.

\section{Candidate Sites}

"Predefined Sites. Includes expanding existing sites, selecting from an inventory of previously identified sites, sites already owned by a utility, and unique sites, such as strip-mined areas or floating ocean platforms.

Favorability Selection. As above.

Exclusion Screening. As above.

Regional Characterization. As above.

III. Proposed Si te

Favorability Selection. A site is proposed on the basis of its merit, rather than on the basis of an alternate site evaluation. This includes selection of a site because it is already utility owned.

Qualitative Comparison. Subjective evaluation.

Cost-Effectiveness Analysis. Usually includes only engineering costs, and most often used when environmental impacts at candidate sites are judged to be equivalent.

Site Rating. Simple rating and/or ranking of sites, no weights.

Formalized Numerical Rating. Attributes are rated and weighted. 


\subsection{RESULTS}

\subsubsection{Overview}

Each site selection study is unique. The attributes used in candidate area selection, generally include availability of cooling water, geology and seismology, population density, and power network considerations. The importance of these attributes, however, varies from region to region. In parts of Tennessee and California, seismology is a limiting factor; in New England, water availability may be a prime consideration. In some site-selection studies, the candidate area is predefined by a utility to be that area within a certain distance of its projected load center; in others, a candidate area is systematically selected from an area larger than the utilities service area. At the candidate area selection level, a quantified methodology was used in 3 of the 48 studies reviewed in this chapter. Table 3.? summarizcs the salient points of this review.

Candidate site selection was frequently found to be a nebulous exercise between selection of a candidate area and the selection of a preferred site. A utility may choose candidate sites within an area by considering additional attributes or, as in 9 studies, by selecting sites from an existing inventory of potential sites. In several studies, sites to be considered were limited to those already owned by the utility. At this level of the site selection process, quantitative methods were used in 5 of the 48 studies reviewed.

Selection of a proposed site may be based on a qualitative comparison or on a formalized quantitative comparison of alternative sites. Quantification was used in only 10 studies. In one, expansion at an existing site was proposed because the time required for a site-selection study would not allow the utility to mect projecled demand. Some siting studies included selection of fuel type and cooling system by comparing site/plant alternatives; in others, these decisions were independent of the site-selection process. Economics is a common attribute in all power plant site selections; yet it may be included in a comprehensive comparison, it may be considered after all other comparisons have been made, or it may not be a separate attribute at al1, but included within several nther attributes.

Perhaps the most striking characteristics of these 48 site-selection studies is absence of specific information about the site-selection process. Many studies contain elaborate descriptions of alternative sites, but few 
Table 3.2

Classiflcation of Site-Selection Studies

\begin{tabular}{|c|c|c|c|c|c|c|c|c|c|c|c|c|}
\hline \multirow[t]{2}{*}{ Docket Number } & \multicolumn{3}{|c|}{ Candl date Area } & \multicolumn{4}{|c|}{ Candidate Sites } & \multicolumn{5}{|c|}{ Proposed Site } \\
\hline & $\begin{array}{l}\text { Favor- } \\
\text { abllity } \\
\text { Selection }\end{array}$ & $\begin{array}{l}\text { Exclusion } \\
\text { Screenling }\end{array}$ & $\begin{array}{l}\text { Regional } \\
\text { Character- } \\
\text { lzation }\end{array}$ & $\begin{array}{l}\text { Pre- } \\
\text { def Ined } \\
\text { Sites } \\
\end{array}$ & $\begin{array}{l}\text { Favor- } \\
\text { abllity } \\
\text { Selection. }\end{array}$ & $\begin{array}{l}\text { Exclusion } \\
\text { Screenlng }\end{array}$ & $\begin{array}{l}\text { Regional } \\
\text { Character- } \\
\text { Ization }\end{array}$ & $\begin{array}{l}\text { Favor- } \\
\text { ablility } \\
\text { Selection }\end{array}$ & $\begin{array}{l}\text { Quall- } \\
\text { tative } \\
\text { Comparison }\end{array}$ & $\begin{array}{l}\text { Cost Effec- } \\
\text { ti veness } \\
\text { Analys Is } \\
\end{array}$ & $\begin{array}{l}\text { Site } \\
\text { Rating }\end{array}$ & $\begin{array}{l}\text { Formal I zed } \\
\text { Numer Ical } \\
\text { Rating } \\
\end{array}$ \\
\hline $50-423$ & $x$ & & & $x$ & & $x$ & & & $x$ & $x$ & & \\
\hline $50-424 / 425$ & $x$ & & & $x$ & $x$ & & & & $x$ & & & \\
\hline $50-434 / 435$ & $x$ & & & & $x$ & & & $x(b)$ & $x$ & & & \\
\hline $50-438 / 439$ & $x$ & & & $\theta$ & & & & & $x$ & & & \\
\hline $50-440 / 441$ & $x$ & & & c & & & & & & $x$ & & \\
\hline $50-443 / 444$ & $-x$ & & & & $x$ & & & & $x$ & $x$ & & \\
\hline $50-445 / 446$ & $x$ & & & & $x$ & & & & $x$ & & & \\
\hline $50-448 / 449$ & $x$ & & & & $x$ & & & & $x$ & & & \\
\hline $50-450 / 451$ & $x$ & & & $x$ & $x$ & & & & & & $\mathbf{a}$ & \\
\hline $50-452 / 453$ & $x$ & & & & & $x$ & $x$ & d & $x$ & & & \\
\hline $50-454 / 455$ & $x$ & & & & & & & & $x$ & & & \\
\hline $50-456 / 457$ & $x$ & & & $f$ & & & $\cdot$ & $t$ & $(x)$ & & & \\
\hline $50-458 / 459$ & $x$ & & & g & & & & & $x$ & & & \\
\hline $50-460$ & $x$ & & & $x$ & & & & $x$ & & & & \\
\hline $50-461 / 462$ & $x$ & & & & $x$ & & & & $x$ & & & \\
\hline $50-463$ & $x$ & & & & $x$ & & & & & & k & \\
\hline $50-466 / 467$ & $x$ & & & & $x$ & & & & & & & h \\
\hline $50-471$ & $x$ & & & c & & & & & $x$ & & & \\
\hline $50-477 / 478$ & $x$ & & & & $x$ & & & & $x$ & & & \\
\hline $50-482$ & & $x$ & & & & & & & & $x$ & & \\
\hline $50-483 / 486$ & $x$ & & & & $x$ & & & & & 1 & & \\
\hline $50-484$ & & $x$ & & & & & j & & & & . & $j$ \\
\hline $50-485$ & $x$ & & & & & & $X(m)$ & & $x$ & & & \\
\hline $50-488 / 490$ & $x$ & & & & $x$ & & & & & $x$ & & \\
\hline $50-591 / 493$ & $x$ & & & & $x$. & & & & & $x$ & & \\
\hline $50-496 / 497$ & $x$ & & & & $x$ & & . & & $x$ & & & \\
\hline $50-498 / 499$ & 1 & & $\mathbf{j}$ & & $x$ & & & & & & & \\
\hline $50-500 / 501$ & & $x$ & & $x$ & & & & $x$ & & & & \\
\hline $50-502 / 503$ & $x$ & & & $x$ & & & . & & $x$ & $x$ & & \\
\hline $50-508 / 509$ & $x$ & & & & & & & & & & & $h$ \\
\hline
\end{tabular}


Table 3.2 (continued)

\begin{tabular}{|c|c|c|c|c|c|c|c|c|c|c|c|c|}
\hline \multirow[t]{2}{*}{ Docket Number } & \multicolumn{3}{|c|}{ Candidate Area } & \multicolumn{4}{|c|}{ Candidate Sites } & \multicolumn{5}{|c|}{ Proposed Site } \\
\hline & $\begin{array}{l}\text { Favor- } \\
\text { abllity } \\
\text { Selection }\end{array}$ & $\begin{array}{l}\text { Exclusion } \\
\text { Screening }\end{array}$ & $\begin{array}{l}\text { Reglonal } \\
\text { Character- } \\
\text { Ization }\end{array}$ & $\begin{array}{l}\text { Pre- } \\
\text { defined } \\
\text { Sites }\end{array}$ & $\begin{array}{l}\text { Favor- } \\
\text { abllity } \\
\text { Selection }\end{array}$ & $\begin{array}{l}\text { Exclusion } \\
\text { Screening }\end{array}$ & $\begin{array}{l}\text { Reglonal } \\
\text { Character- } \\
\text { Ization }\end{array}$ & $\begin{array}{l}\text { Favor- } \\
\text { abllity } \\
\text { Selection }\end{array}$ & $\begin{array}{l}\text { Qualli- } \\
\text { tative } \\
\text { Comparison }\end{array}$ & $\begin{array}{l}\text { Cost Effec- } \\
\text { tiveness } \\
\text { Analys is }\end{array}$ & $\begin{array}{l}\text { Site } \\
\text { Rating }\end{array}$ & $\begin{array}{l}\text { Formalized } \\
\text { Numerical } \\
\text { Rating }\end{array}$ \\
\hline $50-510 / 511$ & $x$ & & & & $x$ & & & & & $x$ & & \\
\hline $50-513$ & $x$ & & & $x$ & & & & $x$ & & & & \\
\hline $50-514 / 515$ & $x$ & & & & $x$ & & & & & $x$ & & \\
\hline $50-516 / 517$ & $x$ & & & & & & $x$ & & & & $n$ & \\
\hline $50-518 / 521$ & $x$ & & & & $x$ & & & & $x$ & & $\circ$ & \\
\hline $50-522 / 523$ & & & & & & & & & & & & $\mathrm{j}$ \\
\hline $50-524 / 527$ & $x$ & & & & & & & & & & & \\
\hline $50-528 / 530$ & & & j & & & & $x$ & $x$ & $(x)$ & & & \\
\hline $50-537$ & $x$ & & & $x$ & & & & & $x$ & $x$ & & \\
\hline $.50-546 / 547$ & $x$ & & & $g$ & & & & & $\dot{x}$ & & & \\
\hline $50-548$ & $x$ & & & g & & & & & & & & $j$ \\
\hline $50-549$ & $x$ & & & j & & & & & $x$ & & & \\
\hline $50-553 / 554$ & $x$ & & & g & & & & & $x$ & & & \\
\hline $50-556 / 557$ & $x$ & & & & $x$ & & & & & & & $j$ \\
\hline $50-564$ & $x$ & & & & $x$ & & & & $x$ & & & \\
\hline $50-566 / 567$ & $x$ & & & $\mathrm{p}$ & & & & & $x$ & $x$ & & \\
\hline $50-568 / 569$ & & $x$ & & & $x$ & & & & $x$ & & & \\
\hline $50-580 / 581$ & & $x$ & & & $x$ & & & & $x$ & & & \\
\hline $50-582 / 583$ & $x$ & & & & $x$ & & & & $x$ & $x$ & & \\
\hline $50-582 / 583$ & & $x$ & $x$ & & & & & & & & & \\
\hline (Append $\mid x$ ) & 1 & & & & & & & & & & & \\
\hline
\end{tabular}

a) Sites ranked for each of 10 factors; added together to give final ranking

b) Expansion at existing site

c) Currently owned sites

d) HIgher rated sites were not considered for current development due to distance from laad center

e: Ongolng site selection studies

f) Abandoned strlp mil ne site

g) Previous site studies

h) weighted ratings for each factor were summec in 3 major categorles; the results were multiplled to glve a final ranking

j) sites rated (0-5) for each factor, ratings multiplled by welghts, sumed to give ranking

k) sites rated 1 (preferred) or 2 (acceptable) for each factor; ratings summed to give rank

1) $3 \mathrm{high}$ rated areas el Imlnated for other reasons

m) sites rated

n) sites rated for each factor, ratings summed to give rank

o) sites were ranked for some factors, but not all. The rankings were not amalgamated, and the flinal decision was qualitative and economic 1) Includes socio-economic benefits 
present a clear picture of the methodology used or the tradeoffs made in choosing a proposed site. When a preferred site is selected on the basis of qualitative comparison, it is not possible to establish whether a rigorous and comprehensive method was used, or site selection was actually the arbitrary and subjective process presented in the Environmental Report. In addition, the attributes used to compare alternative sites are not concisely defined. In both qualitative and quantitative studies, this obscures tradeoffs and creates an impression of a vague and subjective site-selection process. From the information presented in most of these Environmental Reports, it is only possible to determine that an acceptable site was chosen, not that a sound and comprehensive site-selection method was used.

\subsubsection{Quantitative Studies}

Four aspects of the site-selection studies are analyzed in this report: 1) attribute definition, 2) attribute scaling and resulting level of measurement, 3) weight selection and resulting level of measurement, and 4) decision rule and theoretical requirements (Table 3.3). In addition to requiring that attributes be independent, each decision rule requires specific levels of measurement of weights and scaled attributes (see Section 2.0). These requirements must be satisfied for application of a method to be theoretically valid.

Most of the studies emphasize descriptions of candidate areas and alternative sites, rather than the site-selection method. Thus, information necessary for a thorough analysis of theoretical validity is often incomplete or absent.

3.2.2.1 Attributes. Every decision rule requires that all important attributes be considered, i.e., that the list of attributes be comprehensive. There is no master list of attributes, however, because some are important in certain regions of the country and not in others. Also, an attribute may be judged to be the same for all sites and thus omitted from consideration in site evaluation. Attributes which are easily quantified, such as cost, and attributes required by NRC regulations, such as population density, are included in all the siting studies. Attributes which are subjective or difficult to measure, such as socioeconomics or aesthetics, are often omitted. Six of. the nine studies at the final site-selection level contain no explicit consideration of socioeconomic impacts. It is difficult to 
TABLE 3.3

SUMMARY OF REVIEW

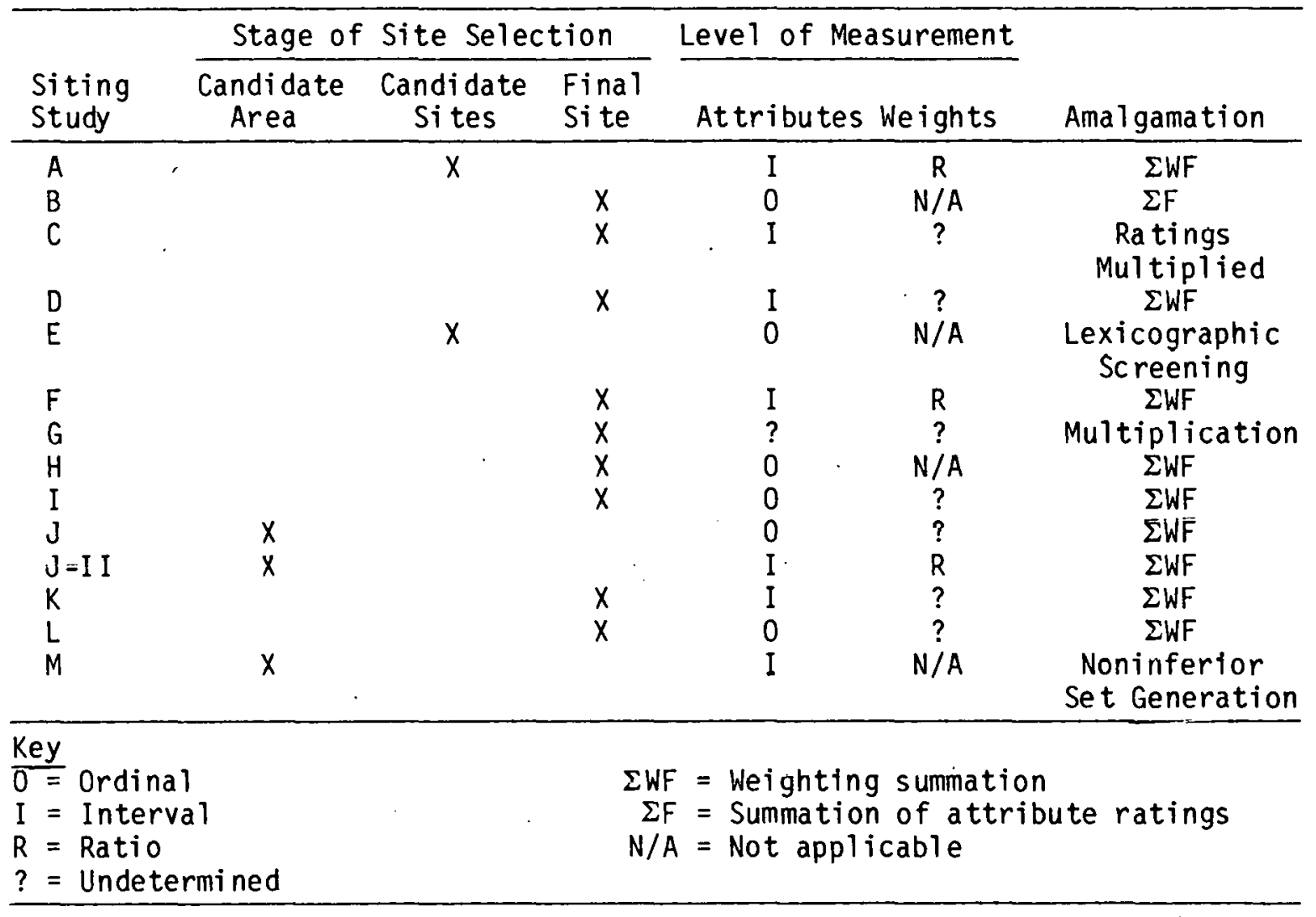

determine if this is because the impact is the same at all sites. One, for example, states that those impacts which were the same at all sites were not considered, but does not list the impacts omitted for this reason.

All decision rules also require that cach atlribute be conceptually independent (see Section 2.0). The importance of independent attributes is obvious. Dependent attributes would be "double counted" and the resulting decision would be biased. It is often not possible to determine if attributes are actually independent, however, because of qualitative, vague definitions. Each attribute should be defined in terms of the specific impact being measured; the method of definition in most Environmental Reports is inadequate.

Two studies present attribute definitions only as site-specific descriptions. 
Site No. 1

Foundation

Conditions

Excavating
Site Elev. $710-750^{\prime} .1^{\prime}-5^{\prime}$ residual soil over geological formation. 10'-23' massive crystalline limestone. $10^{\prime}-25^{\prime}$ shale and limestone. Possible fractures, solution channels in limestone but not extensive. Generally favorable foundation stability.

Limestone may require blasting. May be difficult to drill because of presence of chert.

This type of attribute definition shows differences among sites, but does not allow analysts to determine whether or not attributes are independent.

Five studies present attribute definitions that are too vague to determine independence. Siting Study $J$ is an example:

"Accessibility ratings were based not only on the proximity of the region to major U.S. highways and railroads but also on the degree of preparation needed for the access road to the region from the main highway or rail road."

"Ease of access was also considered in evaluating regions for the ecological impact. The construction of access roads and transmission lines requires the disruption of some plant and animal communities and may open the area to potential further disturbance as relatively inaccessible areas are made available to more people."

The above explanation of ecological impact is not useful; it is no more. than a justification for including access-related considerations in the measurement of ecological impact. It is not possible to determine from this description whether or not accessibility is "double counted." Another example defines material transportation as "...an assessment of the variation in material transportation costs throughout the study area." Site preparation includes "...road and bridge construction and relocation." Without detailed definitions of the attributes, it is again not possible to determine if these are actually separate considerations.

At least five studies contain instances of possible "double counting." In one example, attributes are defined in terms of a rating scale and several attributes seem to overlap or to be overrepresented. Si te Accessibility considers railroad, highway, and river navigation separately. It is possible that the importance of each $k$ ind of access depends on the levels of the other two and that the three types of access should be considered as a single 
attribute. In the same study, it is unclear exactly what the difference is between "Land Consumption of Critical Environmental Importance," and "Land Consumption (Plant Site Only)"; both are defined in terms of acres of 1 and removed. Gamelands appear to be included in two attributes, and terrestrial biology in three.

A consultant report which considerably improves upon the information presented in the Environmental Report nevertheless seems to contain "double counting." Pumping requirements for the cooling water supply is included in both topography and hydrolngy. Topography is

"based on the criterion that an ideal region should not vary more than 100 feet in elevation over an area of 1000 acres. This would minimize large earth moving requirements in site preparation, as well as pumping requirements for the cooling water supply."

Yet, hydrology ratings

"were influenced not only by the distance of the regions from the three hydrological alternatives, but also by the pumping head requirements for transferring water from the source to the region. Thus, the differences in the elevations of the candidate regions and the corresponding water sources had to be considered."

The most quantitative, specific definitions found in any of the 48 studies may still contain "double counting." For example, Loss of Existing Land Use is defined as the weighted number of acres of open land, swamp, or forest converted to site use; Loss of Recreational Land Use, is defined as "qualified opinion of the relative worth of existing land uses." It is unclear what the difference is between these two impacts, or whether in fac: they are the same.

These examples demonstrate that determination of attribute independence is not clear cut or simple. Part of the problem stems from the nature of the attributes themselves and part from inadequate definition in the Environmental Reports. Some instances of apparent "double-counting" may instead be ambiguous definition.

3.2.2.2 Scaling. In quantitative site-selection methods, raw impact measurements, such as dollars or persons, are transformed to some type of value scale in order to compare one attribute with another and in order to combine values for all attributes to obtain one measure of suitability for each site. The levels of measurement of the scaled attributes required by 
each amalgamation technique (usually ordinal or interval) are defined by measurement theory (see Section 2.0).

To verify the level of measurement achieved in transformation of raw impact measurements (such as dollars or miles) to attribute value functions, it is necessary to know how the transformation is made. Only one study presents such complete information; all raw impact measurements are either interval or ratio scaled, and transformation produces interval-scaled attributes. Most studies present only partial raw data and no information about scaling techniques. An analyst can only assume a particular level of measurement and cannot verify this "guess."

Six studies use ordinal-level attribute values of the form:

$$
\begin{aligned}
& 1=\text { poor } \\
& 2=\text { fair } \\
& 3=\text { good } \\
& 4=\text { excellent }
\end{aligned}
$$

In this type of scale, magnitudes of differences between numbers are usually not meaningful.

Six studies use interval-scaled attributes, including some questionable but apparently higher-than-ordinal studies classified as using interval scales. An example is

"a point scale from zero to five with five representing a particularly favorable condition and zero conditions not presently feasible from an engineering or economic standpoint."

Because decimal ratings are permitted, this study is described as using interval-scaled attributes even though transformations are not presented with which to verify the level of measurement they might be ratio scaled.

3.2.2.3 Weights. Weights used in any amalgamation technique should be on a ratio level of measurement, and it should be clear whose values the weights represent and if they measure the correct type of relative importance lexpressed in terms of willingness to make tradeoffs among units of attributes as opposed, for example, to "political significance" or relative range of values represented or relative "importance" where importance is not defined). To determine if they meet these requirements, it is necessary to know how weights are selected. Of the ten studies that use weights, none states who chose the weights or how they were chosen. This is a serious omission in all of the studies. 
In two studies, weights are presented as percentages, so these may achieve a ratio level of measurement. One does not even present the weights, although the consultant report contains weights expressed as decimals and is classified as possibly achieving a ratio level of measurement. Other studies assign weights of 1, 2, or 3, for example, or distribute "points" among attributes (Metfessel Allocation?); no attempt is made to judge the level of measurement on the basis of the limited information in these Environmental Reports.

3.2.2.4 Amalgamation. Eight of the thirteen siting studies examined use weighting summation as the decision rule. Three of these may be theoretically valid in terms of measurement theory. Four use ordinal-scaled attributes and are thus not theoretically valid whatever the level of measurement of the weights. Three studies use a variation of weighting summation which simply adds the attribute ratings, or adds weighted ratings for subcategories, then multiplies categories. One uses lexicographic screening (sequential screening in order of attribute importance) at the candidate site-selection level and is theoretically valid in its use of ordinal-scaled attributes. Another uses a simplified form of noninferior set generation, which is also theoretically valid in terms of measurement theory.

\subsection{DISCUSSION}

Violations of measurement theory, such as algebraic manipulation of ordinal numbers, incorrect application of a method, and weighting before scaling of attributes, can result in unintended tradeoffs and unreliable results. None of the siting studies recognize the implications of not meeting theoretical requirements.

Addition of ordinal numbers is not theoretically valid. Ordinal measures should not be manipulated algebraically because such manipulation depends on magnitudes of differences, and these differences are not meaningful in an ordinal scale. At least five site-selection studies violate this important theoretical requirement. In one example, attributes were scaled into one of two categories, preferred or acceptable. This is similar to Copeland's Reasonable Welfare Function, a valid method for ordinal numbers, which involves a site-by-site comparison of each attribute, and choosing the site "winning" the most comparisons. When this method is applied to that study, the top-ranked site remains the same, but the other sites are ranked 
differently. Thus, different results can be obtained when ordinal numbers are manipulated incorrectly.

:Two studies used a variation of Power Law, not described in the existing siting methodology literature, in which ratings for a few major categories are multiplied instead of added to yield a total site score. These provide good examples of the problems that can result from misapplication of siting methodologies. Multiplication causes differences among sites to produce proportional differences in total site score instead of additive differences; therefore, small differences among inferior sites (low ratings) have a much larger influence on total site score than small differences among good sites. This causes the actual relative importance of each attribute to the total site score to be different from the stated relative importance implied by weights. Although in these examples the final site rankings are not changed by multiplication instead of addition, it is clear that under other circums tances this might not be the case.

This difference between stated weights and what we call "effective" or "implied". weights (the actual relative effect of each attribute on total suitability) can be found in several studies. Five slightly varying types of differences between effective weights and true weights have been identified. The first is use of multiplication instead of addition, as described above, which causes weights to have a proportional instead of additive effect on total suitability. The second is double counting (usually of cost) which causes the double-counted attribute to have more than its stated share of influence. The third is unspecified nonlinear transformations at the scaling stage (Figure 3.1) which causes extreme attribute levels to have a relatively. greater impact than less extreme levels. This general category includes scale ranges used in equally weighted categories. The fourth is aggregation of different numbers of attributes into equally weighted categories so that the relative weights of the components of the categories are different. The fifth is possible reverse order of the scaling and weighting exercises so that the stated weights are not properly applied to the scaled attribute levels. This can occur whenever attributes are weighted in a general sense without specification of the range of measured impacts under consideration.

\subsection{CONCLUSIONS}

The purpose of quantitative siting methodologies is to assist in making tradeoffs among different levels of attributes to choose one site from among 


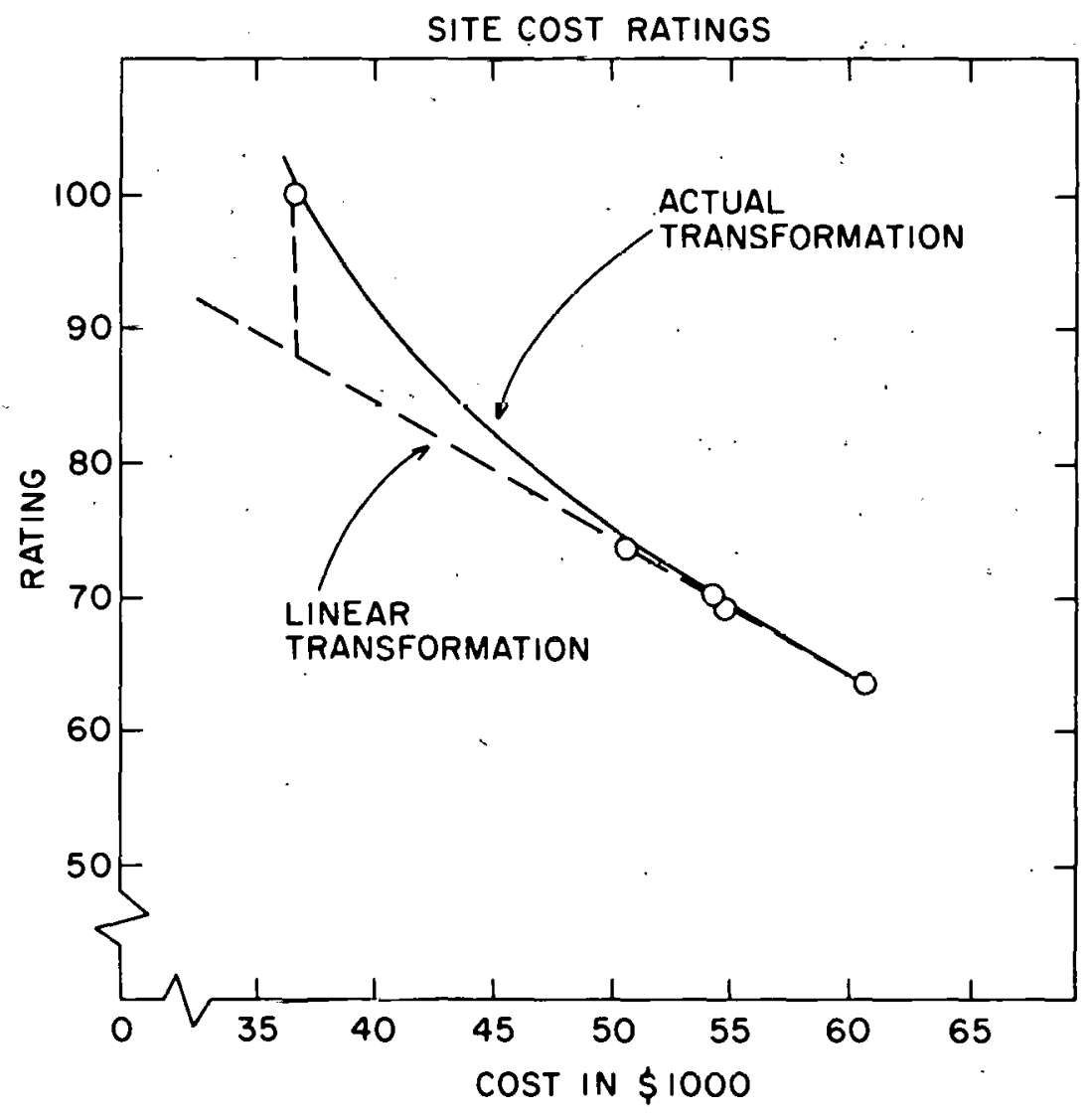

Figure 3.1. Nonlinear Attribute Valuc Function Favoring Extreme Values. 
others. This requires both objective and subjective judgments. They should be specifically designed to formalize combination of these objective and subjective judgments. They should also provide rigorous methods for dealing with subjectivity. If the methods are poorly designed or applied, then the results of the application will not accurately represent the subjective judgments of the persons involved.

None of the studies examined acknowledge the existence of theoretical requirements, and most appear to violate one or more of the above requirements. Eight of 13 studies using Weighting Summation appear to violate the assumption of attribute independence; 10 of the 13 studies appear to violate theoretical requirements of measurement theory. Conclusions about particular studies are necessarily less than definitive, however, because a study may appear to be theoretically incorrect only because insufficient information was presented in the Environmental Report. Attribute definitions are generally inadequate for determination of independence; descriptions of scaling and weighting techniques are absent. Lack of such information is a severe constraint to an analysis of theoretical validity. 


\section{TESTS OF REGIONAL SCREENING METHODS}

\subsection{INTRODUCTION}

Regional screening is used to search a region for areas having high probability of containing suitable power plant sites (Candidate Areas). Candidate Site selection and Final site selection follow. Of the various methods discussed in Section 2.0, three decision rules, Exclusion Criteria, Weighting Summation, and Power Law, are appropriate for large-scale regional screening. Weights for Weighting Summation and Power Law are generated using only the more common and simpler methods of weight estimation. In general, this stage of the site-selection process tends to be viewed as being relatively coarse, and the methods required are correspondingly less rigorous.

This section discusses results of tests of different decision rules and weighting methods applied to regional screening for nuclear power plant Candidate Areas in two regions, western Maryland and the western United States, each having different characteristics and different physical requirements as well as different levels of available siting information. Two sets of tests were conducted using the western Maryland data base; one with a panel composed of persons directly associated with some aspect of nuclear power plant siting in the area, and the other with an Advisory Panel composed of persons from throughout the United States having extensive experience in nuclear power plant siting issues. Tests conducted using data from the western United States used only the Advisory Pane 1.

For a more detailed presentation of results and discussion, readers are referred to Hobbs and Rowe (4) of which this section is a summary.

\subsection{WESTERN MARYLAND ANALYSIS I}

\subsubsection{Methods}

Five counties in western Maryland comprise the study area for a hypothetical regional screening for sites suitable for a pair of $1000 \mathrm{MW}(\mathrm{e})$ nuclear plants with evaporative cooling towers. The study area includes forested mountains, widc agricultural valleys, a number of small cities, and the upper Potomac River. The data base used in the Maryland Automated Geographic Information Systems (MAGI) which is gridded into 18,500 cells of 91.2 acres each. Seventeen cell attributes from MAGI were chosen for the screening (Table 4.1). Personnel of the Maryland Power Plant Siting Program 
defined each attribute's value function. 'That agency is charged with monitoring environmental impacts of electric utilities and creating a site "bank" for the State of Maryland.

Five persons from the Maryland agency, State University of New York, and Oak Ridge National Laboratory chose weights for the attributes by the Rating and Indifference Tradeoff Methods. The 2 Maryland participants selected weights in the presence of the researcher. The others used questionnaires. Consistency checks were applied in the Indifference Tradeoff Method. Weighting Summation "suitability scores" were calculated for each cell in the study area for each of 10 resulting weight sets using the Weighting Summation and Power Law models. Candidate areas were then defined for each weight set as continguous sets of 4 or more cells, each of which scored in the top $8 \%$. Four cells (about 360 acres) are the minimum size needed for a nuclear plant with evaporative cooling towers.

\subsubsection{Results}

The resulting weights vary greatly among the participants, and between the 2 methods for each person. The sets of Weighting Summation candidate areas are strikingly different (Figures 4.1 and 4.2). Few cells are chosen by all weight sets (Figure 4.3). Differences between areas chosen by the 2 Weighting methods are, on average, as large as, differences between areas chosen by 2 persons using the same method. The mean overlap of participants' Rating and Indifference Tradeoff areas is $52 \%$, while the mean overlap of every possible pair of persons' Rating areas is $62 \%$. The means are not significantly different. Because site specific investigations would subsequently eliminate most candidate areas in an actual study, Rating and Indifferent Tradeoff can lead to site choices in different locations; however, these choices are not necessarily different in quality.

Weighting Summation suitability scores were also analyzed using correlations (Pearson's $r$ ) between pairs of sets of suitability scores. A "between-methods" correlation was calculated for each person between his Indifference Tradeoff and Rating suitability score sets. "Between-persons" correlations were calculated between each possible pair (5 persons and 10 pairs) of Rating suitability score sets.' The mean between-methods correlation $(0.776)^{\prime}$ is not significantly different from the mean between-persons correlation (0.774). Thus, variability due to choice of weighting method is 
TABLE 4.1

MAGI VARIABLES INCLUDED IN WESTERN MARYLAND REGIONAL SCREENING I

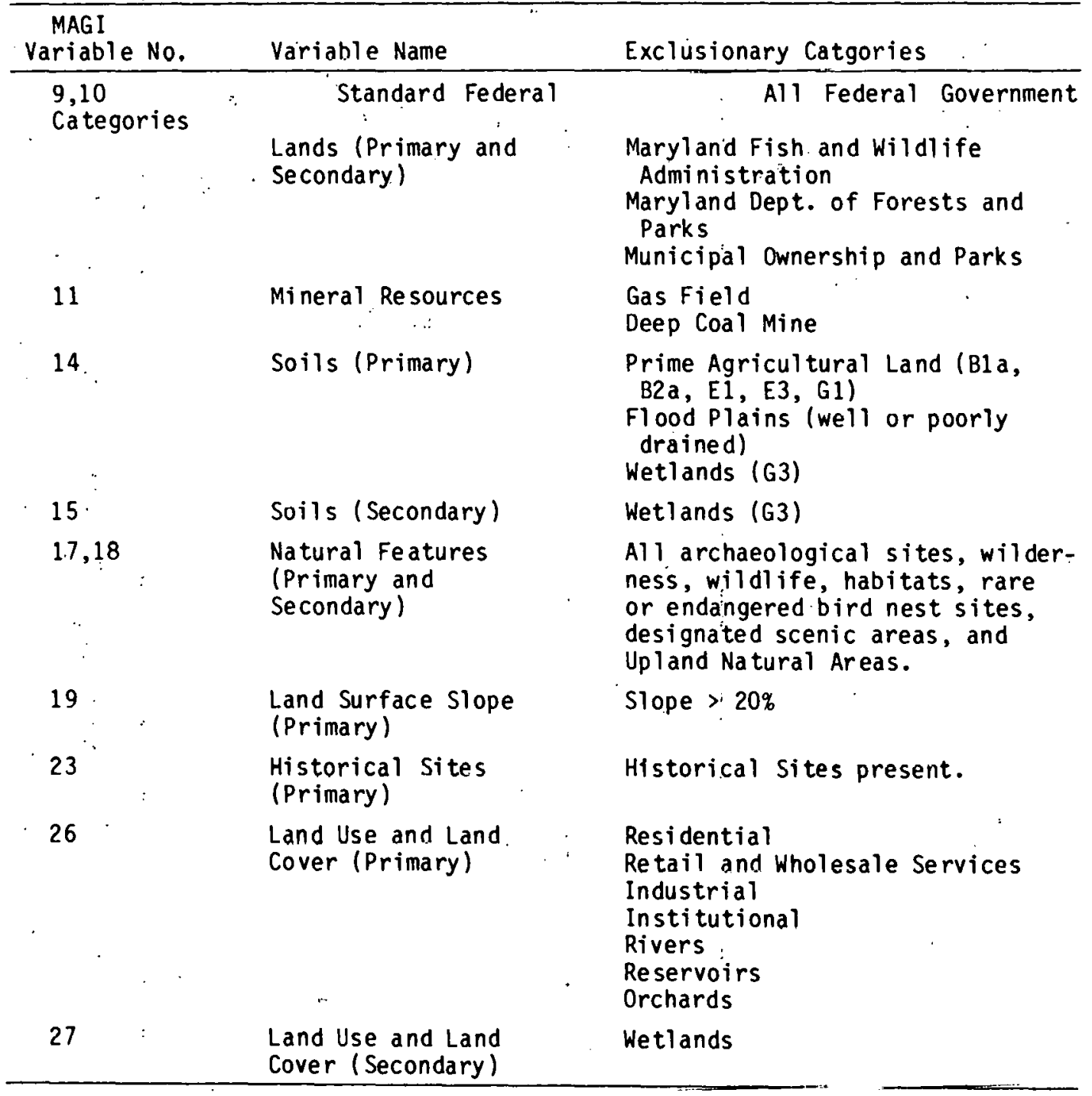




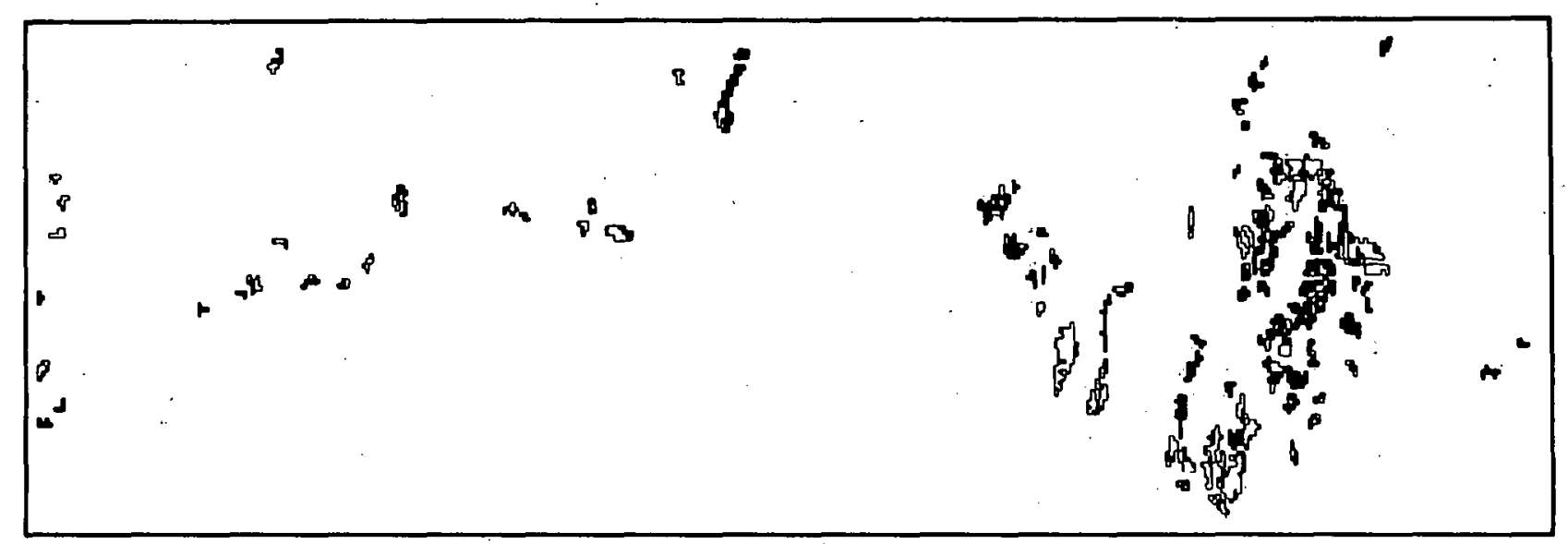

a. Rating Weighting Method

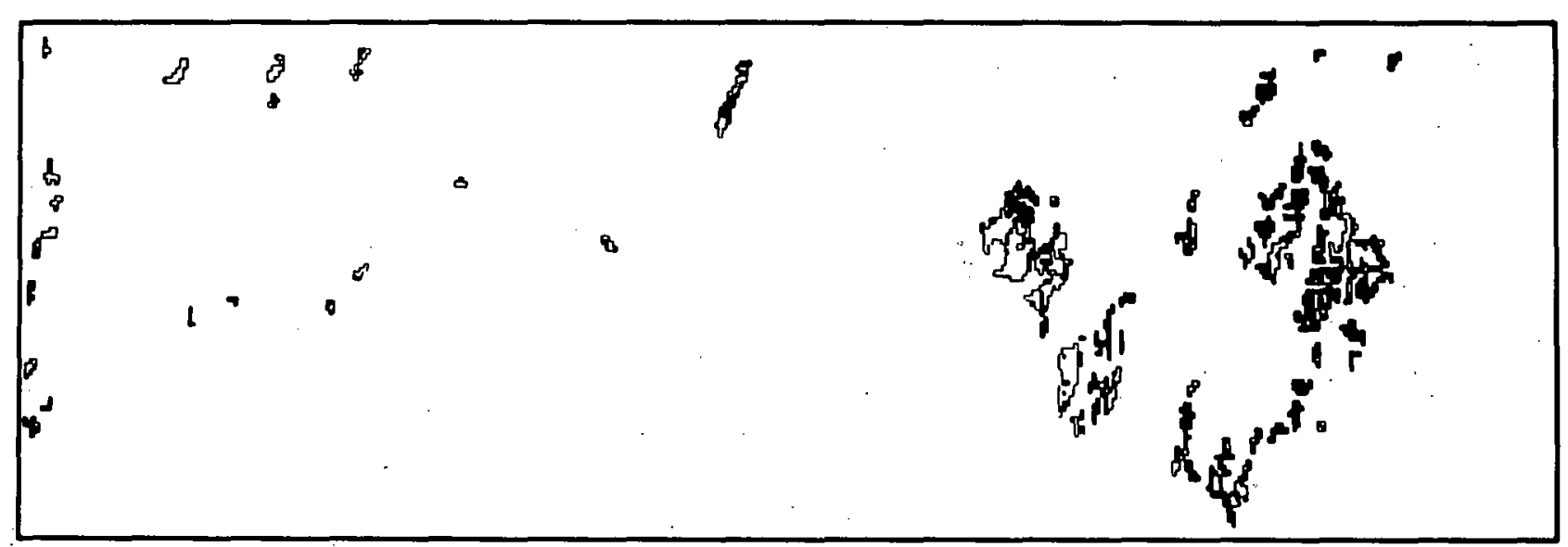

b. Indifference Tradeoff Weighting Method

Figure 4.1. Weighting Summation Candidate Areas, Mr. Mueller, Maryland Screening I. 


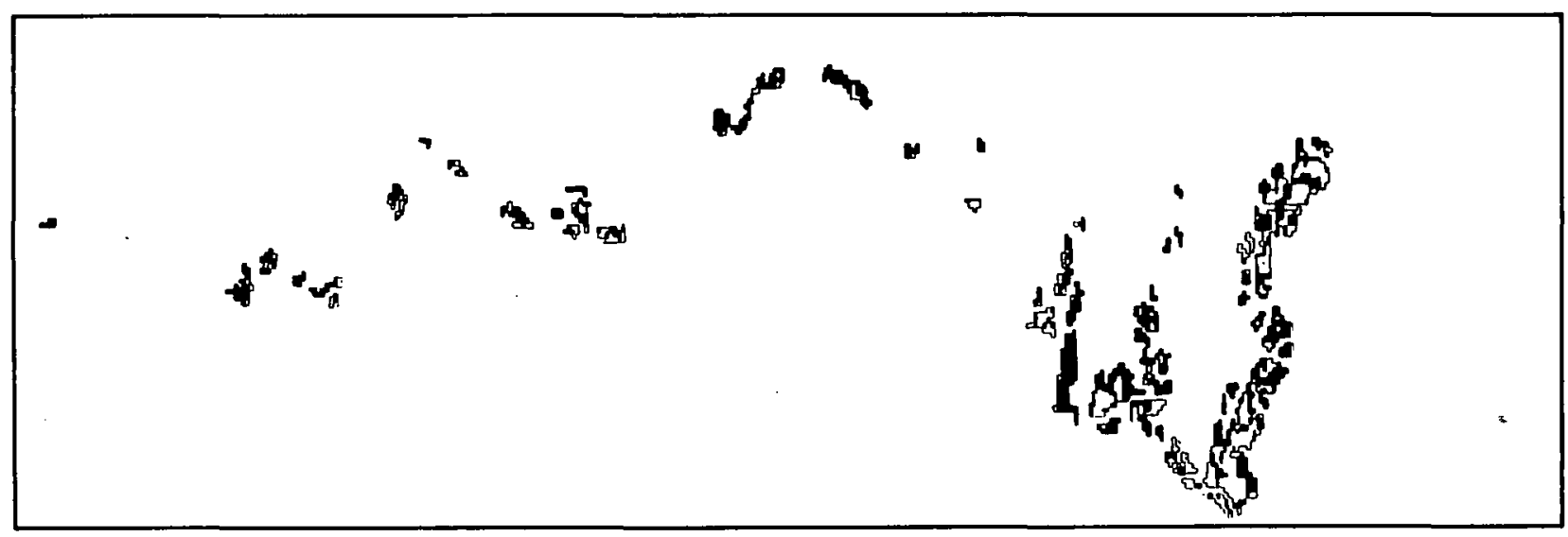

a. Rating Weighting Method

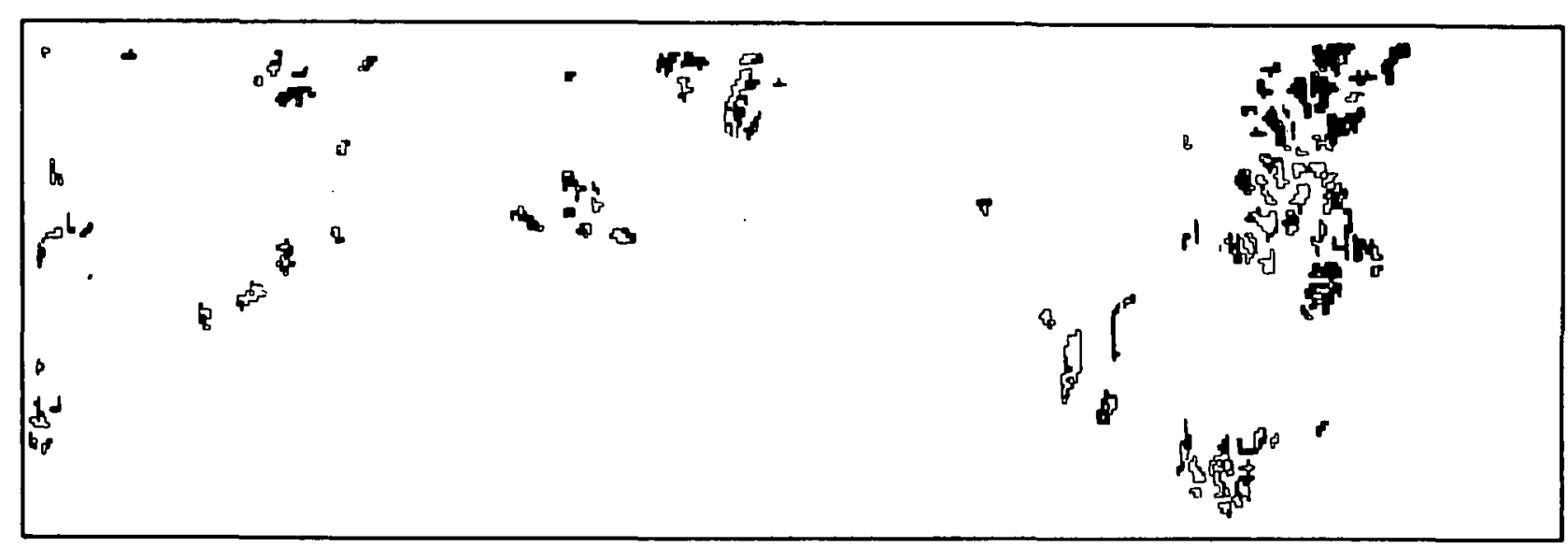

b. Indifference Tradeoff Weighting Method

Figure 4.2. Weighting Summation Candidate Areas, Dr. Canham, Maryland Screening I. 


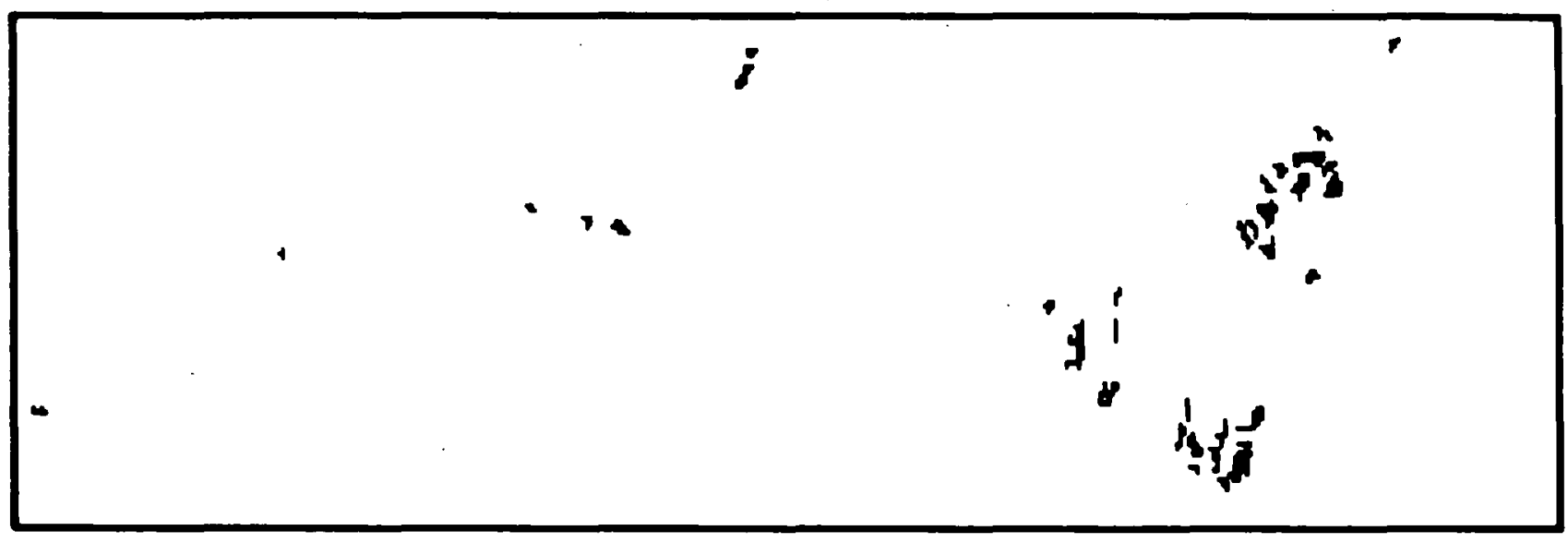

Figure 4.3. Cells Shared by the top $8 \%$ of All Five Rating-Weighting Summation Candidate Areas, Maryland Screening I.

as important as variability due to choice of person. Use of correlations between weights instead of between suitability score sets leads to the same conclusion; the mean between-persons correlation (0.306) is not significantly different from the mean between-persons correlation (0.176).

The Indifference Tradeoff Weighting Method was considered more difficult than Rating. This led 3 of the 5 participants to prefer Rating for regional screening studies. At that time, however, they did not know whether or not choice of method makes a difference in candidate areas. Nevertheless, participants thought that the more difficult method might be better because it forces explicit consideration of the trade offs implied by weights. They thought that the "magic numbers" one chooses in a Rating exercise may bear little relationship to tradeoffs he is willing to make among attributes.

The Rating weights have less variation among themselves than Indifference Tradeoff weights. This is consistent with a hypothesis that logarithmic perception of values causes a greater distortion in Rating weights than in Indifference Tradeoff weights.

The second stage of the Churchman-Ackoff weighting method was also applied by the Maryland participants to their Indifference Tradeoff weights. 
The modified weights are almost identical to the original Indifference Tradeoff weights.

The Maryland participants each applied the Decision Analysis lottery weighting method to 4 attributes. The resulting Decision Analysis weights and Indifference Tradeoff weights are not proportional, in contradiction of theory, which says that both methods should choose valid weights. One reason for this is the difficulty of dealing with hypothetical probabilities.

Indifference Tradeoff weights were used to infer 4 sets of Decision Analysis weights for each participant, each set being based on one of the Decision Analysis weights. Because of inconsistencies, the implied risk attitudes of the two decision makers varied considerably. Nevertheless, when each set was used in the Decision Analysis multiplicative decision rule, candidate area sets were almost identical. Hence, risk attitudes make little difference in candidatc are selecliun in this case, and one can use weighting Summation (with the same value functions and weights).

Candidate areas for each Rating and Indifference Tradeoff weight set were also generated using the Power Law (Figures 4.4 and 4.5). Those areas differed less among themselves than did corresponding Weighting Summation candidate areas. This is because the Power Law favors cells with moderately good values in all attributes over cells with both very good and very bad levels.

Choice of decision rule between Weighting Summation and Power Law makes more of a difference in candidate areas than does choice of weighting method or choice of person. On the average, less than half the cells picked by one decision rule are also picked by the other. Therefore, users should check the applicability of these methods with respect to underlying assumptions.

One of the Maryland participants also chose criteria for Exclusionary Screening. The criteria closely resemble those used in an actual screening of eastern Maryland. About $9 \%$ of the study area passed a 11 screens (Figure 4.6). Differences between Exclusionary Screening and Weighting Summation areas are striking. Only a third of the cells passing all screens also score in the top $9 \%$ of that person's Rating or Indifference Tradeoff Weighting SumIlation cells. Hence, the exclusionary cutoffs imply tradeoffs that the decision maker in this case would not approve were he presented with them directly. 


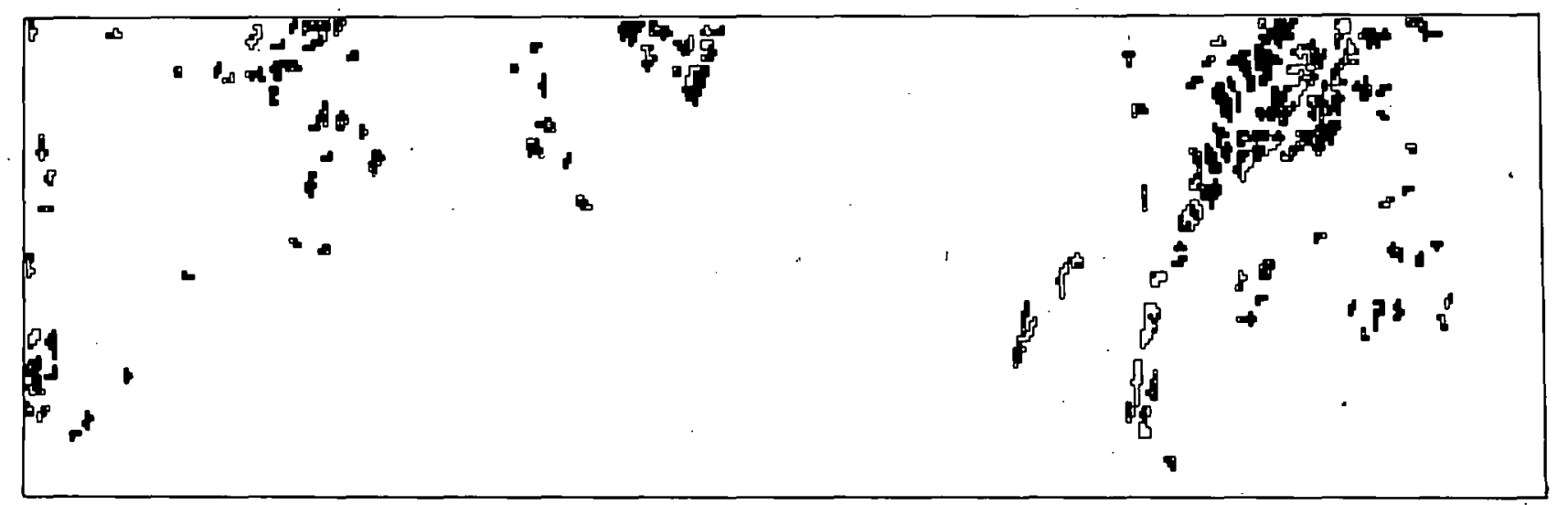

a. Rating Weighting Method

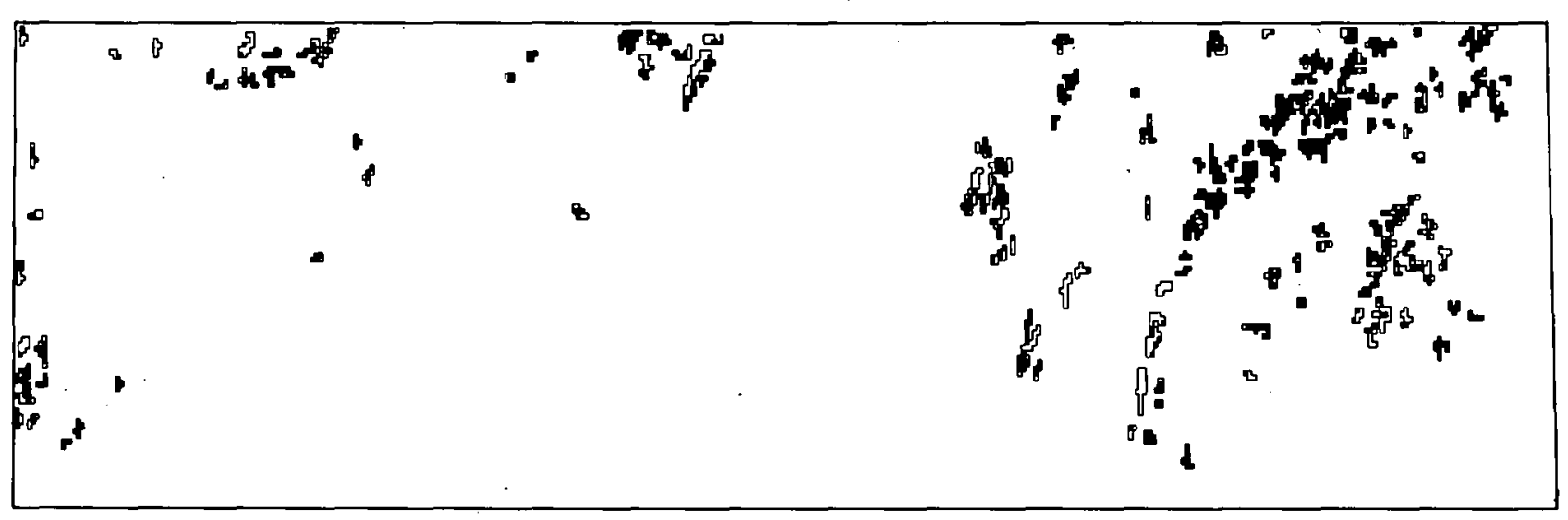

b. Indifference Tradeoff Weighting Method

Figure 4.4. Power Law Candidate Areas, Mr. Mueller, Maryland Screening I. 


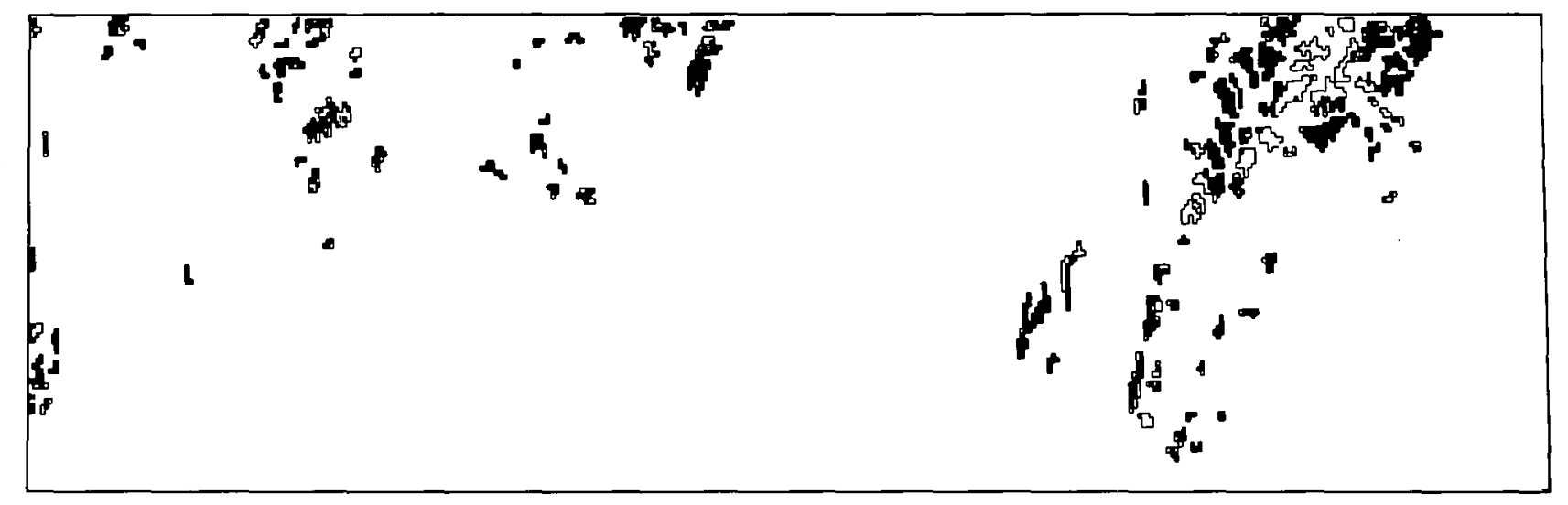

a. Rating Weighting Method

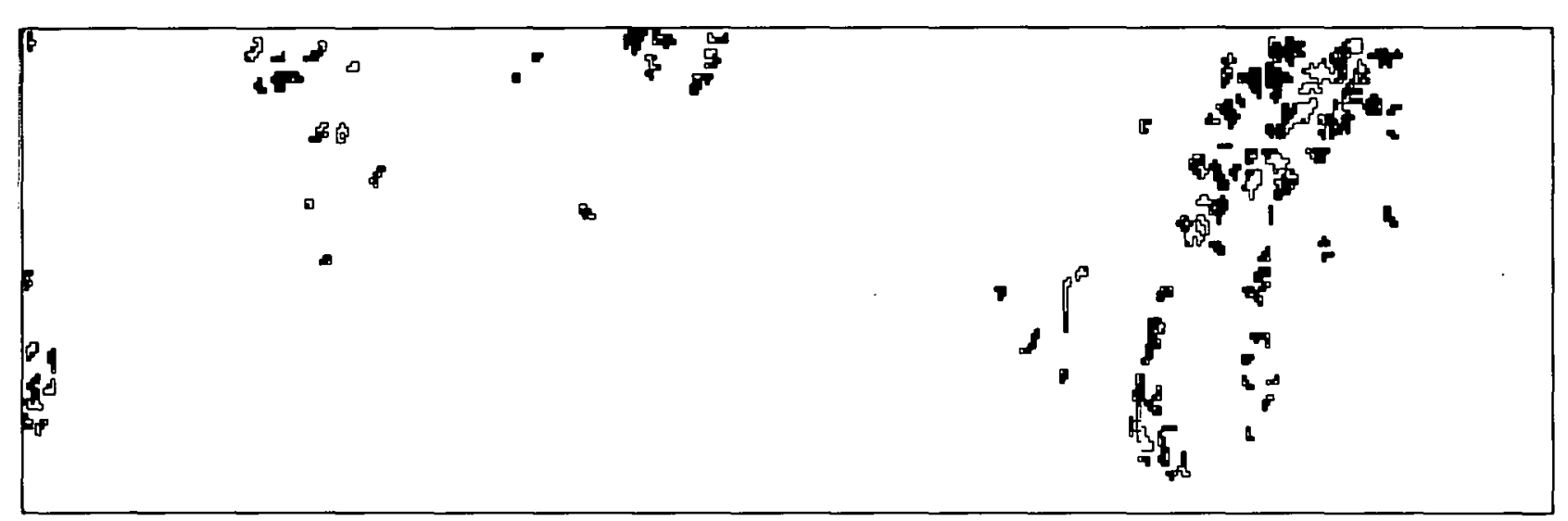

b. Indifference Tradeoff Weignting Me thod

Figure 4.5. Power Law Candidate Areas, Dr. Canham, Maryland Screening I. 


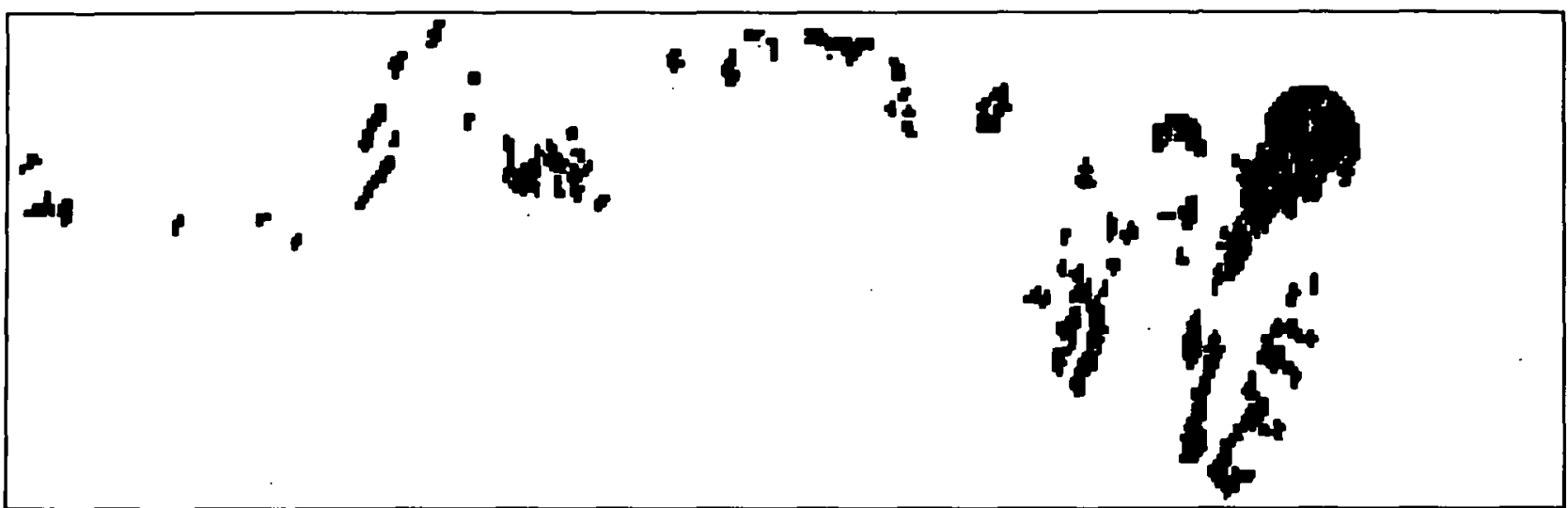

Figure 4.6. Exclusionary Screening Candidate Areas, Maryland Screening I. (Black areas are cells satisfactory in all variables. White areas are all other cells.)

\subsection{WESTERN MARYLAND ANALYSES I I}

\subsubsection{Methods}

The same study area and many of the same attributes used in the first Maryland study are also used in a second study. Again, candidate areas were sought for a pair of nuclear plants. A panel of 14 siting experts from academia, consultant firms, government agencies, utilities, and a public interest group helped choose the attributes to be weighted. The attribute value functions, where possible, were based on those used in the analyses deseribed in the previous section. A key difference between this study and the preceding one is that only 9 instead of 17 variables were selected (Table 4.2). Three overlapping attributes compounded the problem, lowering the effective number to 7 .

Each of the 14 panel members chose exclusion criteria for the 7 attributes. They also applied 3 weighting methods: Categorization, Rating, and Metfessel Allocation. None of the 3 assesses the correct type of attribute importance, and only Metfessel Allocation attempts to assure a ratio level of measurement. Because the methods ask directly for weights (encouraging panel members to try to remember weights and be consistent between methods), and because the techniques were applied on the same afternoon, each person's 3 weight sets are more alike than they would be if the assessments were truly 


\begin{tabular}{|c|c|c|}
\hline \multicolumn{3}{|c|}{ TABLE 4.2} \\
\hline MAG I & \multicolumn{2}{|c|}{ VARIABLES INCLUDED IN WESTERN MARYLAND SCREENING II. } \\
\hline $\begin{array}{l}\text { MAGI } \\
\text { Variable No. }\end{array}$ & Variable Name/Category & Ratinga \\
\hline \multirow[t]{8}{*}{9,10} & STATE AND FEDERAL LAND & \\
\hline & (PRIMARY AND SECONDARY) & \\
\hline & None & 10 \\
\hline & Maryl and Dept. of Forests and Parks & 0 \\
\hline & Maryland Dept. of Fish and Wildlife & 0 \\
\hline & Other State of Maryland & 5 \\
\hline & Al1 Federal Government Categories & 0 \\
\hline & Municipal Ownership & 0 \\
\hline \multirow[t]{3}{*}{23} & HISTORIC SITES & \\
\hline & None in Cell & 10 \\
\hline & One or more in $\mathrm{Cell}$ & 0 \\
\hline \multirow[t]{17}{*}{26} & LAND USE AND LAND COVER (PRIMARY) & \\
\hline & Residential & 0 \\
\hline & Commercial & 0 \\
\hline & Industrial & 3 \\
\hline & Extractive & 0 \\
\hline & Transportation, Communication, Utilities & 0 \\
\hline & Institutional & 2 \\
\hline & Strip and Clustered Settlement & 1 \\
\hline & Mixed & 5 \\
\hline & Urban Open and Other & 3 \\
\hline & Cropland and Pasture & 8 \\
\hline & $\begin{array}{l}\text { Orchards, Groves, Vineyards, Bushfruits, } \\
\text { or Horticul tural Areas }\end{array}$ & 2 \\
\hline & Other Agriculture & 8 \\
\hline & Forest, Shrub & 8 \\
\hline & Water Areas & 0 \\
\hline & Wetlands (Vegetated and Unvegetated) & 0 \\
\hline & Other Barren Land & 10 \\
\hline
\end{tabular}

akey: $10=$ Best Category in variable

$0=$ Worsc catcgory in variable 


\section{TABLE 4.2 (Continued)}

\begin{tabular}{|c|c|c|}
\hline $\begin{array}{l}\text { MAGI } \\
\text { ariable No. }\end{array}$ & Variable Name/Ca tegory & Rating \\
\hline \multirow[t]{10}{*}{29} & 1980 COUNTY PLANS (PRIMARY) & \\
\hline & $\begin{array}{l}\text { Residential (MAGI Codes 10,12,13, } \\
14,15,16,17,18,19,67,68 \text { ) }\end{array}$ & 0 \\
\hline & $\begin{array}{l}\text { Commercial (Codes } 30,31,32,33,34 \text {, } \\
35,36,37,38,39,85,86,99,00)\end{array}$ & 0 \\
\hline & Industrial (Codes $20,21,22,23,24,75$ ) & 3 \\
\hline & Emp l oyment Center (Co des $40,41,42$ ) & 0 \\
\hline & Agriculture (Codes $50,51,52,53$ ) & 8 \\
\hline & $\begin{array}{l}\text { Recreation, Conservation, Open Spaces, } \\
\text { Parks (Codes } 60,61,62,63,64,65,66 \text {, } \\
\text { 83) }\end{array}$ & 0 \\
\hline & $\begin{array}{l}\text { Public and semipublic (Codes } 70,71,72 \\
73,74,76,77,78,81,82,84 \text { ) }\end{array}$ & 0 \\
\hline & Institutional (Codes $26,80,87$ ) & 0 \\
\hline & Rural-Vacant (Code 11) & 10 \\
\hline \multirow[t]{4}{*}{33} & SEISMICITY & \\
\hline & $\begin{array}{l}\text { ZONE } 1 \text { - Se ismically suitable sites } \\
\text { can be found with little difficulty }\end{array}$ & 10 \\
\hline & $\begin{array}{l}\text { ZONE } 2 \text { - Detailed site-specific studies } \\
\text { would be required to determine seismic } \\
\text { suitability }\end{array}$ & 3 \\
\hline & $\begin{array}{l}\text { ZONE } 3 \text { - Considerable time and money } \\
\text { would be required to determine seismic } \\
\text { suitability of a specific site, or near } \\
\text { known epicenters or inactive faults. }\end{array}$ & 0 \\
\hline \multirow[t]{5}{*}{35} & 30-MILE POPULATION FACTOR & \\
\hline & 0.0 to 0.2 & 10 \\
\hline & 0.2 to 0.5 & 7 \\
\hline & 0.5 to 1.0 & 3 \\
\hline & Greater than 1.0 & 0 \\
\hline \multirow[t]{3}{*}{36} & ENDANGERED SPECIES & \\
\hline & Observed Location of Indiana Bat & 0 \\
\hline & other & 10 \\
\hline
\end{tabular}


TABLE 4.2 (continued)

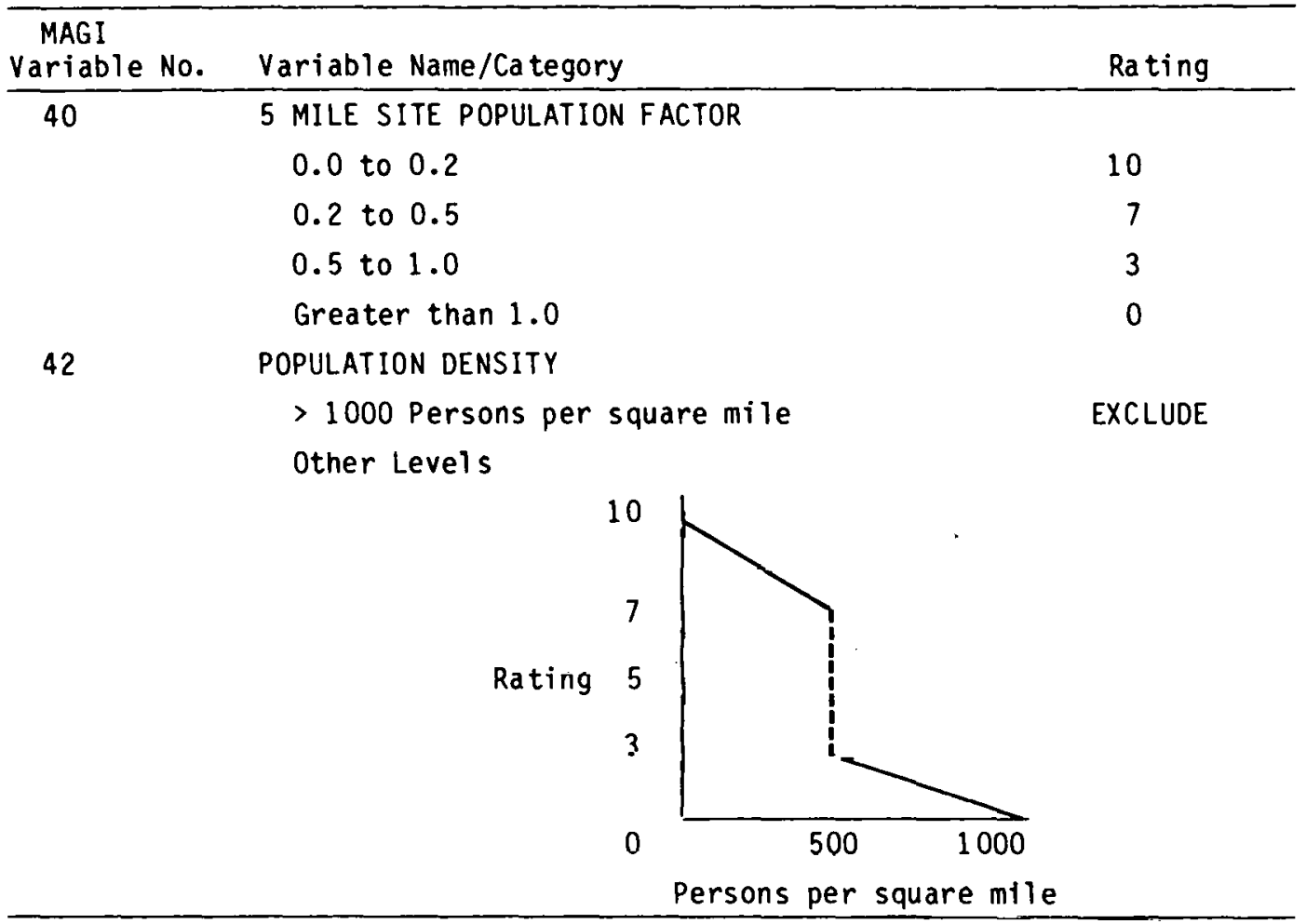

independent. This carryover effect biases results, making individual uncertainty and choice of method appear to be less important than they would be were applications independent.

\subsubsection{Results}

Between-methods correlations of weights are very high; few are less than 0.8 , much higher than those found in the first Maryland study, above. If one of the methods had produced theoretically valid weights, correlations might have been lower. Bctween-methods conrelations are significantly higher than between-persons correlations (correlations between pairs of Rating weights), which had a mean of 0.4 .

Conclusions regarding importance of choice of weighting method versus choice of person are confirmed by analysis of Weighting Summation suitability scores and candidate areas. Between-methods correlations of suitability scores are much higher than between-persons correlations for Metfessel Allo- 
cation. Candidate areas from different weighting methods generally overlap almost completely (Figures 4.7 to 4.9 ), although important differences exist for some participants. This is in contrast to the analyses summarized in the previous section, where Rating chose candidate areas strikingly different from Indifference Tradeoff. In general, little practical difference exists between the Categorization, Rating, and Metfessel Allocation weighting methods for the Conditions of this study.

Almost everyone's Categorization weights did, however, vary much less among themselves than did Rating or Metfessel Allocation weights. Categorization tends to compress ratios because of a lack of a range of well-quantified responses.

Almost everyone's Exclusionary Screening areas contain the same $8 \%$ of the cells as acceptable. Between-persons differences in Exclusionary Screening are inconsequential.

Exclusionary Screening (Figure 4.10, for example) and Weighting Summation (with all three weighting methods) picked the same areas for only two participants. Group median exclusionary criteria and group mean weights select areas which, on the average, overlap less than 50\% (Figure 4.11). In that case, however, Categorization disagrees 1ess with Exclusionary Screening than do the other two weighting methods. Again, Exclusionary Screening makes

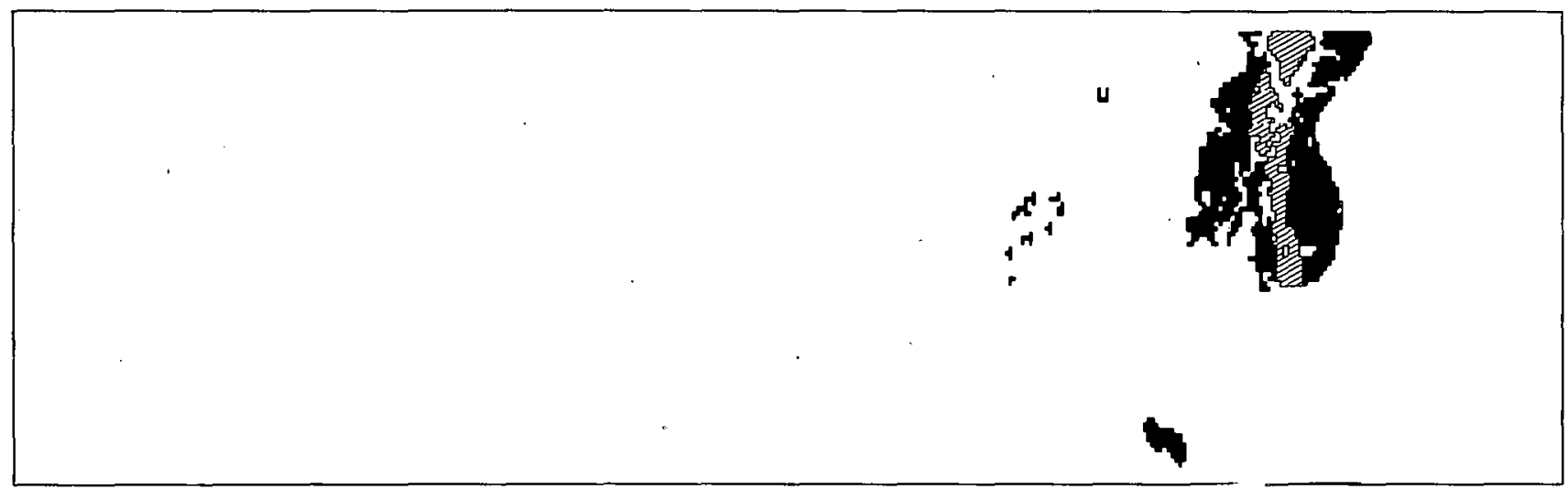

Figure 4.7. Categorization Candidate Areas, Advisory Panel (HM), Maryl and Screening II. 


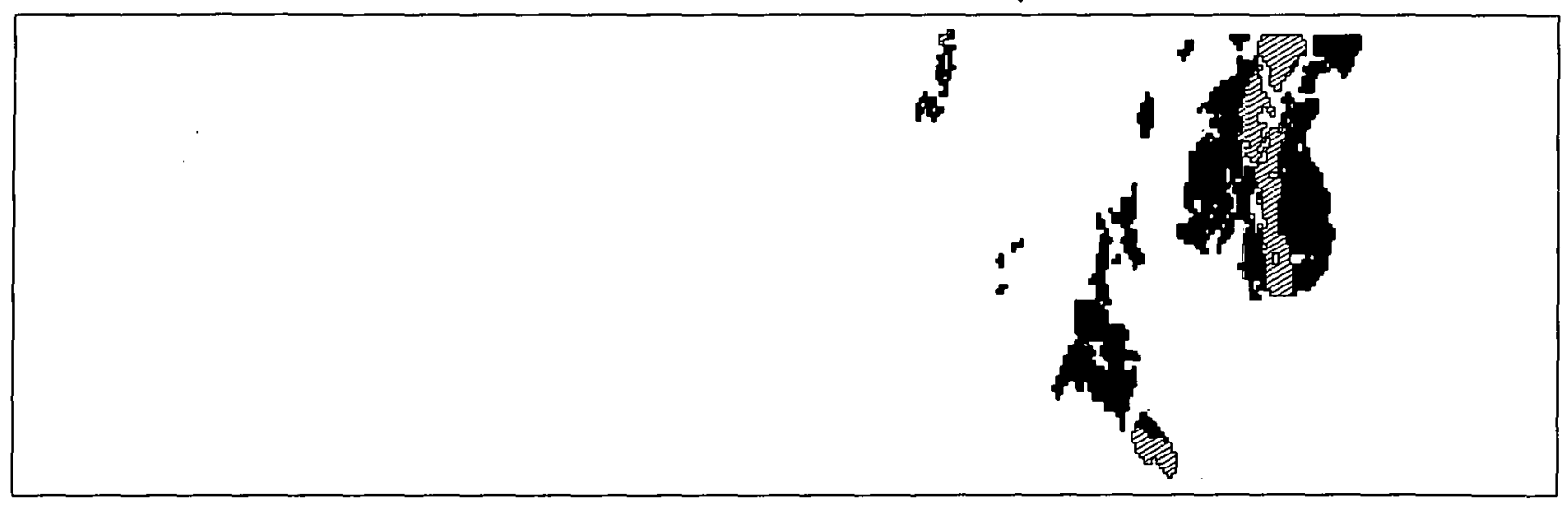

Figure 4.8. Rating Candidate Areas, Advisory Panel (HM), Maryl and Screening II.

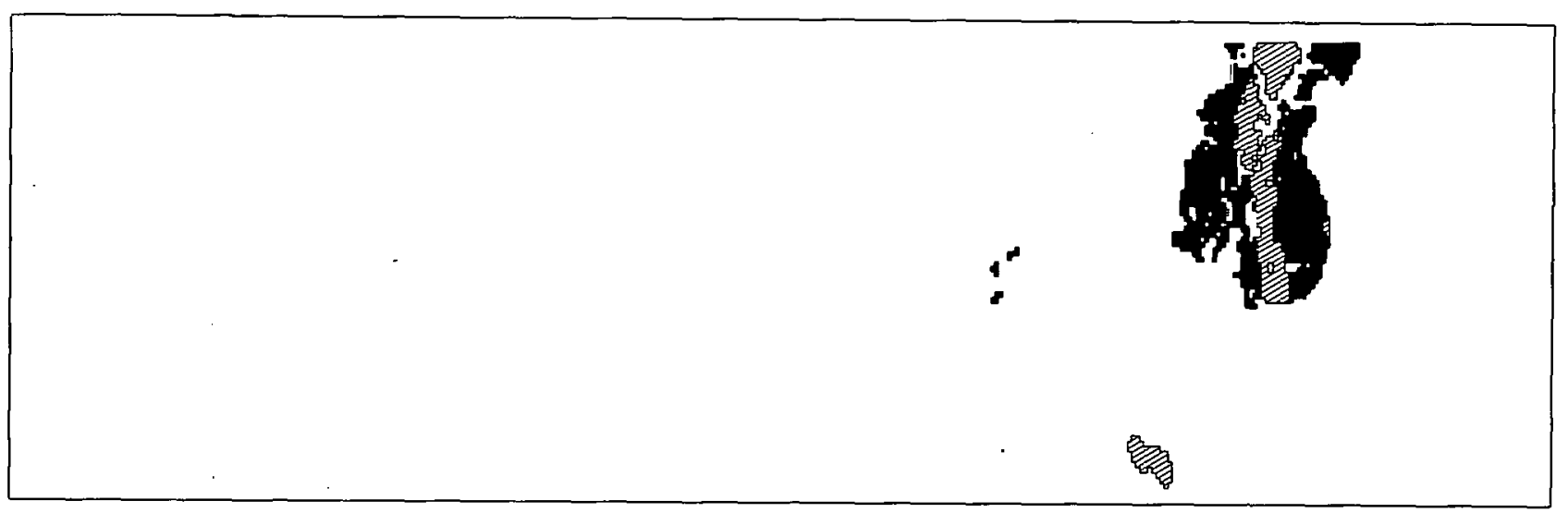

Figure 4.9. Metfessel Allocation Candidate Areas, Advisory Panel (HM), Maryl and Screening II. 


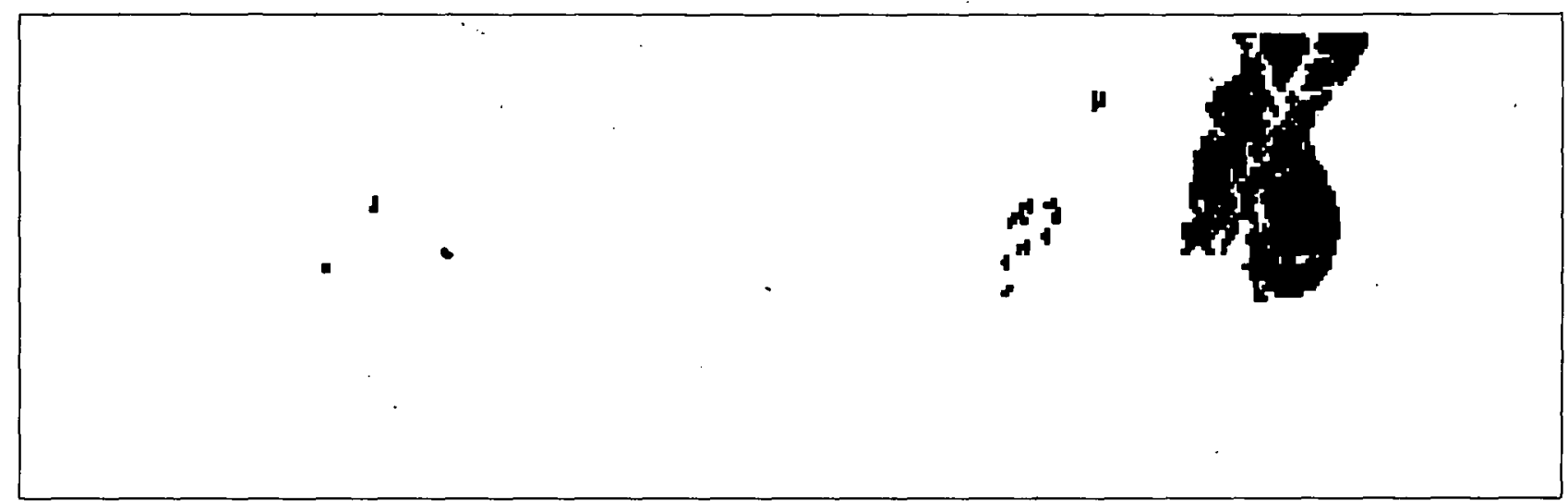

Figure 4.10. Exclusionary Screening Candidate Areas, Advisory Pane1 (MH), Maryl and Screening II.

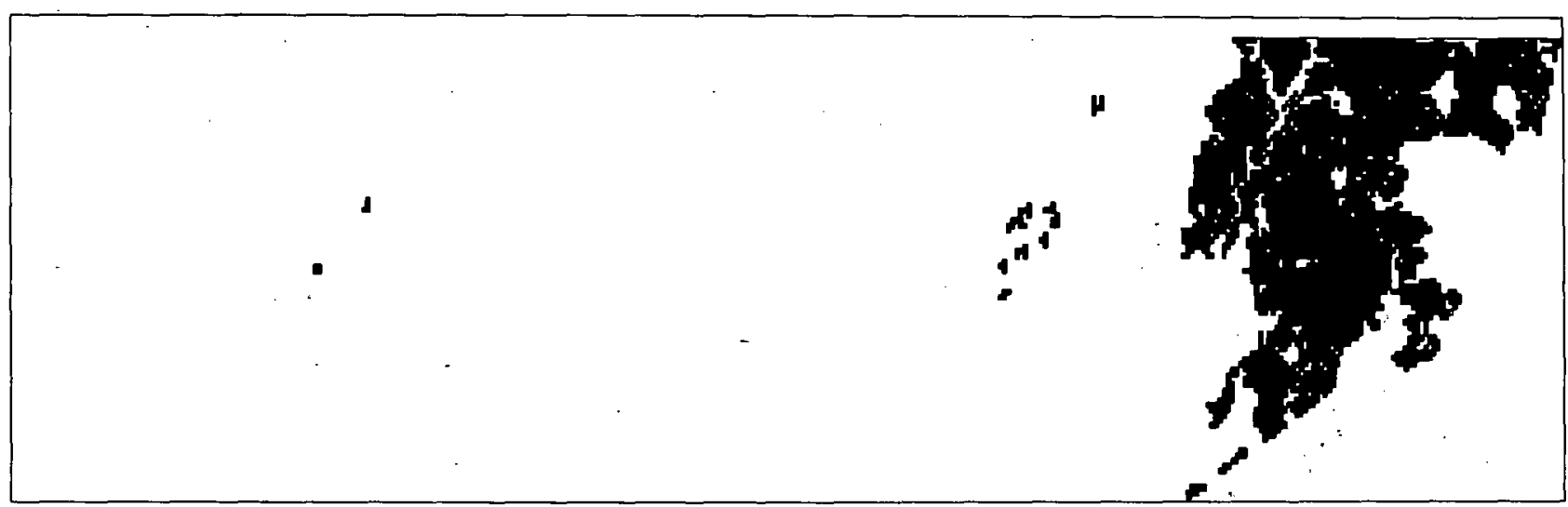

Figure 4.11. Exclusionary Screening Candidate Areas, Advisory Panel Group Median Criteria, Maryl and Screening II. 
tradeoffs among attributes of which the group would not approve if presented with them directly. It appears that Weighting Summation and Exclusionary Screening may be more likely to choose similar areas if there are few attributes than if there are many.

\subsection{WESTERN UNITED STATES ANALYSES}

\subsubsection{Methods}

This hypothetical study sought candidate areas in the western continental U.S. for 2 nuclear power plants with a mix of dry and wet cooling towers, optimized for each of 11,924 cells of 10 miles square in the study area. Seven siting attributes and value functions were adapted from a previous $\mathrm{Nu}-$ clear Energy Center study of the region (Table 4.3). The 14-member Advisory Panel which chose weights and exclusionary criteria in the second Maryland study did the same for this one, choosing exclusionary criteria and weights using Categorization, Rating, and Metfessel Allocation all on the same day. As in the second Maryland study, the results of the 3 methods are more similar than would be the case if the application of each method had been truly independent. This makes individual uncertainty and choice of method appear less important than they would be were applications independent.

\section{4 .2 Results}

Correlations were calculated between each person and each method. As in the second Maryland study, these between-methods correlations are high; only 2 persons had correlations $<0.8$. Between-persons correlations are generally higher than the between-persons correlations from the second Maryland study. The small number of attributes (7, as opposed to 9) might account for this. Nevertheless, between-persons correlations are significantly less than betwecn methods correlations of weights. Therefore, choice of person in this case affects weights more than choice of weighting method (from among categorization, Rating, and Metfessel Allocation). This agrees with the conclusions of the second Maryland study.

Analysis of overlaps of different sets of Weighting Summation candidate areas confirms this conclusion (Figures 4.12 to 4.15 ). Nevertheless, on the average, candidate areas from individual's Metfessel Allocation weights differ more than do Categorization and Rating areas. 
TABLE 4.3

ATTRIBUTES INCLUDED IN WESTERN U.S. SCREENING

Attribute Ca tegory

Ra tinga

1. Protected and Restricted Lands

National Parks, Forests, Historic

Monuments, or Wilderness Areas

other

0

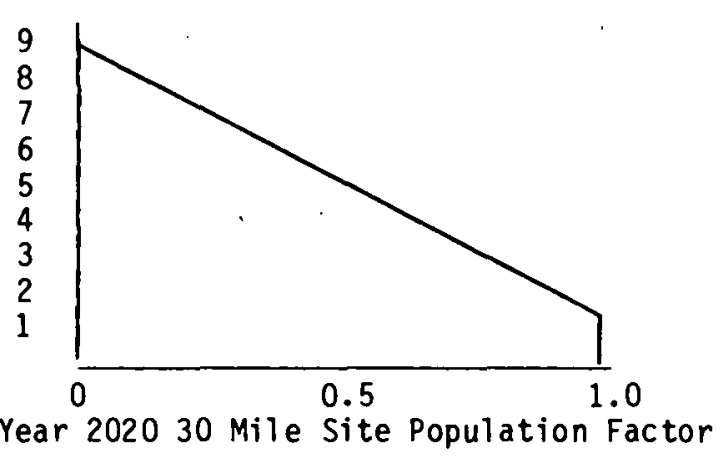

3. Airports and Air Corridors

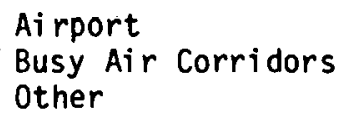

Ai rport

Busy Air Corridors Other

2. 30-Mile Site Population Factor

4. Sei smic Design Costb

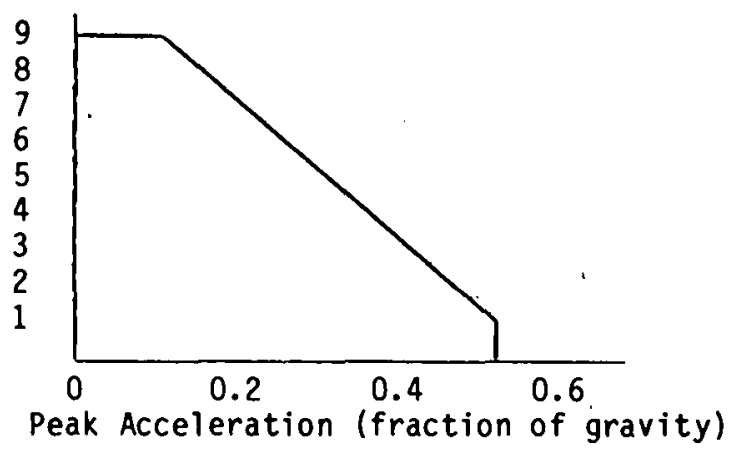

5. Power Transmission Costc.

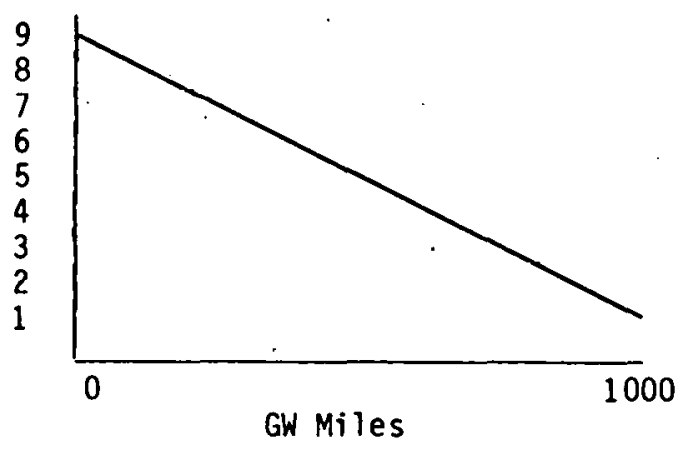




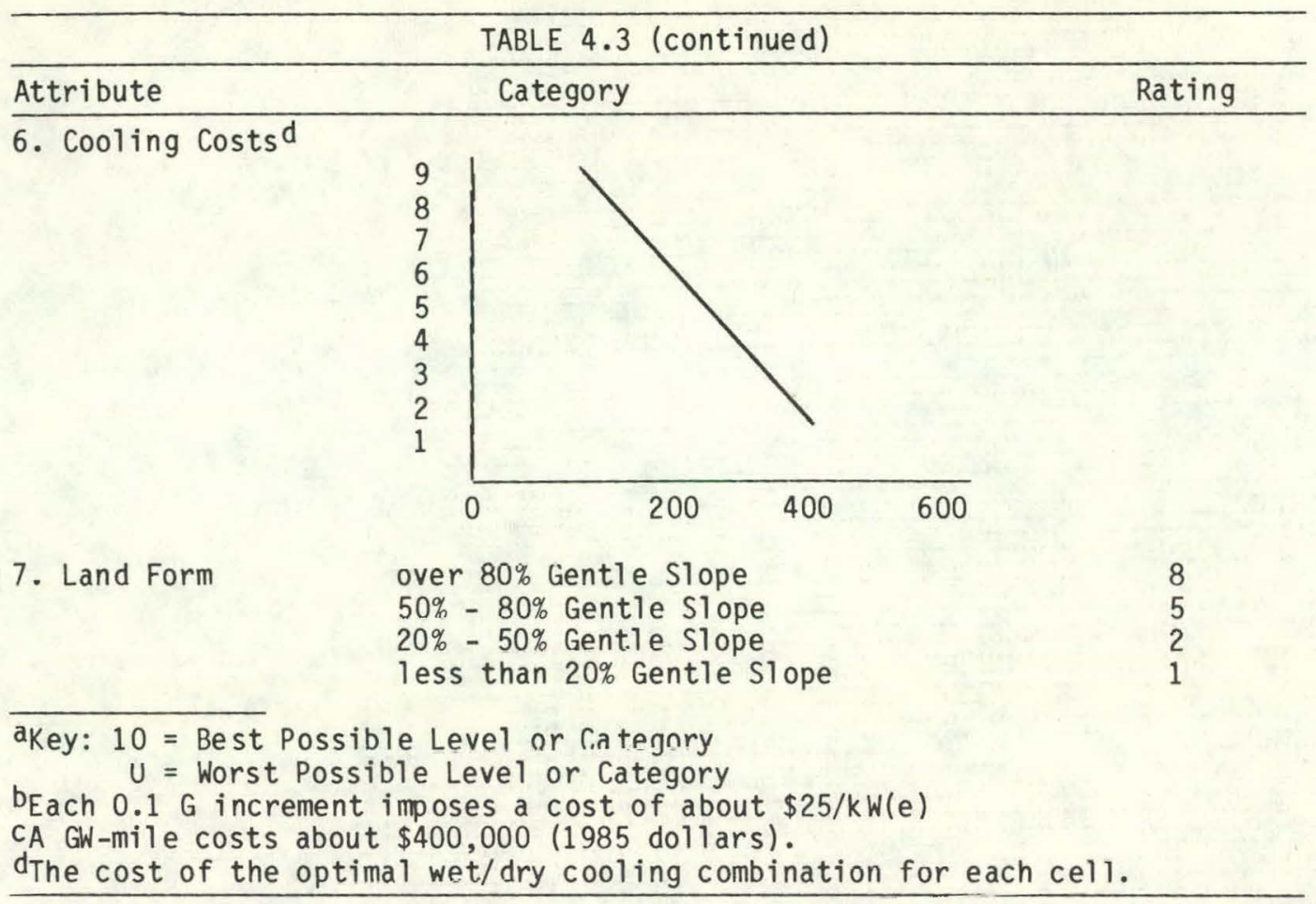

As in the second Maryland study, Categorization weights vary less among themselves than do either Rating or Metfessel Allocation weights. This again supports the hypothesis that Categorization compresses ratios of importance.

Exclusionary Screening areas of 6 persons are compared among themselves (Figure 4.16) and with corresponding weighting summation areas (for all 3 weighting methods). For 3 of the 6 persons, the disagreement in decision rules is greater than the agreement. Candidate areas from the different methods overlap more than 50\% for the other 3 persons and for the group as a whole (represented by mean weighls and exclusionary criteria). Nevertheless, the differences are still larger than most of the between - weighting methods and between-persons differences discussed above.

\subsection{CONCLUSIONS}

Choice of method clearly can influence results of screening exercises, and among methods choice of decision rule is most important. Decision makers choosing between Exclusionary Screening and other decision rules must, there- 


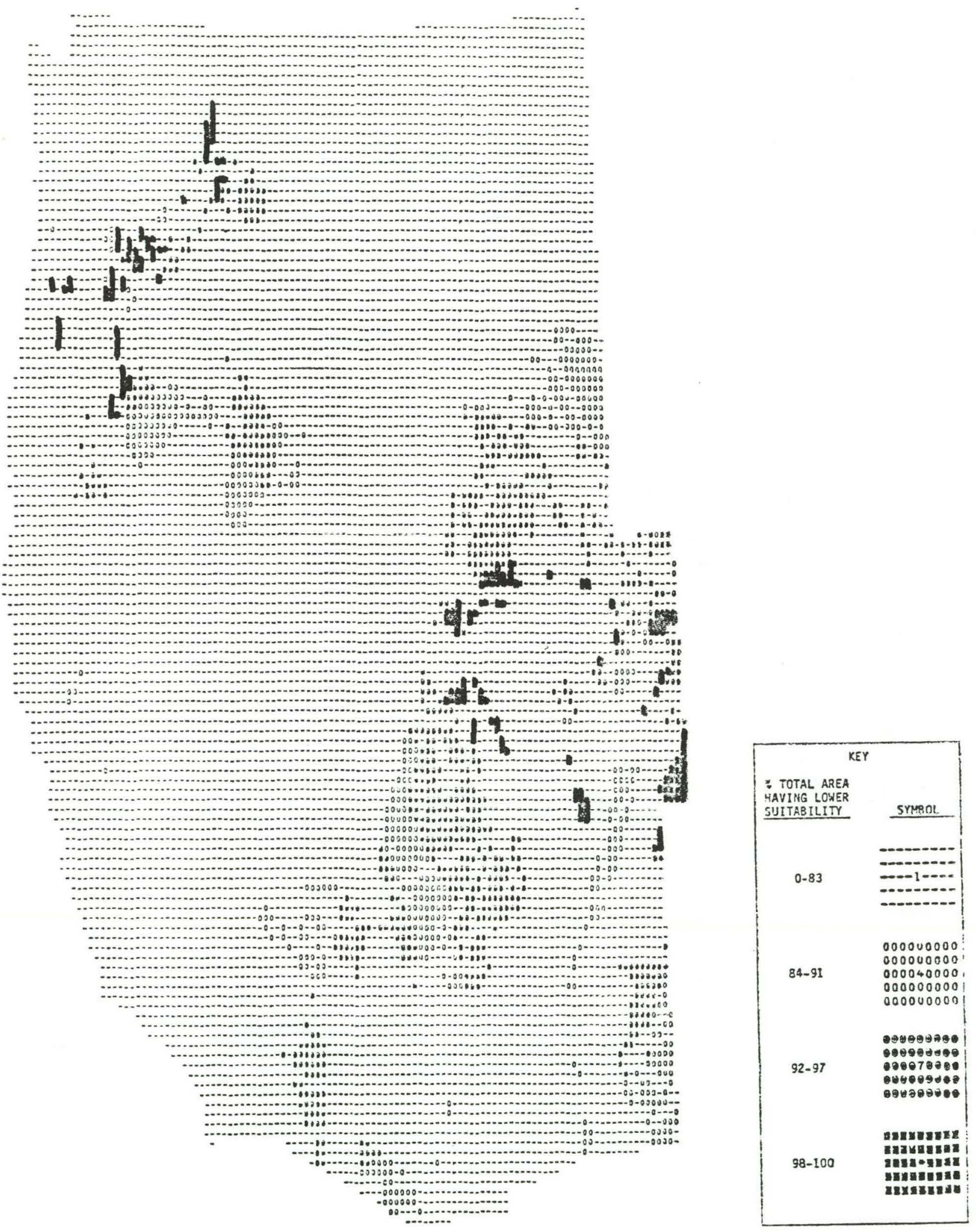

Figure 4.12. Categorization Candidate Areas, Advisory Panel (KN), Western U.S. Screening. 


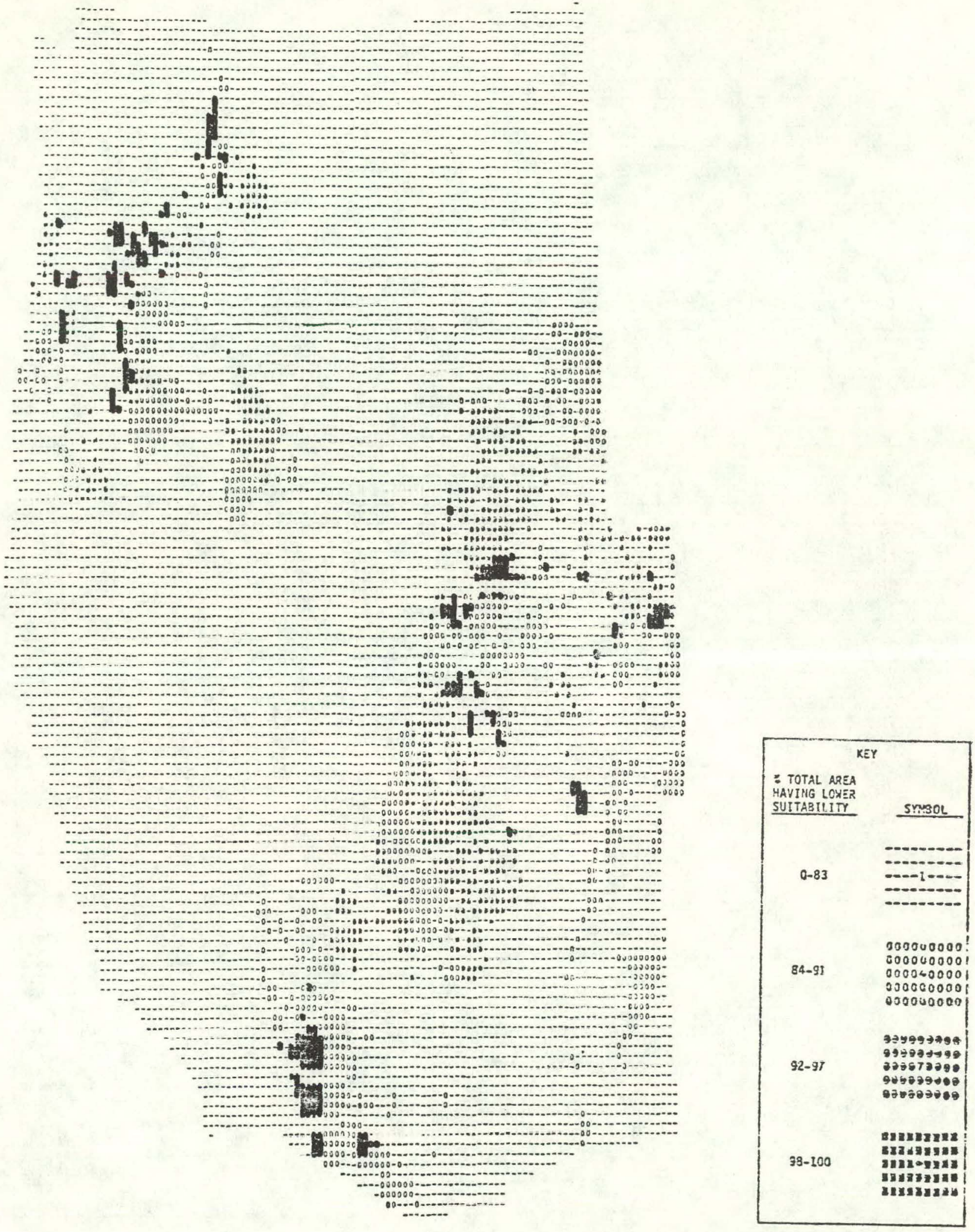

Figure 4.13. Metfessel Allocation Candidate Areas, Advisory Panel (KN), Western U.S. Screening. 


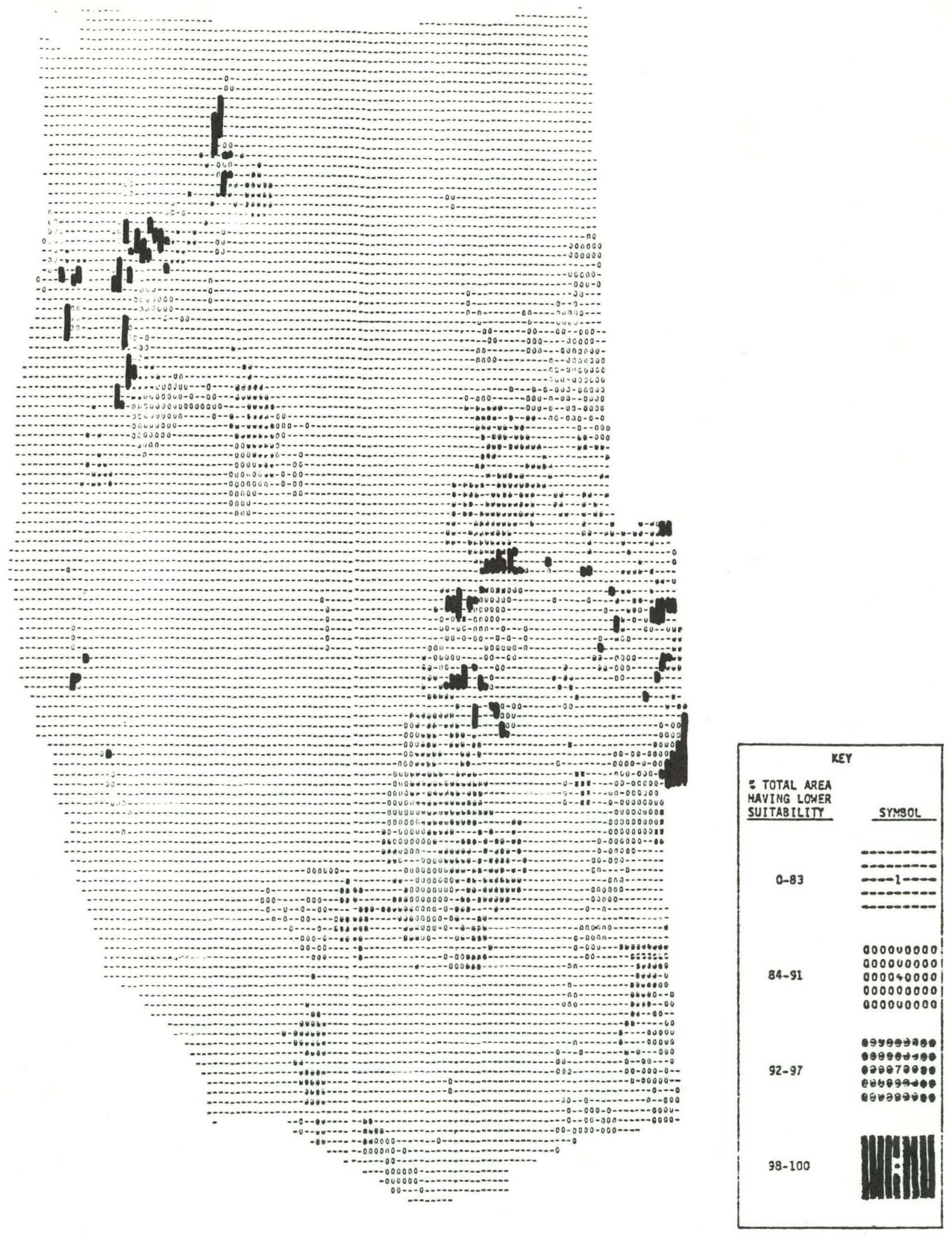

Figure 4.14. Categorization Candidate Areas, Advisory Panel (RK), Western U.S. Screening. 

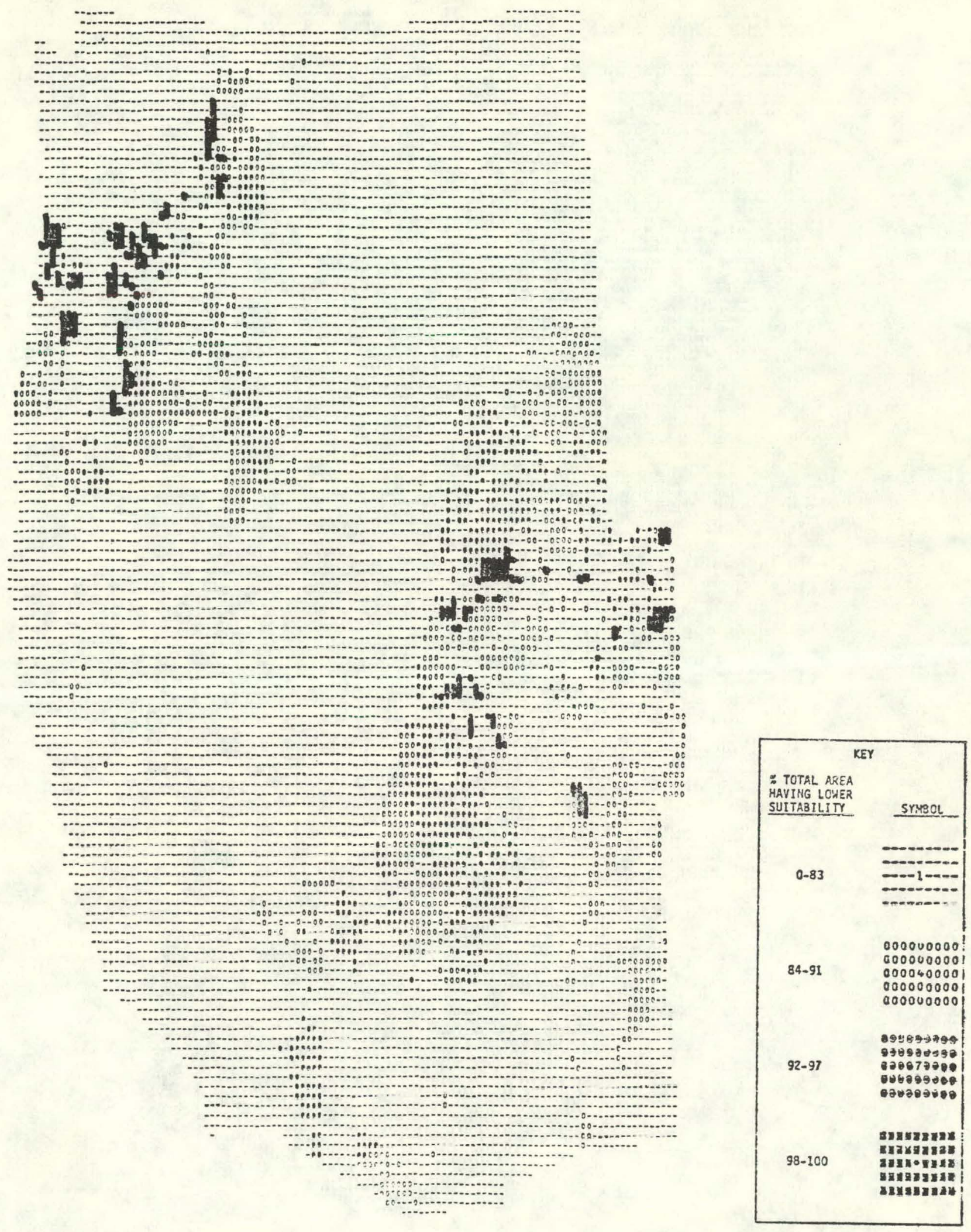

Figure 4.15. Metfessel Allocation Candidate Areas, Advisory Panel (JH), Western U.S. Screening 


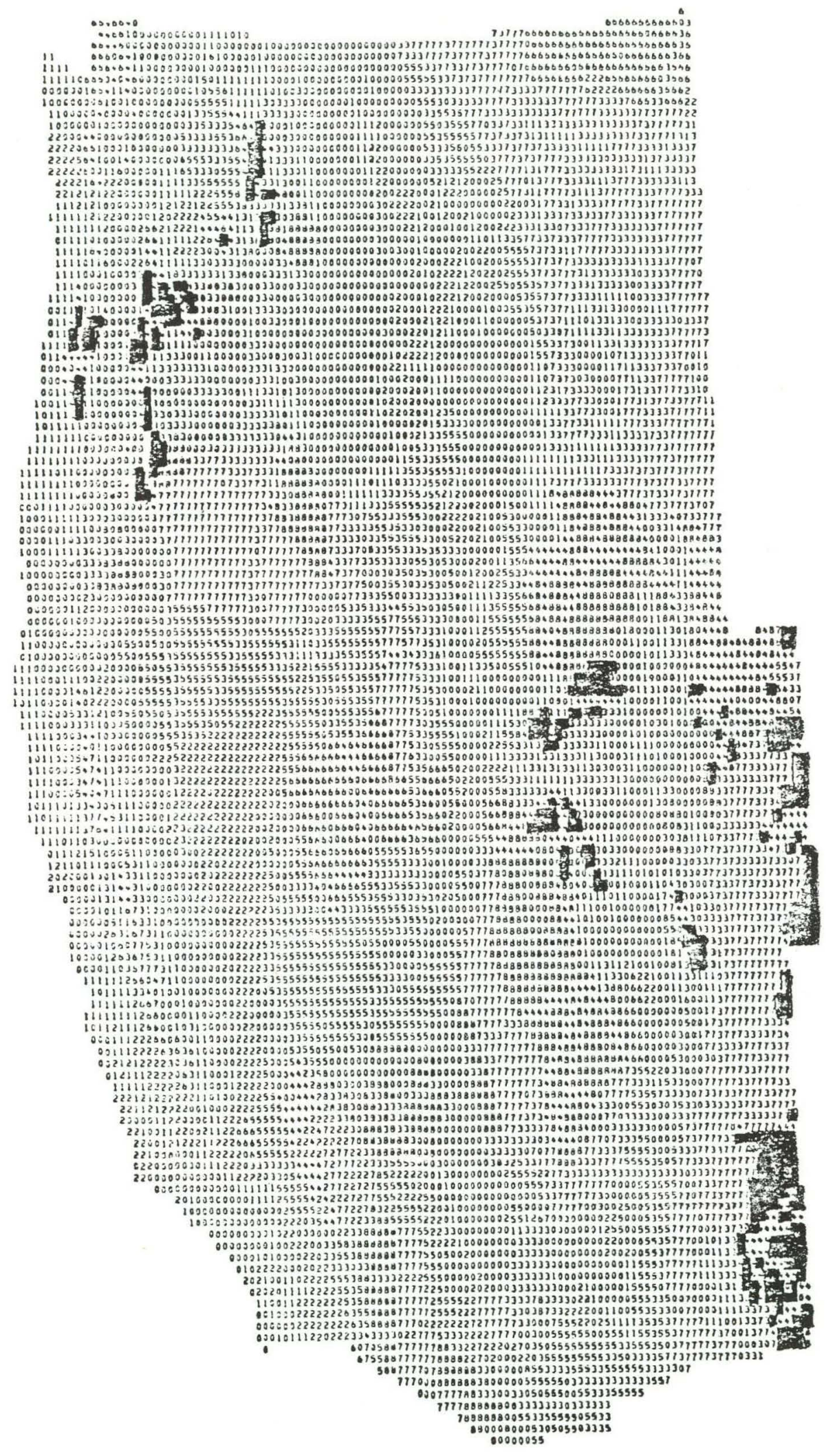

Figure 4.16. Number of Persons for Which Each Cell Passed A11 Exclusionary Criteria, Advisory Panel, Western U.S. Screening. Darkened areas were passed by more than 10 persons. 
fore, give careful consideration to the nature of their screening problem. Exclusionary screening is useful for selecting candidate areas which meet mandatory legal and engineering requirements. It tends to perform poorly if discretionary criteria are added because it does not allow for marginally unacceptable conditions of one $k$ ind to be overridden by unusually good conditions of another kind. As a result, Exclusionary Screening using discretionary criteria forces tradeoffs which decision makers might not consider acceptable were they presented with them directly. If a screening problem requires tradeoffs among discretionary criteria, then some form of Weighting Summation decision rule should be applied.

Among different methods for generating weights for Weighting Summation screening, the importance of method depends on the nature of the problem. Weighting Summation using a small number of attributes appears to be more sensitive to persons generating weights than to weight-generation method. For a larger number of attributes, weighting method may be more important.

The results reported herein compare candidate areas selected by different methods. No evaluation is made of the quality of the sites that might befound in these areas. It is not necessarily the case that different candidate areas will yield different qualities of candidate sites. To a certain extent, quality of candidate sites depends on the skill and experience of the persons involved in the candidate site-selection stage which follows screening, but more important, the probability that "good" candidate areas can yield "good" candidate sites is a function of correlations among variables used in screening, candidate site selection, and final site selection. The greater the correlations among these variables in the region, the more likely that a screening and candidate site-selection process will be successful in identifying sites that are among the "best" available with respect to the variables and values used. Also, the greater the correlations among variables, the more important is the success of each stage in providing choices to the next stage which have high probability of yielding "good" sites and, therefore, the more important are the methods to that success. Some of the characteristics that determine relative need for high quality results in the early stages of site selection are, therefore, outside the control of the persons doing the analysis.

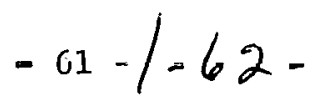




\section{TESTS OF FINAL SITE EVALUATION METHODS}

\subsection{INTRODUCTION}

Final site evaluation follows candidate site selection and reduction of the slate of candidate to a manageable number, usual 3 to 10 . All of the methods discussed in Section 2.0 can be used for final site evaluation and selection. Most of them have been used for this type of analysis at one time or another, although not all have been applied specifically to power plant siting problems.

Final site selection is the stage in the siting process which commonly receives the most attention from regulatory authorities and the general public; therefore, it is also the stage which has been most developed by utilities and the consultants who assist them with power plant siting. Methods can become exceedingly complex and, occasionally, can become ends in themselves so divorced from the problem at hand that persons involved lose site of the uncertainties of the basic information with which they are working. This produces a tendency to view the results of such analyses as "truths" arising from first principles.

This section examines some of the sources of error inherent in final site evaluation methods, and the extent to which it is possible to have confidence in quality of results.' Results of tests of a number of different decision rules and weighting methods are analyzed with respect to consistency and potential for introducing decision errors. Special attention is given the sensitivity of the Weighting Summation decision rule, which is the most commonly used method in final site selection for nuclear power plants. For more detailed presentation of results and discussion readers are referred to Rowe and Pierce (5) of which this section is a summary.

\subsection{METHODS}

Three test panels having different levels of siting experience applied 8 weight estimation methods and 5 decision rules (amalgamation methods) to hypothetical site descriptions based on data from Long Island, New Yürk (Table 5.1 summarizes one set of descriptions). Weight estimation methods including Ranking, Categorization, Rating, Ratio Estimation, Metfessel Allocation, Indifferent Tradeoff, Decision Analysis lottery, and Global Evaluation; decision rules included Weighting Summation, Power Law, Decision Analy- 
TABLE 5.1

SLMMARY OF SITE DESCRIPTIONS EVALUATED BY THE BNL PANEL

\begin{tabular}{|c|c|c|c|c|c|c|c|}
\hline Site & Site Cost & Land Use & Transmission & $\begin{array}{l}\text { Water Quality/ } \\
\text { Ecosystems }\end{array}$ & $\begin{array}{l}\text { Terrestrial } \\
\text { Ecosystems }\end{array}$ & Population & Aesthetics \\
\hline 1 & $\$ 13.0 \times 10^{6}$ & $\begin{array}{l}8 \text { homes on } \\
\text { site }\end{array}$ & $\begin{array}{l}24 \text { miles } \\
\text { through farm- } \\
\text { land }\end{array}$ & $\begin{array}{l}\text { Quality good, } \\
\text { offshore shoal, } \\
\text { fish traps }\end{array}$ & $\begin{array}{l}10 \text { acres } \\
\text { coastal } \\
\text { marsh }\end{array}$ & $\begin{array}{l}25 \text { homes within } \\
1 / 2 \text { mile, } 1340 \\
\text { persons with in } \\
10 \text { sq miles }\end{array}$ & $\begin{array}{l}\text { Pastoral setting, } \\
\text { some natural } \\
\text { screening }\end{array}$ \\
\hline 2 & $\$ 14.7 \times 10^{6}$ & $\begin{array}{l}8 \text { homes on } \\
\text { site, } 255 \mathrm{ft} \\
\text { height limit, } \\
200 \text { acres } \\
\text { farmland }\end{array}$ & $\begin{array}{l}23 \mathrm{miles} \\
\text { through } \\
\text { farmland and } \\
\text { woodland }\end{array}$ & $\begin{array}{l}\text { Deep, cool water, } \\
\text { less sensitive } \\
\text { ecosystem than } \\
\text { others }\end{array}$ & $\begin{array}{l}2 \text { small } \\
\text { ponds with- } \\
\text { in marsh. }\end{array}$ & $\begin{array}{l}15 \text { homes within } \\
1 / 2 \text { ml le, } 3240 \\
\text { persons within } \\
10 \text { sq miles }\end{array}$ & $\begin{array}{l}\text { Open farmland } \\
\text { and beach, low } \\
\text { line-of-sight } \\
\text { in all direc- } \\
\text { tions }\end{array}$ \\
\hline 3 & $\$ 15.7 \times 10^{6}$ & . & $\begin{array}{l}40 \mathrm{miles} \\
\text { through } \\
\text { land and } \\
\text { woodland }\end{array}$ & $\begin{array}{l}\text { Quality good, } \\
\text { productive bays } \\
\text { nearby, commer- } \\
\text { cial shell } \\
\text { fisheries }\end{array}$ & . & $\begin{array}{l}720 \text { persons } \\
\text { within } 10 \mathrm{sq} \\
\text { miles }\end{array}$ & $\begin{array}{l}\text { Woods, some } \\
\text { natura! } \\
\text { screening }\end{array}$ \\
\hline 4 & $\$ 11.1 \times 10^{6}$ & $\begin{array}{l}3 \text { homes cn } \\
\text { site, large } \\
\text { land devel- } \\
\text { opment plan- } \\
\text { ned, } 40 \text { acres } \\
\text { farmland }\end{array}$ & $\begin{array}{l}13 \text { miles } \\
\text { through } \\
\text { residential }\end{array}$ & $\begin{array}{l}\text { Quality fair, } \\
\text { tanker port } \\
\text { nearby }\end{array}$ & $\begin{array}{l}28 \text { acres } \\
\text { coastal } \\
\text { marsh }\end{array}$ & $\begin{array}{l}17 \text { homes within } \\
1 / 2 \text { mi le, } 5270 . \\
\text { persons within } \\
10 \text { sq mi les }\end{array}$ & $\begin{array}{l}\text { Pastoral setting, } \\
\text { noise-sensitive } \\
\text { area at } 2500 \mathrm{ft}\end{array}$ \\
\hline 5 & $\$ 13.2 \times 10^{6}$ & $\begin{array}{l}4 \text { homes on } \\
\text { site, } 160 \\
\text { acres far.nland }\end{array}$ & $\begin{array}{l}9 \mathrm{mil} \text { es through } \\
\text { farmland }\end{array}$ & $\begin{array}{l}\text { Quality fair } \\
\text { to good }\end{array}$ & & $\begin{array}{l}10 \text { homes within } \\
1 / 2 \text { mile, } 1880 \\
\text { persons within } \\
10 \text { sq miles }\end{array}$ & $\begin{array}{l}\text { Pastoral bluff, } \\
\text { little screening }\end{array}$ \\
\hline 6 & $\$ 23.0 \times 10^{6}$ & $\begin{array}{l}2 \text { homes on } \\
\text { site, } 160 \\
\text { acres farml and }\end{array}$ & $\begin{array}{l}5 \mathrm{mil} \text { les through } \\
\mathrm{farmland}\end{array}$ & $\begin{array}{l}\text { Quality fair to } \\
\text { good, tanker port } \\
\text { nearby, offshore } \\
\text { shoal }\end{array}$ & & $\begin{array}{l}3 \text { homes within } \\
1 / 2 \text { mi le, } 2500 \\
\text { persons within } \\
10 \text { sq mi les }\end{array}$ & $\begin{array}{l}\text { Pastoral bluff, } \\
\text { some natural. } \\
\text { screening, noise- } \\
\text { sensitive area } \\
\text { at } 1000 \mathrm{ft}\end{array}$ \\
\hline
\end{tabular}




\begin{tabular}{|c|c|c|c|c|c|c|c|}
\hline & & & & ABLE 5.1 (Continued) & & & \\
\hline Site & Site Cost & Land Use & Transmission & $\begin{array}{c}\text { Water quality/ } \\
\text { Ecosystems }\end{array}$ & $\begin{array}{l}\text { Terrestrial } \\
\text { Ecosystems }\end{array}$ & Population & Aesthetics \\
\hline 7 & $\$ 18.3 \times 10^{6}$ & $\begin{array}{l}425-f \infty o t \\
\text { helght } \\
\text { limit, } \\
90 \text { acres } \\
\text { farmland }\end{array}$ & $\begin{array}{l}4 \mathrm{mil} \text { es through } \\
\text { farmland }\end{array}$ & $\begin{array}{l}\text { Quality fair to } \\
\text { good }\end{array}$ & & $\begin{array}{l}1 \text { home within } \\
1 / 2 \text { mile, } 1530 \\
\text { persons } \\
\text { within } 10 \\
\text { sq miles }\end{array}$ & $\begin{array}{l}\text { Pastoral bluff, } \\
\text { elevated, noise- } \\
\text { sensitive area } \\
\text { at } 2500 \text { feet }\end{array}$ \\
\hline 8 & $\$ 9.8 \times 10^{6}$ & $\begin{array}{l}425-f \infty 0 t \\
\text { height } \\
\text { limit, } \\
\text { LILCO-owred }\end{array}$ & $\begin{array}{l}7 \text { miles through } \\
\text { fields and wood- } \\
\text { land }\end{array}$ & $\begin{array}{l}\text { Quality, fair to } \\
\text { good, river out- } \\
\text { flow, offshore } \\
\text { shoal }\end{array}$ & $\begin{array}{l}12 \text { acres } \\
\text { coastal marsh, } \\
1 \text { small point }\end{array}$ & $\begin{array}{l}3 \text { homes within } \\
1 / 2 \text { mi le, } 3270 \\
\text { persors, with- } \\
\text { in } 10 \mathrm{sq} \text { miles }\end{array}$ & $\begin{array}{l}\text { Woods, natural } \\
\text { screening }\end{array}$ \\
\hline 9 & $\$ 14.5 \times 10^{6}$ & $\begin{array}{l}\text { LILCO-owned } \\
85 \text { acres } \\
\text { farmland }\end{array}$ & $\begin{array}{l}7 \mathrm{miles} \text { through } \\
\text { farmland }\end{array}$ & $\begin{array}{l}\text { Quality fair to } \\
\text { good, tanker } \\
\text { port nearby }\end{array}$ & $\begin{array}{l}1 \text { small } \\
\text { pond }\end{array}$ & $\begin{array}{l}2 \text { homes within } \\
1 / 2 \text { mile, } 2500 \\
\text { persons within } \\
10 \mathrm{sq} \text { miles }\end{array}$ & $\begin{array}{l}\text { Open bluff scarred } \\
\text { by sand pits, no } \\
\text { sensitive areas } \\
\text { adjacent }\end{array}$ \\
\hline 10 & $\$ 17.8 \times 10^{6}$ & $\begin{array}{l}9 \text { nomes on } \\
\text { site, } 190 \\
\text { acres farm- } \\
\text { land }\end{array}$ & $\begin{array}{l}14 \mathrm{miles} \text { through } \\
\text { farmland }\end{array}$ & $\begin{array}{l}\text { Quality fair to } \\
\text { good }\end{array}$ & & $\begin{array}{l}13 \text { homes within } \\
1 / 2 \text { mile, } 1270 \\
\text { persons within } \\
10 \mathrm{sq} \text { miles }\end{array}$ & $\begin{array}{l}\text { Pastoral, } \\
\text { low elevation }\end{array}$ \\
\hline 11 & $\$ 12.1 \times 10^{6}$ & $\begin{array}{l}200 \text { acres } \\
\text { farmland }\end{array}$ & $\begin{array}{l}12 \text { miles through } \\
\text { farmland }\end{array}$ & $\begin{array}{l}\text { Quality fair to } \\
\text { good }\end{array}$ & & $\begin{array}{l}4 \text { homes within } \\
1 / 2 \text { mile, } 1270 \\
\text { persons within } \\
10 \text { sq miles }\end{array}$ & $\begin{array}{l}\text { Pastoral, } \\
\text { low elevation }\end{array}$ \\
\hline
\end{tabular}


sis, Goal Programming, and Goal Attainment. In addition, special studies were conducted of sensitivity of the Weighting Summation method to conceptual errors and theoretical problems associated with the various weight estimation methods.

\subsection{RESULTS}

Among the weight estimation and decision rules chosen for study, there is a range of theoretical validity and difficulty of application. In general, the more theoretically valid methods are also more difficult. There is, therefore, a tradeoff between potential for error due to theoretical problems and potential for error due to inability to provide the required responses. The simplest methods tested, Global Evaluation, Goal Programming, and Goal Attainment, all produce results which are obviously different from those of more valid methods (Figure 5.1). There are several reasons why these methods are expected to yield results that do not agree with other methods, and most probably they do not correctly accomplish the desired evaluation process.

The most theoretically valid method tested, Decision Analysis, is also the most difficult. Results from Decision Analysis lotteries were for the most part so inconsistent among themselves that no weights could be calculated with which to estimate site suitability. This method is clearly not appropriate for application by inexperienced persons without extensive training and consistency checking. We have no results with which to compare application of Decision Analysis by persons experienced in use of the method.

The remaining methods all elicit weights for application in the Weighting Summation, or Power Law, Goal Programming, and Goal. Attainment decision rules. Indifference Tradeoff is the most theoretically valid among these. Weights elicited by this method were consistently different from those of other methods (Tables 5.2 and 5.3). Since this method requires direct assessment of tradeoffs between a unit of one impact against a unit of another impact, and since at least one panel preferred this method over all others because of that direct comparison, it may be that the weights elicited more closely represent the value systems of the individuals involved. There is no measure of "goodness" of results, however, so this is only conjecture. It may be that other methods are better able to capture relative preferences under suboptimal conditions. 


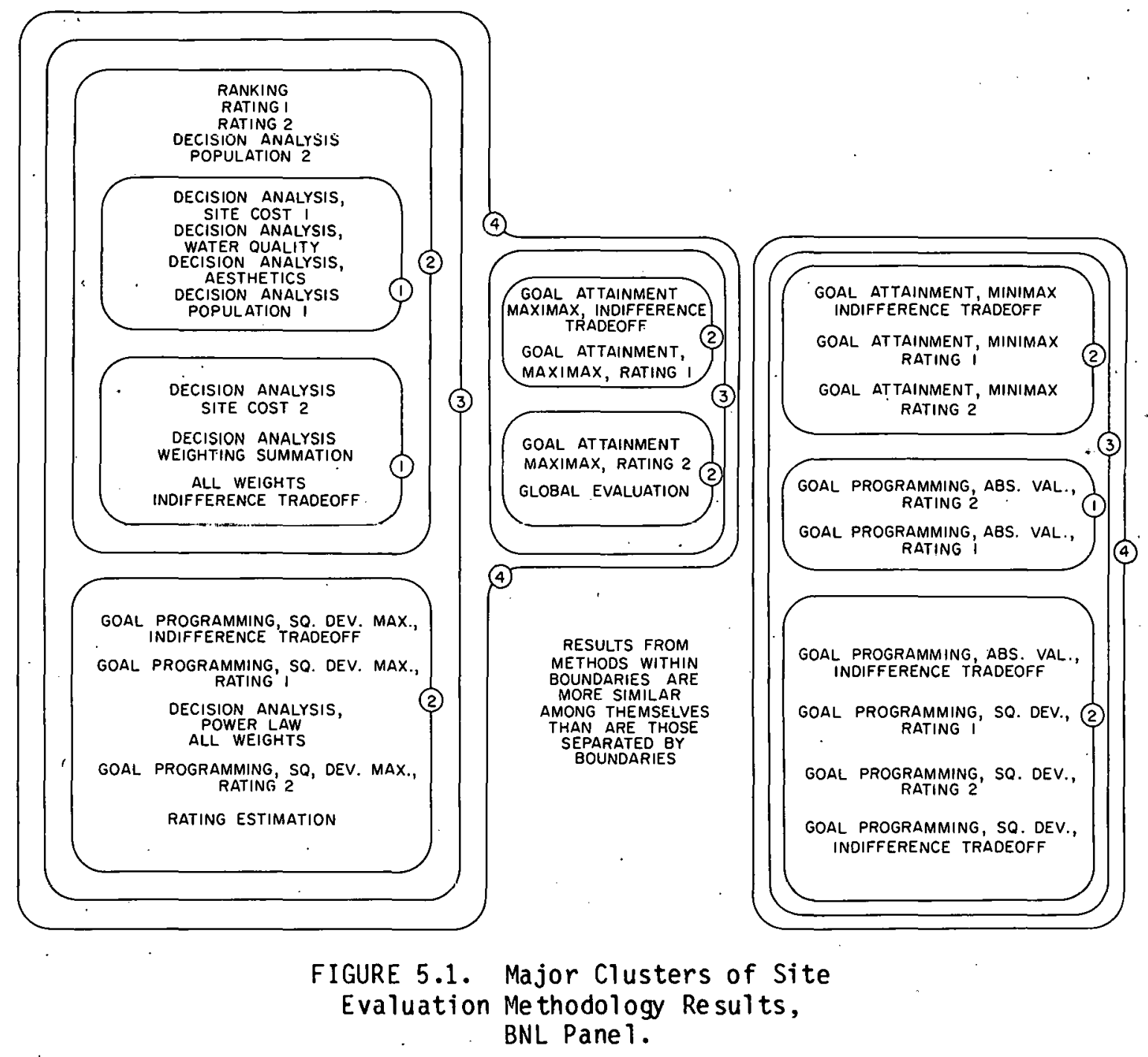


TABLE 5.2

MEAN BETWEEN-METHODS CORRELATIONS OF WEIGHTS, BNL PANEL

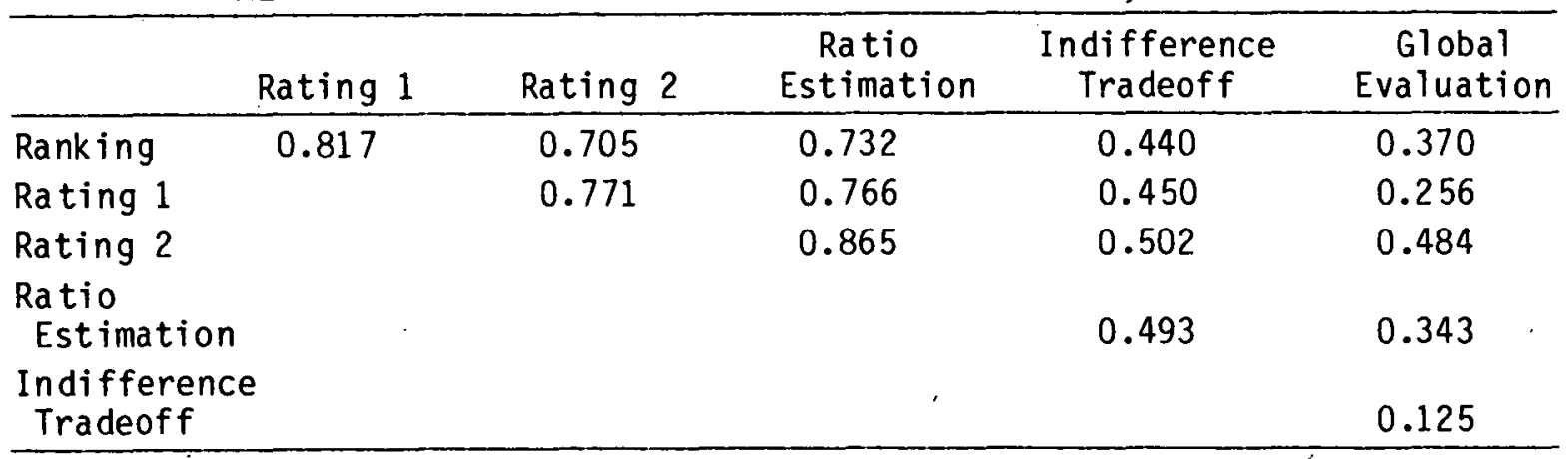

Ranking, Categorization, Rating, Ratio Estimation, and Metfessel Al location all require roughly equivalent responses, and their results are correspondingly similar. These methods are once-removed from Indifference Tradeoff in that they all require that tradeoffs be made implictly rather than explicitly. The same tradeoffs are involved, but they must be made on the basis of more general information and without any mechanisms which force all tradeoffs to be considered. The tradeoffs are diluted to general impressions about relative importance. Under this condition the elements of the assumption of additive independence, value independence, and preference independence, probably do not hold. This assumption is fundamental to the Weighting Summation amalgamation method (see Section 2.0).

TABLE 5.3

MEAN BETWEEN-METHODS CORRELATIONS OF ATTRIBUTE VALUES AND WEIGHTS, LONG ISLAND PANEL, FIRST MEETING

\begin{tabular}{lccccccc}
\hline & \multicolumn{1}{c}{$\begin{array}{c}\text { Impact } \\
\text { Severity }\end{array}$} & \multicolumn{1}{c}{ Weights } \\
\cline { 2 - 7 } Method & Rating & RATE 1 & METF 1 & CAT 2 & RATE 2 & METF 2 \\
\hline Categorization & 0.55 & 0.89 & 0.87 & 0.76 & 0.82 & 0.85 \\
Rating 1 & & & 0.92 & 0.87 & 0.91 & 0.90 \\
Metfessel Allocation 1 & & & 0.82 & 0.90 & 0.93 \\
Categorization 2 & & & & 0.92 & 0.84 \\
Rating 2 & & & & & 0.93 \\
\hline
\end{tabular}


of the methods above, only Categorization stands out as producing obviously different results (Figure 5.2). Because of its potential for large ambiguities in definitions of categories, this method has significantly reduced capability for dealing rigorously with the level of quantification required of the Weighting Summation and Power Law decision rules.

Among the weight estimation methods tested there occasionally were large differences in weights, both for individuals and, less so, for group means. Nevertheless, the sites selected by application of these weights are all nearly identical among the 2 or 3 top-ranked sites (Tables 5.4 and 5.5). This robustness of outcome arises from the structure of the siting problems under evaluation with respect to numbers and kinds of tradeoffs that were made between good levels of one impact and bad levels of another impact. If one site is better in all attributes than all other sites, then it is dominant and it will be first-ranked for all possible combinations of weights. Such a siting problem is completely insensitive to magnitudes of weights or methods used to elicit them. If, in contrast, there are large numbers of tradeoffs that must be made between relatively good and bad levels of attributes for all sites, so that each has a few good levels and a few bad levels, then results can be exceedingly sensitive to the specific magnitudes of weights and, therefore, to any differences attributable to methods for eliciting them. This is especially true if there is a large diversity of sites and it happens that there is no case in which all good attributes are much more important, and all bad attributes are much less important to the particular persons involved.

An index was derived which quantifies the magnitudes of tradeoff that must be made in a particular siting problem, including consideration of the likelihood that the tradeoffs will be among attributes of high-ranked sites. It is a measure of the complexity of the decision that must be made and, therefore, the relative sensitivity of the decision to magnitudes of weights. Tests of artificial siting problems of known complexity ranging from zero to near the maximum possible show that complexity has on the order of twice the potential to introduce error in a decision as do other variables associated with estimation of weights, including method and individual uncertainty.

Since it is difficult in these results to separate effects of differences among methods from effects of individual uncertainty and experimental 


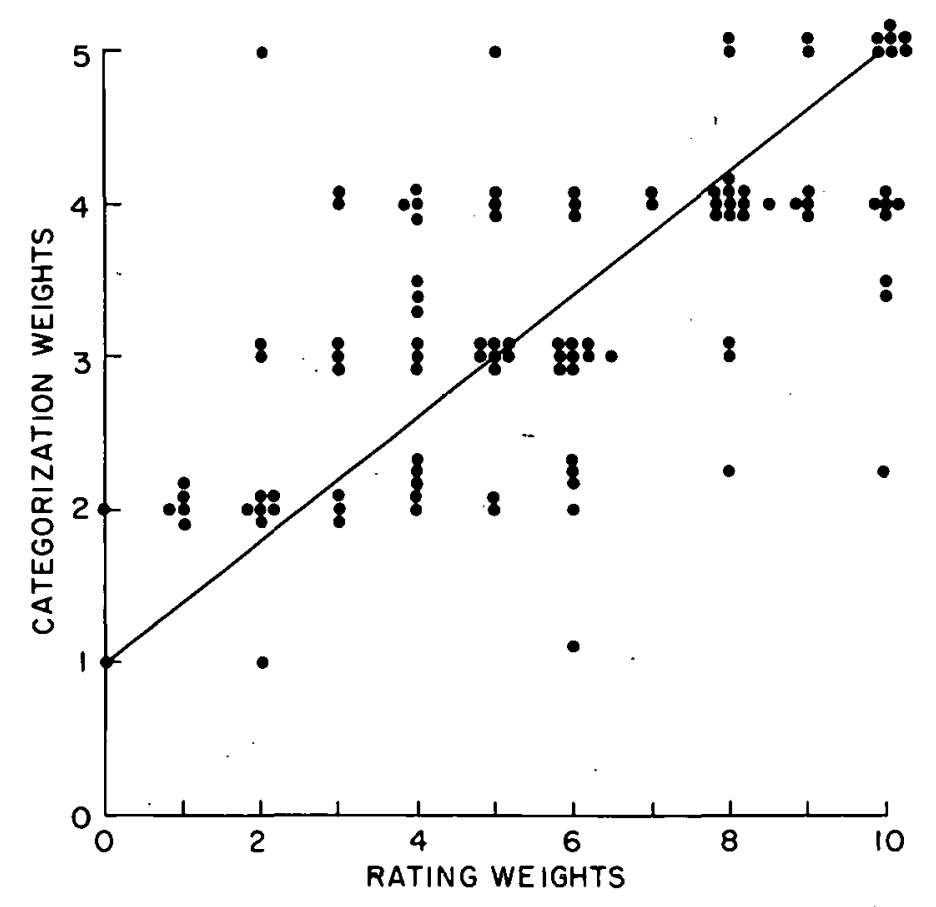

Figure 5.2. Comparisons of Categorized and Rated Weights, Advisory Panel. 
TABLE 5.4

SITE RANKS BY WEIGHT ESTIMATION AND AMALGAMATION METHOD, BNL PANEL

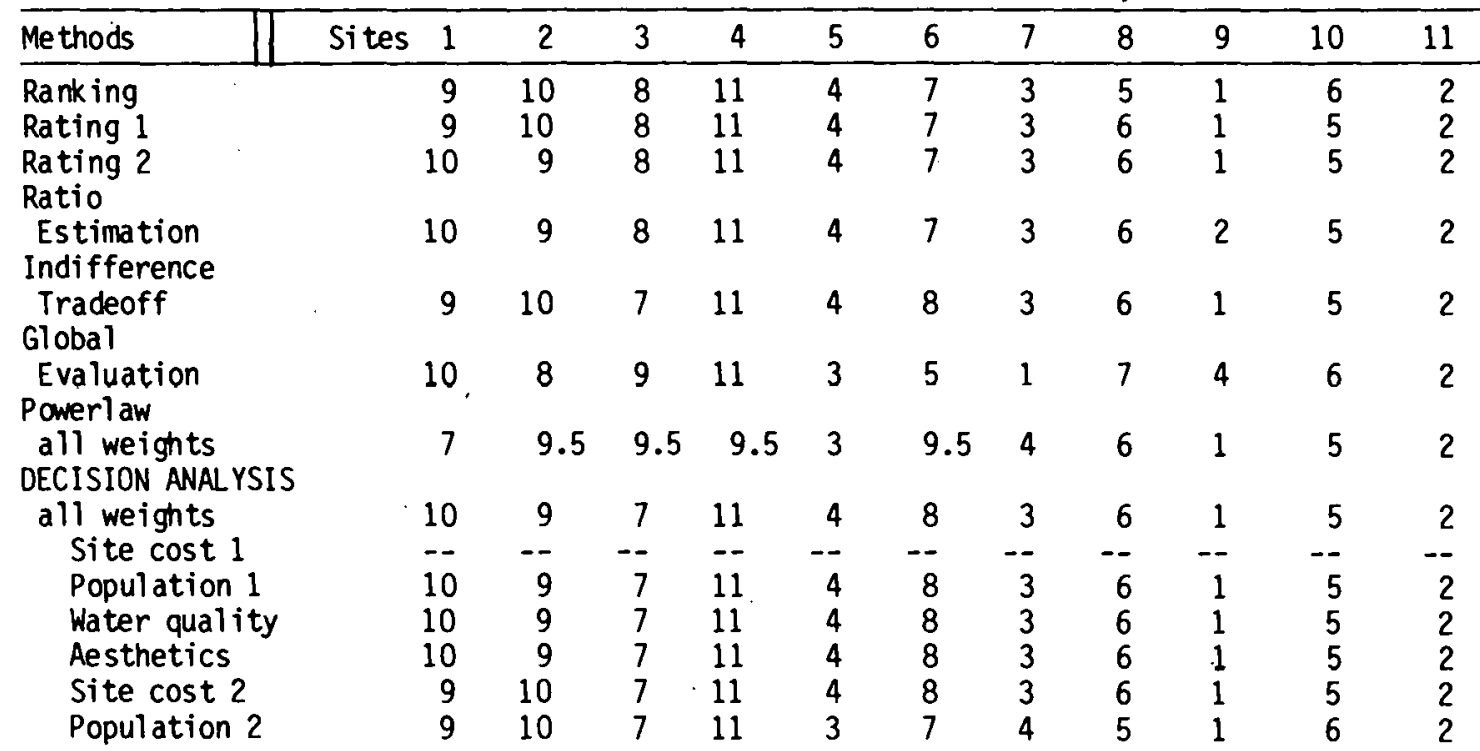

1. Goal Programing (Rating weights)

a. Absolute value of deviations

b. Squared deviations

c. Squared deviations from maximum

2. Goal Programming

$$
\begin{array}{lllllllllll}
8 & 7 & 10 & 11 & 1 & 3 & 5 & 9 & 6 & 2 & 4 \\
7 & 8 & 10 & 11 & 2 & 3 & 4 & 9 & 6 & 1 & 5
\end{array}
$$

(Indifference Tradeoff weights)

a. Absolute value of deviations

h. Squared deviations

c. Square deviations from maximum

3. Goal attainment (rating weights)

a. Minimix

b. Maxiniax

810

$9 \quad 11$

3

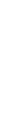$$
\begin{array}{lll}
7 & 8 & 1
\end{array}
$$$$
\begin{array}{llll}
8 & 7 & 9
\end{array}
$$

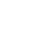$$
\begin{array}{lllllllllll}
7 & 10 & 9 & 11 & 3 & 8 & 4 & 6 & 1 & 5 & 2
\end{array}
$$$$
\begin{array}{lllllllllll}
8 & 9 & 10 & 11 & 3 & 4 & 5 & 7 & 6 & 1 & 2 \\
8 & 9 & 11 & 10 & 3.5 & 6.5 & 2 & 6.5 & 1 & 5 & 3.5
\end{array}
$$

4. Goal Attainment

(Indifference Tradeoff weights)
a. Mi millax
b. Maximax
$\begin{array}{lll}8 & 9 & 10\end{array}$
$11 \quad 2 \quad 4$

$\begin{array}{lll}11 & 3.5 & 5.5\end{array}$

\begin{tabular}{llll}
7 & 6 & 1 & 3 \\
5.5 & 1 & 7 & 3.5 \\
\hline
\end{tabular}

5




\begin{tabular}{|c|c|c|c|c|c|c|c|c|c|c|c|c|c|c|c|}
\hline \multicolumn{16}{|c|}{ TABLE 5.5} \\
\hline \multicolumn{16}{|c|}{$\begin{array}{l}\text { SITE RANKS FROM CATEGORIZATION (I), RATING (II), } \\
\text { AND METFESSEL ALLOCATION (III) METHODS, } \\
\text { ADVISORY PANEL }\end{array}$} \\
\hline \multirow[b]{3}{*}{ Person } & \multicolumn{15}{|c|}{ Si te } \\
\hline & \multicolumn{3}{|c|}{ A } & \multicolumn{3}{|c|}{ B } & \multicolumn{3}{|c|}{$C$} & \multicolumn{3}{|c|}{$\mathrm{D}$} & \multicolumn{3}{|c|}{$E$} \\
\hline & I & I I & I I I & I & II & III & I & II & III & I & II & III & I & II & II I \\
\hline JT & 3 & 5 & 5 & 5 & 2 & 2 & 4 & 3 & 4 & 1 & 4 & 3 & 2 & 1 & 1 \\
\hline SL & 3 & 5 & 5 & 4 & 4 & 4 & 1 & 2 & 3 & 2 & 1 & 1 & 5 & 3 & 2 \\
\hline KN & 5 & 5 & 5 & 4 & 4 & 4 & 2 & 3 & 4 & 3 & 1 & 1 & 1 & 2 & 2 \\
\hline DS & 5 & 5 & 4 & 4 & 4 & 5 & 2 & 3 & 2 & 1 & 1 & 1 & 3 & 2 & 3 \\
\hline$D C$ & 3 & 4 & 4 & 5 & 5 & 5 & 2 & 2 & 2 & 1 & 1 & 1 & 4 & 3 & 2 \\
\hline wo & 4 & 4 & 4 & 5 & 5 & 5 & 3 & 3 & 2 & 1 & 2 & 1 & 2 & 1 & 3 \\
\hline $\mathrm{BH}$ & 3 & 4 & 4 & 3 & 5 & 3 & 2 & 1 & 2 & 1 & 2 & 1 & 5 & 3 & 5 \\
\hline HM & 4 & 5 & 4 & 5 & 4 & 5 & 2 & 3 & 3 & 1 & 1 & 1 & 3 & 2 & 2 \\
\hline$E H$ & 4 & 4 & 3 & 5 & 5 & 4 & 3 & 2 & 1 & 1 & 1 & 2 & 2 & 3 & 5 \\
\hline $\mathrm{JL}$ & 4 & 4 & 4 & 5 & 5 & 5 & 3 & 2 & 1 & 1 & 1 & 2 & 2 & 3 & 5 \\
\hline TH & 5 & 5 & 5 & 3 & 1 & 2 & 1 & 4 & 4 & 2 & 3 & 1 & 4 & 2 & 3 \\
\hline $\mathrm{MH}$ & 5 & 5 & 4 & 3 & 3 & 2 & 4 & 4 & 5 & 2 & 1 & 1 & 1 & 3 & 3 \\
\hline $\mathrm{FL}$ & 4 & 4 & 2 & 5 & 5 & 5 & 1 & 3 & 4 & 2 & 1 & 1 & 3 & 2 & 3 \\
\hline$P M$ & 5 & 5 & 4 & 2 & 3 & 1 & 4 & 4 & 5 & 1 & 1 & 3 & 2 & 2 & 2 \\
\hline WH & 4 & 5 & 4 & 5 & 4 & 5 & 1 & 2 & 3 & 3 & 1 & 1 & 2 & 2 & 3 \\
\hline $\mathrm{JH}$ & 5 & 5 & 3 & 4 & 4 & 5 & 1 & 1 & 1 & 2 & 1 & 2 & 3 & 3 & 4 \\
\hline $\begin{array}{l}\text { Group } \\
\text { based or } \\
\text { mean } \\
\text { weights }\end{array}$ & 5 & 4 & 4 & 4 & 5 & 5 & 2 & 2 & 2 & 1 & 1 & 1 & 3 & 3 & 3 \\
\hline
\end{tabular}


methodology, a series of tests was made of differences in results produced by differences in weights attributable to known characteristics of each method (Figure 5.3). Categorization, for example, in an ideal case, might cause truncation of correctly ratio-scaled weights to integers. The truncation causes loss of resolution of weights falling between category boundaries. If apparently linear categories (low, medium, high) are perceived in a nonlinear manner, so that the magnitude of the difference between low and medium is different from that between medium and high (a common response), then truncation will also be nonlinear. In addition, some categorization schemes start at zero, some at one.

Rating methods can produce interval-scaled weights having an arbitrary zero; the least important attribute can be assigned to have zero weight even though it does not have zero importance. Rating procedures that do not assign a zero weight to the least important attribute usually have no mechanism for fixing the values and ratios of the weights so that a non-arbitrary zero point is assured. Both of these cause an arbitrary shift of scale.

All weighting methods introduce uncertainty, the magnitude of which may depend on method.

Repeated tests of the above classes of differences attributable to weighting methods (Figure 5.4) show that potential for decision errors attributable to systematic differences among methods is roughly equal to that attributable to individual uncertainty (Table 5.6). Depending on the structure of the decision problem involved, probability of causing a decision error can be as high as $30 \%$ due to either methodology or to individual uncertainty alone. (The two types of error are not strictly additive.) As stated above, however, complexity of siting problem has on the order of twice the potential for introducing error through increased sensitivity to weights than do methods and individual uncertainty.

\subsection{CONCLUSIONS}

The results presented above demonstrate that the final site-selection method can, in fact, affect siting decisions and that the probability that incorrect application of methods will cause suboptimal decisions can be relatively high. The simpler methods yield obviously different results and probably do not correctly represent the intended value systems and decision processes. The most complex methods are too difficult to be applied by any but 


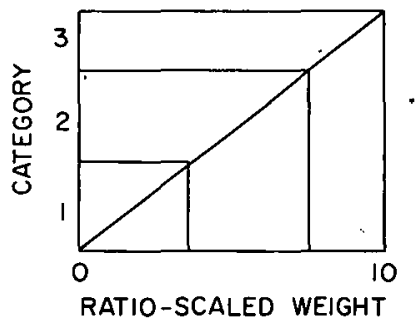

a. LINEAR CATEGORIZATION

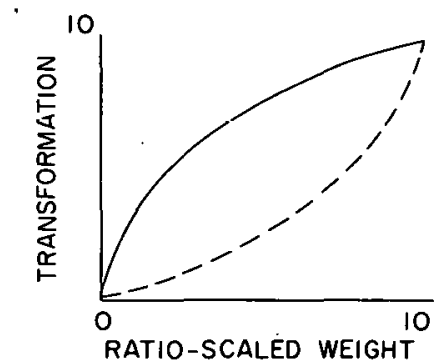

C. NONLINEAR - PERCEPTION

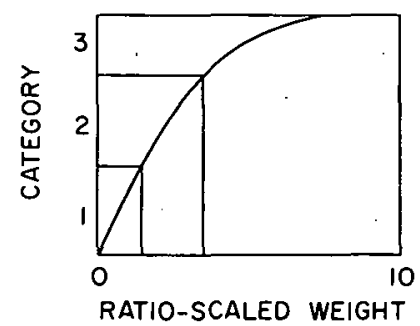

b. NONLINEAR CATEGORIZATION

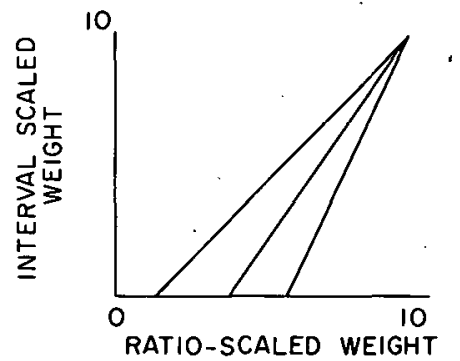

d. SCALE SHIFT WITH ARBITRARY ZERO

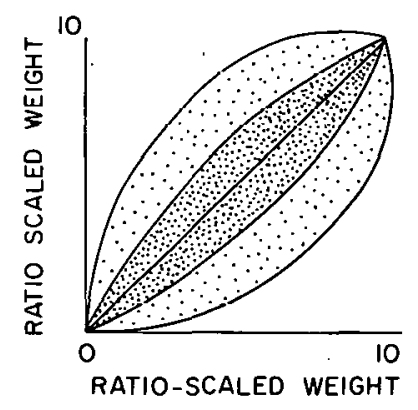

e. RANDOM VARIATION

Figure 5.3. Weight Transformations Attributable to Weight Estimation Me thods. 


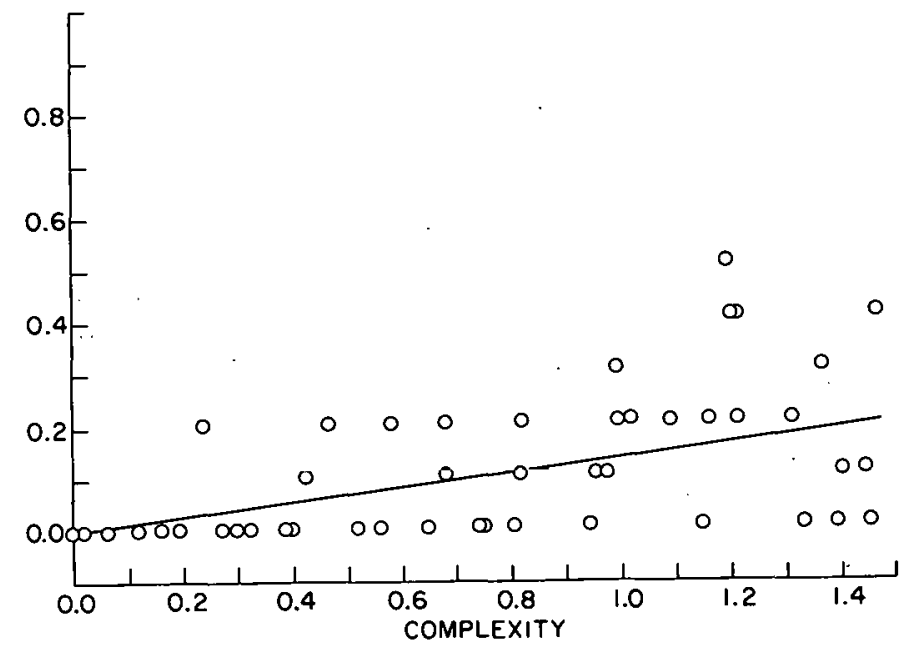

(a). Proportion of Decision Errors in 10 Random Trials, Logarithmic Transformation.

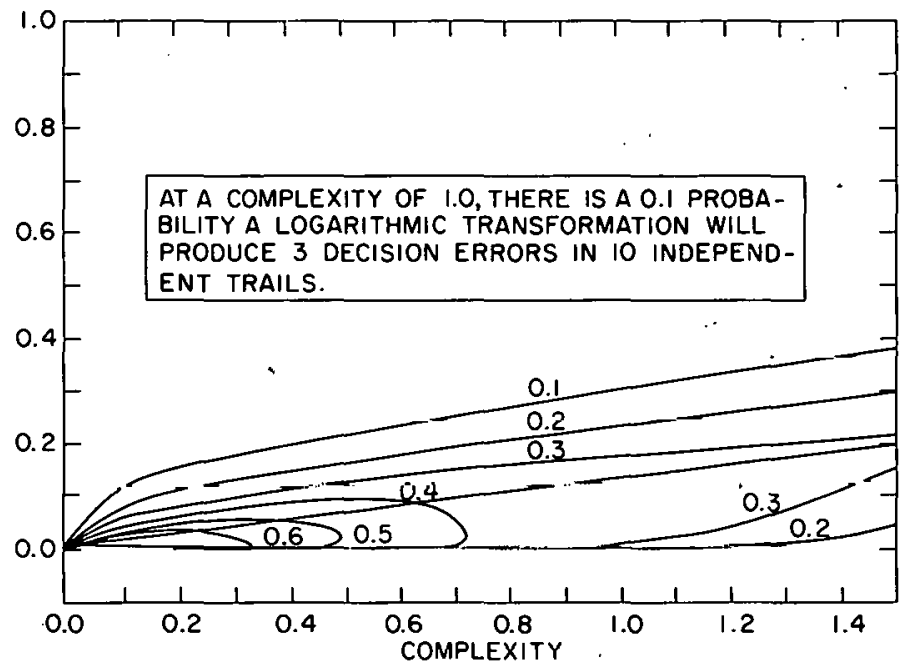

(b). Distribution of Probability of Decision Errors for 10 Random Bernoulli Trials, Logarithmic Transformation.

Figure 5.4. Probability of Decision Error Due to Logarithmic Perception as a Function of Decision Complexity. 
TABLE 5.6

CHANGE IN PROBABILITY OF ERROR PER UNIT COMPLEXITY FOR VARIOUS TRANSFORMATIONS OF RATIO-SCALED WEIGHTS

Changes in Probability

Transformation of Error per Unit Complexity

Linear categorization

2 categories

0.22

3 categories

0.10

5 categories

0.08

Categorization based at 0 vs

categorization based at 1

2 categories

0.09

3 categories

0.05

5 categories

0.00

Nonlinear categorization

logarithmic transformation

$\begin{array}{ll}2 \text { categories } & 0.22 \\ 3 \text { categories } & 0.18 \\ 5 \text { categories } & 0.13\end{array}$

Nonlinear transformation

logarithmic

0.12

exponential

0.13

Ratio to interval scale

Random zero point

+2 zero point

+4 zero point

0.04

+6 zero point

0.07

0.14

0.20

Random variability (Means $=0$ to 10 )
$=0.5$
$=1.0$
0.04
$=2.0$
0.08
0.15
$=3.0$
0.27 
the most experienced decision makers, and then only with extensive consistency checking.

In spite of evaluation methods' high potential for causing decision errors, the actual impact of incorrect application of methods depends on the complexity of the specific siting problem addressed. Low complexity problems are exceedingly robust, and even gross methodological errors may not affect results. High complexity problems are sensitive to all sources of errors, methods, and individual differences in preferences.

Complexity of a final site evaluation is controlled by the stage in the siting process immediately preceding final selection in which candidate sites are identified from candidate areas and reduced to a manageable number. This is the least formalized state of the process and the one most likely to be conducted "by the seat of the pants." Usually, experienced persons sit down with a large number of maps and hunt up places that "look good." There is no reason why this method can not yield high quality choices. Depending on the skill and biases of the persons involved, however, it has high potential for introducing error, bias, and sloppy workmanship, none of which is easy to discover after the fact. Strong preconceived notions about characteristics of a "good" power plant site, for example, reduce diversity of the sites finally evaluated, not only reducing the probability that any one site will be dominant or clearly superior, but also the likelihood that there will be sites that are "good" under value systems other than those of the persons choosing candidate sites. Political or NRC requirements that there be sites from several different geophysical or jurisdictional areas increase diversity, but cause sites to be included which might otherwise have been unsuitable. It is possible for final site selection to be made from among sites which are considered inferior by all except those who have done the selecting, and there is no reliable way to determine that this is the case other than by finding an obviously superior site. This places a burden of proof on interveners that should rightfully fall on utilities.

In view of the importance of the candidate site-selection stage to the complexity and quality of final results, and in view of the relatively inforIllal manner in which it is conducted, careful attention should be given to the quality of workmanship required of this stage. 


\section{EVALUATING SITING METHODS}

\subsection{INTRODUCTION}

The purpose of this report is to provide information and guidance to NRC reviewers who must determine whether or not alternative site analyses submitted in Environmental Reports are adequate. There are two aspects to such a review. First, a determination of whether or not the methods used in the analysis are correctly applied and appropriate to the special circumstances of that particular siting problem, and second, a determination of whether or not the results of the analysis are acceptable. To a certain extent, the second determination obviates the first. If the site selected is "good" by some prespecified set of criteria, the method by which it was selected need not be of concern. Historically, however, persons having limited experience with siting methods tend to believe that the first determination obviates the second, that a formula for siting exists which, if followed correctly, must necessarily yield a "good" site. In fact, this misconception extends even farther to a belief that such a formula can yield "the best" site.

It is easy to understand how this concept developed for site evaluations. Prior to NEPA, "best" meant cheapest (perhaps with addition of a few political considerations) or having the highest benefit:cost ratio. As siting techniques improved, different kinds of costs and benefits were included in analyses -- system considerations, long-range planning, etc. -- but all were eventualiy translated to estimates of dollar cost or some relative importance based on an estimate of potential dollar cost. Now, however, under NEPA, utilities are required to include environmental considerations for which estimates of dollar cost are difficult or impossible. Levels of subjectivity (and uncertainty) are orders of magnitude greater than that required of a standard engineering cost estimate, as are differences of opinion among individuals as to the relative significance of different environmental impacts. These problems vastly complicate what formerly was a relatively simple process.

A brief scan of the sections of this report dealing with subjective judgments of attribute values and weights suggests that, in all cases involving tradeoffs among desirable and undesirable levels of different attributes, the concept of "best" is not meaningful. "Best" is not only a function of the value systems of the individuals making judgments, but also of time. In 
time, power plants change in size and nature of impacts, siting requirements change, new environmental regulations are promulgated, and public perceptions and special concerns change. The time scale of these changes, especially the last two, can be shorter than the time required for planning and building a nuclear power plant. What is "best" this year may not even be "good" next year. There may also be a question of how good a site must be. If the slate of potential sites in a region is limited and a plant is built on the "best" site, is the "second best" site good enough for the next plant? If it is, does it really matter whether or not the first plant is built on the "second plant" site? Until such time as a set of univeral values is established by which goodness can be measured to the satisfaction of all, the concept of "best" has 1 imited usefulness in site evaluations.

If this is true, then what is the purpose of making complex alternative site evaluations? In this study we have viewed siting methodologies first to be means of minimizing the amount of data and effort required to reach reasonable solutions to complex problems, and second to be methods of formalizing that data collection and use such that tradeoffs among different values are apparent and it is possible to determine, at least in a general way, who wins and who loses in a siting decision.

With respect to the first purpose, it is not the function of an NRC review to determine whether or not an alternative site study has used time and information efficiently in reaching a decision. It can, however, determine that the objective of the study is achieved and that the total amount of information (area) that must be considered is reduced in a manner which increases the probability of a high-quality decision. The second purpose is clearly within the scope of an NRC review. If tradeoffs must be made among desirable and undesirable levels of different attributes, then different interest groups may perceive alternatives in different ways, especially if the problem happens to be of high complexity and, therefore, highly sensitive to differences in value judgments. Under such a circumstance, site evaluations should be conducted and described in such a manner that the magnitudes of these tradeoffs and value judgments are apparent and sensitivity analyses should be conducted to establish the range of possible solutions.

At first glance this requirement might be considered unnecessary, since in many cases solutions are reached by taking means of value judgments of 
different interest groups and the mean is taken to represent the group concensus. Figure 6.1, however, illustrates a simple example in which a group mean value judgment is not an optimal solution. One participant (or interest group, etc.) prefers to have combination $\left(X_{1}, Y_{1}\right)$ of two attributes. He is unwilling to change his position with respect to attribute $Y$, but is relatively unconcerned about the levels of attribute $X$. The other participant is the opposite, preferring combination $\left(X_{2}, Y_{2}\right)$, uncompromising with respect to attribute $X$, and relatively unconcerned about levels of attribute $Y$. The mean preference, $\overline{(X, Y)}$ falls on a line between the two individual preferences. It is clear from the figure that both individuals would prefer point $\left(X_{3}, Y_{3}\right)$ to $(\bar{X}, \bar{Y})$ because, in their perception of relative importance, the latter is closer to what they prefer than the mean. Under this circumstance, use of the mean makes everyone more unhappy with the outcome than is necessary, because the mean does not represent anyone's preferences very well.

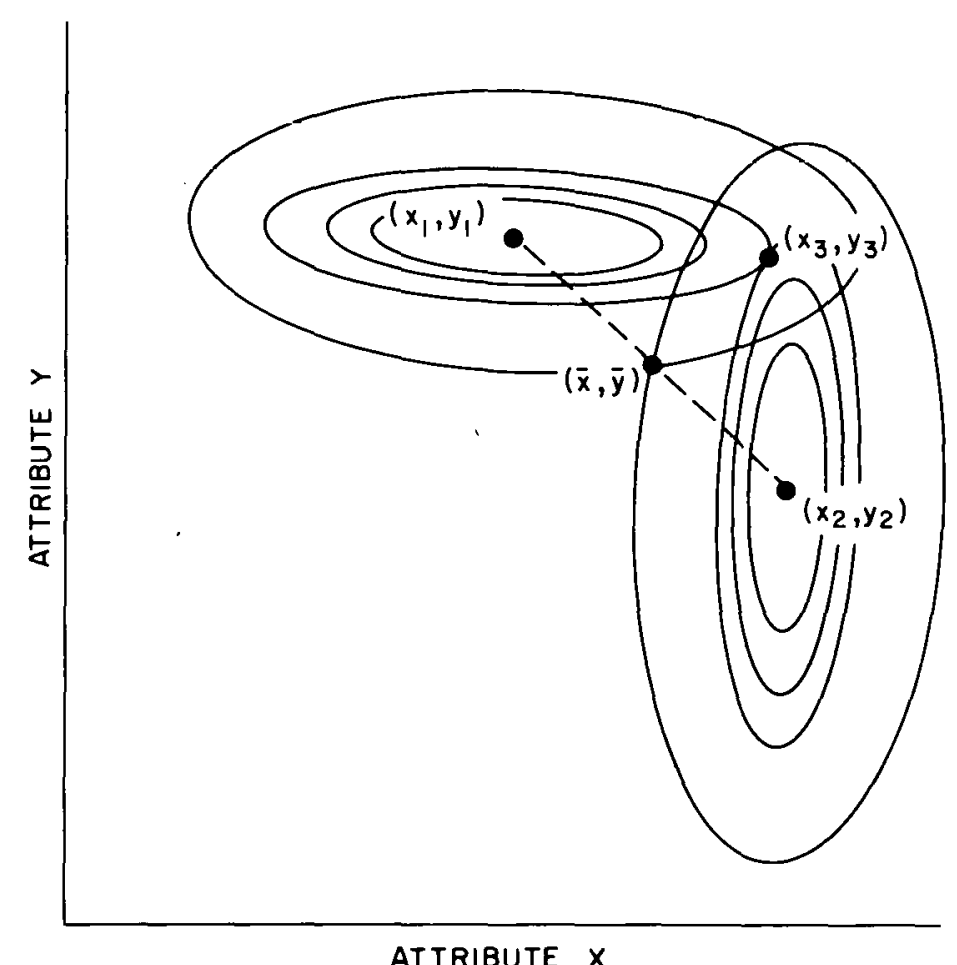

Figure 6.1. Voter Indifference Curves and the Mean. 6 
In quantitative siting methodologies this problem can be considerably exacerbated by an increase in dimensionality, both of attributes and of decision makers, and by a separation of value judgments from decisions. From the perspective of persons selecting weights, this selection is independent of calculation of site suitability. Decision makers might not like the package of attributes selected by their weights even though the subjective judgments for individual weights seemed appropriate when made in isolation. Most decision rules assume value independence of attributes. We have shown that this may not be correct in siting, and that decision makers may evaluate complete packages of attributes and the importance of each attribute relative to that package. Because of this lack of independence the solution may be suboptimal like the mean solution in Figure 6.1 .

An implication of the above discussion is that, in the end, all decisions involving tradeoffs among different sets of values must provide for political interactions which ensure that there is not some alternative, other than that based on mean value judgments, for which total satisfaction is greater. It is unclear at which stage of the siting process such political inputs are best included. The earlier they are included, the less is the likelihood that large expenditures of time and money will be obviated by a political decision.

Another implication of the above discussion is that reviewers must not become engulfed in methodologies for their own sake and forget the objectives of the siting process. The primary objective is to find a suitable site which is not obviously dominated by any other available site. It is not to demonstrate understanding of the intricacies of esoteric siting methods or to display creativity in developing new methodologies. Methodologies are useful only if they help to decrease the difficulty. of finding suitable sites and increase confidence in the quality of the final siting decision. It is the results that count.

The following portions of this section discuss details of each stage of the site-selection process separately: Included with each is a checklist of important questions to be considered in a review.

\subsection{REGION OF INTEREST}

Region of interest is usually defined as the service area of the utility building the power plant. Occasionally the region is expanded to include 
other service areas when several utilities are involved and system considerations favor transfers of.power among them. Region of interest can also be expanded to include an entire state when state planning agencies participate.

Reviewers need be concerned with definition of region of interest only if that region is something less than the utility's service area. Restriction of region of interest to less than the total area means that unstated tradeoffs have been made between the characteristics on which the restriction is based and other characteristics of the region.

Restrictions of this kind are usually based on the cost of transmission to demand centers from remote sites. There is no question that this cost is important; the problem is one of determining the level of cost that represents a reasonable cutoff. Establishing a "reasonable" cutoff criterion requires a value judgment about the cost of transmission relative to total cost, and the significance of that cost relative to other siting considerations. Such value judgments should be made openly in the candidate area or candidate site-selection stage rather than hidden away earlier in the siting process.

Occasionally this stage and all following stages before final site selection are bypassed by adoption of a slate of candidate sites from a previous study. Since the study may be relatively old, not only the data on which it is based but also the values expressed therein may be different from those currently accepted. Reviewers should include descriptions of these existing studies in their evaluations and judge them by the same criteria as new studies.

TABLE 6.1

REGION OF INTEREST CHECKLIST

I. How is a region of interest defined?

A. Service Area.

B. If less than service area, by what criteria is the region reduced?

1. Nondiscretionary?

2. Discretionary? Can a reasonablc case be made that these criteria are of importance so great that it is not possible for other characteristics to override them?

c. If this slage is bypassed by substitution of results of a previous study, does that study meet current requirements? 


\subsection{REGIONAL SCREENING}

The function of regional screening is first to reduce the total data collection effort required of the siting process and second to eliminate areas having low (or zerol probability of containing suitable sites so as to increase the probability of finding suitable sites in the areas that remain. Any reduction of the total area under consideration will meet the first part ' of this function. Problems arise only when the screening is conducted in a manner that eliminates high probability areas. Note that this is not the same as eliminating "the best" site. It is possible that there are some unusually high suitability sites isolated in areas otherwise unsuitable and unlikely to contain any sites at all, but the time and money required to include such areas on the off chance that some unlikely combination of attribute values might be found is unreasonably large relative to the expected return. Low probability areas should be included in analyses only if characteristics in the region of interest are so restrictive that all possibilities must be examined.

A way to ensure that the second part of the function of regional screening is met is to base screening on nondiscretionary criteria -- legal and engineering requirements that must be met under all conditions. Inclusion of areas that violate nondiscretionary criteria in an analysis would serve no purpose. The extent to which discretionary criteria can successfully be added to a regional screening depends on the importance of the attributes chosen relative to those used later in the screening process, and the extent to which screening attributes are spatially correlated with those used later in the process.

Attributes that are so important to the siting process that they would overwhelm a final site evaluation can usefully be included at the screening stage. The problem is one of determining. which attributes might have sufficient importance when the ranges of attribute values that must be considered in final site evaluation are not known. An attribute that appears important at the screening stage can become relatively unimportant through skillful work in the candidate site-selection stage yieiding candidates with have low levels of that attribute. Other attributes can become overwhelmingly important because of some widely distributed problem which is difficult to avoid without encountering some other important problem (spatial correlation of attribute value levels). 
Spatial correlation can help or hinder at all stages of the siting process. If important siting attributes tend to be correlated, then one can serve as a surrogate for all. A discretionary attribute which is both important and correlated with other attributes included later in the siting process can be added to regional screening with confidence that the probability that the screened areas will contain suitable sites is increased. If attribute values are randomly distributed among sites, then screening based on discretionary criteria of all but the highest importance does not increase the probability that screened areas will contain suitable sites. Such attributes are more appropriately included in Weighting Summation screening than Exclusionary screening because there is no "natural" point at which to establish an exclusionary criterion and there are always some tradeoffs that must be considered.

Choice between Exclusionary screening and Weighting Summation screening depends on the extent to which tradeoffs must be considered. Exclusionary screening is the obvious choice for nondiscretionary criteria, and it can work well for a few very important discretionary criteria, provided that they are not set so stringent that large proportion of the total area is eliminated by them alone. Exclusionary screening does not work well for 1 arge numbers of discretionary criteria because it forces tradeoffs that do not reflect decision makers values. Only Weighting Summation is useful for screening when there are important tradeoffs to be made.

TABLE 6.2

REGIONAL SC.RFENING CHECKLIST

I. Exclusionary Screening (Sections 2.5.1.1 and 4).

A. Are exclusion criteria nondiscretionary?

B. If not, are discretionary criteria of highest importance?

1. Avoiding important local political or environmental problems?

2. Avoiding other problems of local importance as demonstrated by previous siting attempts?

C. Is there any logic behind levels of discretionary criteria or are they set arbitrarily at levels established by historical precedent?

D. Are discretionary exclusion criteria established lonsely at levels that allow for uncertainty?

E. Are discretionary exclusion criteria cost related? 
1. Does the report specify how much money is involved (expressed as proportion of total cost and as unit cost of electricity)? Is the cost increase in fact large?

2. Is there anything special about excluded areas that might make sites there worth the extra cost?

II. Comparison Screening (Weighting Summation, Sections 2.5.2.1, 2.5.2.4, and 4).

A. Comparison attributes must necessarily be discretionary.

B. Do the attributes meet requirements for independence, clarity of definition, and quantifiability required of the Weighting Summation decision rule?

c. What are the bases for converting attribute levels to subjective value estimates?

D. What weighting method is used (Sections $2.5 .4,4$, and 5)?

1. Does the report specify whose weights are represented?

2. Is the weighting method described? Is it a standard form?

3. Does the method ensure ratio-scaled weights?

4. If not, is its use justified?

a. Is there awareness of problems related to implied weights arising from misapplication of method.

E. Is the decision rule correctly applied (Sections 2.5, 4, and 5)?

1. Weighting Summation is the only commonly used method for screening. Are attribute values multiplied by weights and added? If not, why not?

F. Does the cutoff for inclusion among candidate areas have sufficient leeway to allow for uncertainty? Are any potential candidate areas excluded for reasons not included in the analysis? If so, are the exclusions justifiable?

III. Is this stage bypassed in deference to results of a previous study?

A. Is the study recent enough so that data are up to date?

B. Has the siting climate changed enough so that important attributes and attitudes towards them are no longer valid? If not, are they appropriate to this level of analysis?

\subsection{CANDIDATE SITE SELECTION}

The function of the candidate site selection stage is to locate potential sites in candidate areas and to reduce them to a manageable number. This is the least well-documented stage in the siting process, and also the least formalized. Most likely it is poorly documented because of its infor- 
mality and because of its function. Informal procedures are difficult to

- document. Often they are "seat of the pants" methods in which experienced persons work in a relatively intuitive manner using whatever large-scale information, such as maps, is available. In many cases the entire set is taken from a previous study. Since the purpose of this stage is to generate a set of sites all of which appear reasonably good, as opposed to selecting one from among many, it appears that procedures and requirements need not be stringent. Through its influence on the following stage, however, this is potentially the most important stage in the entire process.

Its importance arises first from the influence of the skill with which it is conducted and second from its influence on decision complexity, which affects sensitivity to uncertainty of results in the following stage. If candidate sites are selected with great skill and understanding of important issues in the region, then final site selection will be from among highquality sites, any of which is likely to be suitable. Only levels of attributes not included in the selection or unusual conditions specific to particular sites will affect the quality of the decision. If the persons involved have good understanding of correlations among attributes included at this stage and those added in the following stage, then it becomes even more likely that the candidate sites will all bësuitable. A decision from among several high-quality. sites may seem difficult, because such a decision will likely be highly sensitive to uncertainty and magnitudes of weights, but under this condition the choice is not critical since all sites are good.

If, in contrast, the choice of candidate sites is poor or made without consideration for important attributes, then final site selection will be from among inferior alternatives, and the quality of the final site evaluation may not significantly affect the quality of the final decision. There is no way to determine whether or not the final site selection is being made from among low-quality alternatives except to find superior ones.

As discussed in Section 5.0, the manner in which candidate site selection is conducted can significantly arfect the complexity of the decision necessary in the final site evaluation which follows. Strong preconceived notions about the qualifications for a "good" power plant site reduce diversity and can produce a set of inferior sites if the values of the persons selecting the candidate sites are sufficiently different from those of other 
decision makers or of the general public. In contrast, exogenous political or legal requirements that there be some specified number of candidate sites from several geophysical or jurisdictional regions can increase diversity, but may bring in sites which would otherwise be considered inferior. Rather. than increasing numbers and kinds of choices, restrictions of this $k$ ind, if poorly conceived, may only reduce the number of suitable sites from which to choose.

The extent to which increased diversity will increase the number of choices rather than reduce the number of suitable sites depends on the spatial correlations among attribute values. High correlations reduce diversity because the probability of dominance is high. Under this condition, exogenous restrictions would reduce the number of suitable sites by increasing the probability of introducing inferior sites which would otherwise not be included. Low correlations would have the opposite effect.

Because the candidate site-selection. stage can be critical to the succes of the siting process, reviewers are cautioned to examine the methods used most carefully. The first requirement is for complete documentation. This should include not only kinds and sources of information, but also the criteria used for determining that a potential site was suitable for inclusion. If, as often happens, many potential sites are selected in a preliminary stage and then the number is reduced, criteria for rejecting potential sites should be specified clearly. This documentation should be sufficient to demonstrate that the informal process has been conducted to the extent possible without unnecessary biases which can unduly restrict choices. In more formal methods, procedures should be specified much as they are for other stages of the siting process.

Problems to watch for include excessive bias as to what particular combinations of attribute levels constitute a "good" site. In some cases there may be only one type of suitable site, but in most there should be several different types with respect to environmental conditions. Major differences are likely to be related to cost, which should not be included among environmental considerations. Cost should be maintained as a separate attribute so that tradeoffs with environmental and system attributes are clear. 
TABLE 6.3

CANDIDATE SITE SELECTION CHECKLIST

I. Is the method of candidate site selection specified (Section 2.5)?

A. If so, is it a standard method or "seat of the pants?"

II. Are selection criteria specified (Section 2.3)?

A. Are they complete or, if incomplete, are they appropriate to this level of analysis?

1. Are they disproportionately cost related?

B. Is there any consideration of tradeoffs among attributes?

1. If so, are weights used?

2. Does the report specify whose weights are represented?

3. Is the weighting method described? Is it a standard form?

4. Does the method ensure ratio-scaled weights?

5. If not, is the reason why not justified?

6. Is the decision rule correctly applied?

III. Are criteria for reducing the original slate to a smaller number of sites specified (Section 4.5)?

A. Are tradeoffs considered?

1. If so, see II.B above.

IV. Does the final slate of alternatives include more than two sites?

A. If not, is the small number justified on some reasonable basis?

$v$. Is anything done that specifically affects complexity? Are there exogenous requirements that affect complexity (Section 5.3)?

A. If it is $10 \mathrm{w}$, is there dominance or are all sites alike?

B. Is there evidence of possible "deck stacking" (extreme dominance)? 


\subsection{FINAL SITE SELECTION}

The purpose of final site evaluation is to bring to bear all readily available information on the suitability of the few sites remaining at this stage of the siting process, and to use this information systematically to determine which of the sites appears most suitable with respect to the various attributes being considered. At this stage, the most detailed level of information is used, often including data that can only be obtained by flyovers and site visits. Also included is information on the most difficult to quantify, site characteristics such as socioeconomic impacts and aesthetics. In addition, conditions known to the local population but not readily avai 1 able or discernable should properly be included at this stage, although this does not always occur.

These new additions of information about difficult-to-quantify attributes and special local conditions can create large problems for the final site selection. Information added at this stage is often difficult and expensive to obtain, and one reason why it is left to the final stage, is to reduce the number of sites for which such detailed information is necessary. Because it enters at the final stage, this new information can generate surprises if otherwise suitable sites turn out to have unexpectedly bad characteristics. Much of the burden of preventing these surprises occurs during the candidate site-selection stage, when skill and understanding of local conditions and attitudes can help decision makers select sites without sitespecific data obtainable only at great cost. Reviewers should examille estimation methods for any new attributes added at this stage with special care to ensure that potential problems have not been glossed over.

In final site selection, "most suitable" is defined by the method chosen for the analysis. Most often the decision rule requires some form of weighted combinations of attribute values, but it can also involve determining the number of times each site "wins" pairwise comparisons of all sites with respect to each attribute, or evaluation of tradeoffs among values of different interest groups, among others (see Section 2.0). The important question at this stage is not so much which site achieves the highest score by whatever method is used, but whose values are represented, how they are determined, and what the method used implies about the nature of the final decision. In other words, what are the characteristics of the highest-scoring site? 
Selection of method should depend on (1) the extent to which risk can be quantified and is important to decision makers, (2) the extent to which the final decision must be politically acceptable, and (3) the number and importance of tradeoffs to be made. The first two conditions are most easily addressed. If risk is quantifiable and important to decision makers, then the Decision Analysis method must necessarily be used. The particular form required depends on decision makers' attitudes towards risk. If comparisons among different interest groups are to be made, then some form of Paratian analysis must be used. The manner in which it is used, however, is not specific to the methodology and can include other decision rules applied using value judgments of each interest group represented.

The third consideration is most important for the final site-selection methods in common use. Number and importance of tradeoffs determine the sensitivity of the final decision to quality of inputs and, therefore, to the skill with which the analysis is conducted. They also influence choice of method, since different methods have different capabilities to include tradeoffs explicitiy.

As discussed in Section 5.0, low-complexity decisions are exceedingly robust. If there are few tradeoffs to be made, the importance of specifics of methodologies is reduced, and any method able to deal adequately with these few tradeoffs should suffice. If complexity is high, however, then the method chosen must be able to address those tradeoffs in a manner which assures that the results will correctly represent the value systems of the decision makers concerned. Failure to do so can lead to unnecessary conflict.

Multiobjective decision methods differ in their ability to address tradeoffs. Exclusionary Screening allows none at all; Weighting Summation holds nothing sarred and anything can be compensated by anything else; Goal Programming, Power Law, and Decision Analysis fall in between. Weighting methods also differ in ability to address tradeoffs. They are discussed bel ow. Each of these methods is based on assumptions about characteristics of the problem addressed. Weighting Summation, for example, assumes linear indifference curves and additive independence among attribute values; Power Law assumes logarithmic perception of attribute importance; Copeland's Reasonable Welfare Function is designed for ordinal attribute values. Application of the methods, therefore, presumes some investigation of the applicability of these underlying assumptions. 
Reviewers are cautioned to examine stated reasons for choice of method to determine whether or not consideration has been given to these assumptions and the choice of method has been justified. Review should begin with attribute value functions, which can be ordinal or interval scaled. Ordinal value functions (Categorization or Ranking) have been shown to be incapable of correctly representing tradeoffs with the rigor required of more complex decision rules (Section 5.0). Most decision rules require interval-scaled attribute values. One or two ordinal attributes probably will not affect methods requiring interval scales. If large numbers of ordinal attribute values are used, however, a method such as Conjunctive Ranking or Copeland's Reasonable Welfare Function should be used. These methods are specifically designed for ordinal values. If attribute values are interval scaled or better, then any of the decision rules discussed in this report can be used.

The method for transforming measured attribute levels to subjective estimates of value should be specified as should the measurements themselves. A matrix of value judgments without some indication of what the numbers mean in terms of real impacts is meaningless. Since interval-scaled attribute values have an arbitrary zero point, there is no way to determine whether or not a particular value level is high or low on an absolute scale. The worst alternative can be judged good by all decision makers on an absolute (ratio) scale, but it scores lowest on an interval scale. If some attribute levels are defined to be discretionary exclusions, some manner of presenting the noninferior set should also be included, so that it is possible to determine the tradeoffs implied by the exclusionary criteria.

Many decision rules require weights. The purpose of weights is to capture quantitatively the tradeoffs decision makers are willing to make. Different methods differ in their ability to achieve this. Only Decision Analysis lotteries, Indifference Tradeoff, and the Churchman-Ackoff procedure correctly assess tradeoffs in the manner required by the Weighting Summation, Power Law, and Decision Analysis methods. These weighting methods produce ratio-scaled weights which express the relative importance of unit changes in attribute values. In addition, Decision Analysis lotteries include attitudes toward risk. Other methods either can produce correct weights, but do not assure them, or are incapable of producing ratio-scaled weights with the correct type of importance. Rating, for example, can produce correct weights if 
decision makers are thinking correctly about the weighting exercise, but - there is no way to determine whether or not they are thinking correctly. Categorization, in contrast, is incapable of producing correct weights. Metfessel Allocation and Ratio Questioning produce ratio-scaled weights, but do not assure the correct type of importance. Some of these problems can be reduced by consistency checking as in the Churchman-Ackoff method. Unless there are circumstances militating against their use, methods not assuring correct weights should be avoided.

One circumstance militating against use of more complex weighting methods is application by untrained citizens' groups. Decision Analysis, in particular, is unsuited to this application and Indifference Tradeoff would probably require extensive training and consistency checking. Under this circumstance, either the Churchman-Ack off method or Rating would probably be best. If Rating is used, great care should be taken that decision makers understand the nature of ratio scaling and the type of importance they are to evaluate.

The question of whose weights are represented in a siting analysis is central to many conflicts with interveners. Attempts to introduce public opinion into the siting process can easily fail because the general public is often indifferent to siting unless it affects individuals directiy. They will tend, therefore, to refrain from participation until it is clear that they must defend their own interests, usually at a stage much too late to inject new value judgments. Consultants must, therefore, attempt to represent the general public as best they can. This can be accomplished through an advocacy approach in which individual decision makers attempt to represent particular interest groups, or by gathering decision makers who, in fact, represent attitudes of different interest groups. Under this condition, a significant distinction must be made between quality of a site with respect to environmental characteristics and licensability of that site. To the extent that siting specialists have different perceptions of relative importance of different environmental impacts, their judgment of what makes "good" and "bad" sites will differ from that of the general public. Specialists' and the general public's perception of the relative health risk of radiation is a good example. For a site to be licensable with respect to political considerations, it must conform to public perception of relative importance of dif- 
ferent impacts and not professional opinion. However insignificant a particular impact may seem to professionals, the public will fight with all available resources if its perception is that the impact is 1arge. To prevent such conflicts, utilities often find it easier to avoid a relatively insignificant problem than to attempt to educate the public to its insignificance. Herein lies the difference between a "good" site and a licensable site, and herein lies the origin. of the need to specify whose values are represented by the weights used. It is up to NRC to determine the extent to which expert opinion would have precedence over public opinion with respect to siting decisions.

Whatever decision rule is used, and whatever methods are used for assessing attribute values and weights, a large amount of uncertainty will remain. Therefore, some form of sensitivity analysis should be performed to determine the robustness of the final decision. This is usually done by changing weights and recalculating site suitabilities. If the solution is robust, then divergences of methodology from the correct form can be forgiven, since they are unlikely to have caused changes in the solution. Sensitive solutions should, however, be examined with considerable care. The two important characteristics for which to look are similarity of sites and large potential differences in opinion. If a solution is sensitive to changes in weights because two or more sites are nearly identical with respect to most attributes, then there is no reason to be concerned about the sensitivity. Any of the sensitive solutions will be of approximately equal quality. If. in contrast, the sensitivity arises out of large tradeoffs among equally important attributes, then some consideration must be given to the distribution of preferences among the interest groups represented in the decision as well as to which interest groups are favored by the various sensitive solutions.

Given the subjective nature of many of the judgments made throughout the siting process, disagreements are inevitable. To the extent possible, some mechanism should be provided to allow political input to the process so that situations like that described earlier in this section, in which mathematical solutions are suboptimal from the perspectives of individual interest groups, are avoided. 
I. Is the method of site selection specified? Is it a standard method (Section 2.5)?

A. If not, is its use justified? Does it seem reasonable with respect to the theoretical considerations discussed in the technical papers associated with this report?

1. How does it deal with tradeoffs?

2. Are weights included? If so, do they meet the requirements of the method with respect to measurement theory?

3. Does the decision rule create implied weights different from the specified weights?

II. If the method is standard, is it applied correctly (Section 2.5)?

A. Do the attributes meet requirements for independence, clarity of definition, and quantifiability?

B. What are the bases for converting attribute levels to subjective value estimates?

C. What weighting method is used?

1. Does the report specify whose weights are represented?

2. Is the weighting method described? Is it a standard form?

a. If not, why not?

3. Does the method ensure ratio-scaled weights or at least a nonarbitrary zero point?

4. If not, is the reason justified?

III. If the method is not correctly applied, is the complexity of the slate of candidate sites sufficiently high so that correct application of the method might make a difference in decision (Section 5.3)?

IV. Have sensitivity analyses been made on results?

A. If results are sensitive, how is the final decision justified? 


\section{REFERENCES}

1. Keeney, Ralph L., Craig W. Kirkwood, Coleen K. Ford, John A. Robinson, and Peter Gottlieb, An Evaluation and Comparison of Nuclear Powerplant Siting Methodologies, NUREG/CR-0407, SAND78-1284, RA, U.S. Nuclear ReguTatory Commission, March 1979.

2. Hobbs, Benjamin F., Analytical Multiobjective Decision Methods for Power Plant Siting: A Review of Theory and Applications, BNL-NUREG-51204, Division of Regional Studies, Brookhaven National Laboratory, Upton, N.Y., September 1979.

3. Pierce, Barbara L., and Michael D. Rowe, Quantitative Nuclear Power Plant Siting Methods: A Review of Current Practice, BNL-NUREG-28115, Division * of Regional Studies, Brookhaven National Laboratory, Upton, N.Y., February 1979.

4. Hobbs, Benjamin F., and Michael D. Rowe, A Comparison of Regional Screening Methods, BNL-NUREG-51205, Division of Regional Studies, Brookhaven NationaT Laboratory, Upton, N.Y., September 1979.

5. Rowe, Michael D., and Barbara L. Pierce, A Comparison of Site Evaluation Methods, BNL-NUREG-51203, Division of Regional Studies, Brookhaven National Laboratory, Upton, N.Y., August 1979.

6. Haef1e, Edwin T., Representative Government and Environmental Management, Baltimore, The Johns Hopkins University Press, 1973. 